UNIVERSIDADE DE BRASÍLIA

FACULDADE DE TECNOLOGIA

DEPARTAMENTO DE ENGENHARIA ELÉTRICA

\title{
AVALIAÇÃO COMPARATIVA ENTRE FONTES ALTERNATIVAS DE ENERGIA CONSIDERANDO INCERTEZAS E EXTERNALIDADES
}

\author{
MÁRCIA DANTAS DE SENNA \\ RENAN FIGUEIRA GARBIN
}

ORIENTADOR: MAURO MOURA SEVERINO

TRABALHO DE CONCLUSÃO DE CURSO

EM ENGENHARIA ELÉTRICA

BRASÍLIA/DF: DEZEMBRO - 2009 
UNIVERSIDADE DE BRASÍLIA

FACULDADE DE TECNOLOGIA

DEPARTAMENTO DE ENGENHARIA ELÉTRICA

\section{AVALIAÇÃO COMPARATIVA ENTRE FONTES ALTERNATIVAS DE ENERGIA CONSIDERANDO INCERTEZAS E EXTERNALIDADES}

\section{MÁRCIA DANTAS DE SENNA RENAN FIGUEIRA GARBIN}

TRABALHO DE CONCLUSÃO DE CURSO SUBMETIDO AO DEPARTAMENTO DE ENGENHARIA ELÉTRICA DA FACULdAdE DE TECNOLOGIA DA UNIVERSIDADE DE BRASÍlIA COMO PARTE DOS REQUISITOS NECESSÁRIOS PARA A OBTENÇÃo DO DIPLOMA EM ENGENHARIA ELÉTRICA.

APROVADA POR:

Prof. Mauro Moura Severino, Dr. (ENE/UnB)

(Orientador)

Prof. Ivan Marques de Toledo Camargo, Dr. (ENE/UnB) (Examinador Interno)

Prof. Fernando Monteiro de Figueiredo, Dr. (ENE/UnB) (Examinador Interno)

BRASÍLIA/DF: DEZEMBRO - 2009 


\section{AGRADECIMENTOS}

Aos meus pais e avós, por acreditarem em mim, me auxiliarem na minha formação pessoal e profissional e por serem as referências da minha vida.

A Gheisa, pela revisão e por me ajudar a superar todas as dificuldades, ser minha companheira e me ajudar a galgar mais este passo em minha vida.

A todos os colegas de trabalho e universidade que fizeram parte desta jornada e colaboraram de alguma forma com minha formação.

Ao meu orientador Mauro Severino e a minha companheira de projeto, Márcia, pelo trabalho realizado e por ajudar na busca de um norte para a realização deste trabalho.

A Deus, acima de tudo, por colocar todas estas pessoas em meu caminho e por me ajudar todos os dias a levantar e ter forças para lutar.

\section{RENAN FIGUEIRA GARBIN}

Aos meus pais e avós por terem me dado a oportunidade e todas as condições necessárias para que eu pudesse continuar morando em Brasília para o término da faculdade, além de terem me apoiado em tudo que foi necessário em todos os momentos da minha vida.

A todos os amigos que me apoiaram durante estes últimos anos, em especial ao Adriano, Pedro, Érico, Diego, Marcus Vinícius e Cruz.

As minhas irmãs por serem pessoas tão especiais pra mim.

Ao meu companheiro de projeto, Renan Garbin, e ao meu orientador Mauro Severino por terem me proposto este trabalho e terem me dado condições de concluí-lo.

E a Deus, obrigada. 


\section{RESUMO}

\section{AVALIAÇÃO COMPARATIVA ENTRE FONTES ALTERNATIVAS DE ENERGIA CONSIDERANDO INCERTEZAS E EXTERNALIDADES}

O presente estudo, que possui foco no suprimento de energia a cargas isoladas por intermédio do conceito de geração distribuída, tem como objetivo a avaliação econômica de diversas alternativas de atendimento. Desta forma, são avaliadas as alternativas de geração por PCH, eólica, fotovoltaica, e biomassa de cana. Além da comparação com a geração a diesel, atualmente muito utilizada no contexto nacional para tais situações.

Sendo assim, este estudo apresenta uma discussão a respeito do tema geração distribuída e a descrição de aspectos atuais a respeito das fontes consideradas, além da descrição da metodologia utilizada para se realizar a avaliação.

A avaliação técnico-financeira, realizada por intermédio do levantamento de parâmetros objetivos e de simulações computacionais considerando incertezas, realça a verificação de aspectos de desempenho econômico das diferentes soluções. Sendo que os diversos resultados obtidos em simulações permitem concluir que a metodologia adotada é adequada às intenções de avaliação propostas e a ferramenta elaborada é de extrema valia para a extensão a outros casos de estudo.

Entretanto, a simples avaliação técnico-financeira de alternativas de geração se tornou muito disseminada e trivial, sendo necessária então a inclusão de aspectos externos ao tema avaliação econômica de geração de energia. Desta forma, fez-se uso da consideração de externalidades ambientais como diferenciais de custo.

A abordagem considerando tais externalidades pode acarretar em significativas alterações na comparação entre as soluções avaliadas. Todavia, a contabilização dos impactos considerados evidencia a maior atratividade na utilização de fontes renováveis de energia em detrimento aos combustíveis fósseis. 


\section{LISTA DE FIGURAS}

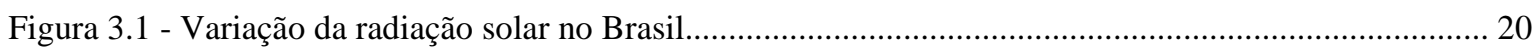

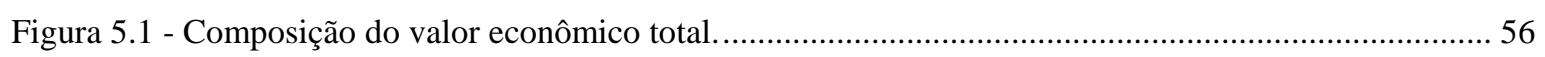




\section{LISTA DE GRÁFICOS}

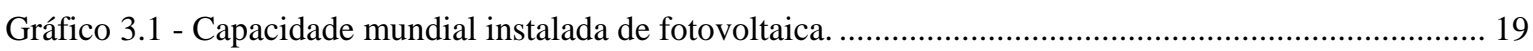

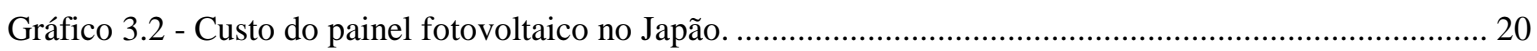

Gráfico 4.1 - Valores de CAT da simulação para 5.000 casos. ...................................................................... 43

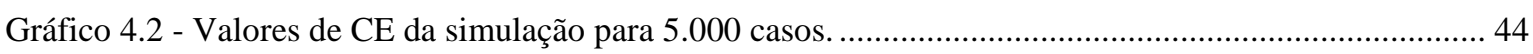

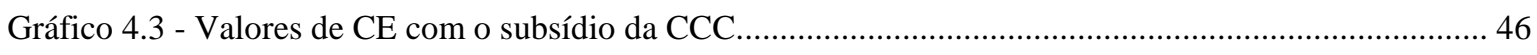

Gráfico 7.1 - Simulação do CAET para 5.000 casos com externalidades. ...................................................... 85

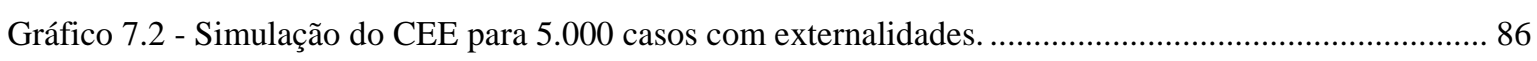

Gráfico 7.3 - Simulação do CAET para 5.000 casos com externalidades (positivas e negativas).................... 90

Gráfico 7.4 - Simulação do CEE para 5.000 casos com externalidades (positivas e negativas)........................ 90

Gráfico A I.1 - Comparação de capacidade instalada SIN e PROINFA contratada/instalada........................ 101 


\section{LISTA DE SIGLAS}

ANEEL - Agência Nacional de Energia Elétrica

ANP - Agência Nacional do Petróleo, Gás Natural e Biocombustíveis

BIG - Banco de Informações de Geração

BNDES - Banco Nacional do Desenvolvimento

BPA - Bonneville Power Administration

CAET - Custo Anual Equivalente Total

CAI - Custo Anual de Implantação

CAP - Custo Anual das Perdas

CAT - Custo Anual Total

CCC - Conta de Consumo de Combustíveis Fósseis

CCX - Chicago Climate Exchange

CE - Custo da Energia

CEAL - Companhia Energética de Alagoas

CEB - Companhia Energética de Brasília

CEEETA - Centro de Estudos de Economia, Energia, Transportes e Ambientes de Lisboa

CELPA - Centrais Elétricas do Pará S.A.

CELTINS - Companhia de Energia Elétrica do estado do Tocantins

CEP - Custo da Energia Perdida

CEX - Custo da Externalidade

EC - Excedente do Consumidor

ECU - European Currency Unit

ECX - European Climate Exchange

ELETROBRÁS - Centrais Elétricas Brasileiras S.A.

ENERSUL - Empresa Energética do Mato Grosso do Sul

EPE - Empresa de Pesquisa Energética

EPIA - European Photovoltaic Industry Association

FGV - Fundação Getúlio Vargas

FRC - Fator de Recuperação de Capital

GEE - Gases do Efeito Estufa

GWEC - Global Wind Energy Council

GWEO - Global Wind Energy Outlook

IAEA - International Atomic Energy Agency 
IDH - Índice de Desenvolvimento Humano

IEA - International Energy Agency

IGPM - Índice Geral de Preços de Mercado

INCC - Índice Nacional da Construção Civil

IPA - Índice de Preços por Atacado

IPC - Índice de Preços ao Consumidor

IPCC - Intergovernmental Panel on Climate Change

IPEA - Instituto de Pesquisa Econômica Aplicada

MME - Ministério de Minas de Energia

O\&M - Operação e Manutenção

OTA - Office of Technology Assessment

PCH - Pequena Central Hidroelétrica

PNUD - Programa das Nações Unidas para o Desenvolvimento

PROINFA - Programa de Incentivo as Fontes Alternativas de Energia

RCE - Redução Certificada de Emissões

RGR - Reserva Global de Reversão

RTS - Rede de Tecnologia Social

SIN - Sistema Interligado Nacional

UNEP - United Nations Environment Programme

VE - Valor de Existência

VET - Valor Econômico Total

VETEF - Valor Econômico da Tecnologia Específica da Fonte

VL - Valor de Legado

VN - Valor Normativo

VNU - Valor de Não Uso

VO - Valor de Opção

VPR - Valor Presente Residual

VQO - Valor de Quase Opção

VU - Valor de Uso

VUD - Valor de Uso Direto

VUI - Valor de Uso Indireto

WEA - World Energy Assessment

WMO - World Meteorological Organization

WTP - Willingness to Pay 


\section{LISTA DE TABELAS}

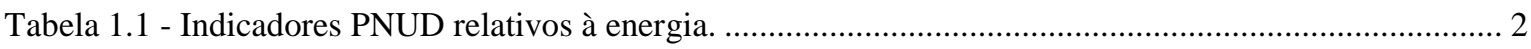

Tabela 2.1 - Tecnologias associadas à geração distribuída...................................................................... 10

Tabela 3.1 - Potencial eólico aproveitável por região brasileira............................................................ 16

Tabela 4.1 - VETEF definidos pelo MME por intermédio de consulta pública. ....................................... 27

Tabela 4.2 - Parâmetros específicos - custo do investimento total. ........................................................... 27

Tabela 4.3 - Valor da tecnologia específica da fonte corrigido pelo IGP-M. ......................................... 28

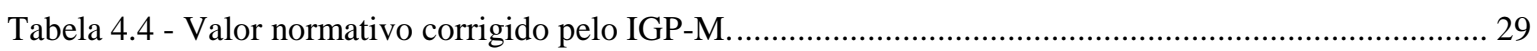

Tabela 4.5 - Comparação dos valores por fonte (data de referência e data atual). ..................................... 30

Tabela 4.6 - Custos de geração em pequenas centrais hidroelétricas. ..................................................... 31

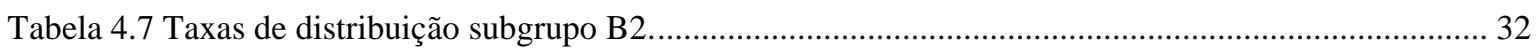

Tabela 4.8 - Custos da geração a óleo diesel. ................................................................................... 33

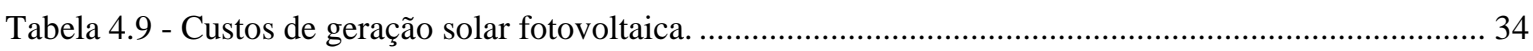

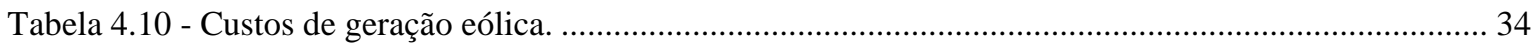

Tabela 4.11 - Custos de geração por biomassa: bagaço de cana............................................................. 34

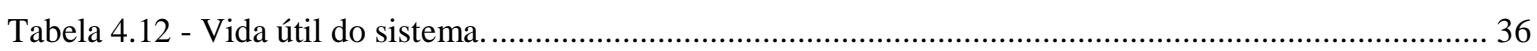

Tabela 4.13 - Planilha com dados de entrada da simulação. .................................................................. 42

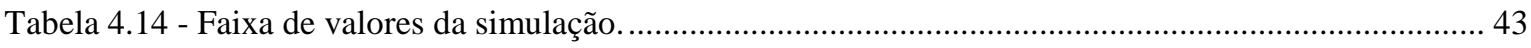

Tabela 4.15 - Resultados da simulação para 5.000 casos. ....................................................................... 44

Tabela 4.16 - Comparação entre CE e VN para cálculo do subsídio......................................................... 46

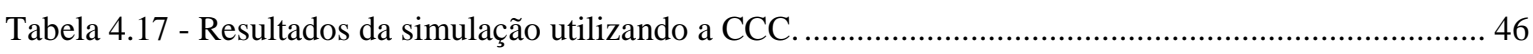

Tabela 5.1 - Impactos ambientais das atividades do setor elétrico. ........................................................... 53

Tabela 5.2 - Classificação de metodologias de avaliação econômica dos impactos ambientais..................... 58

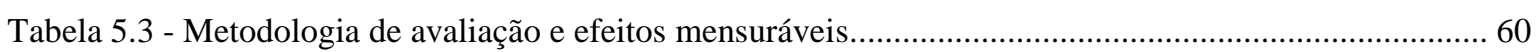

Tabela 6.1 - Estimativa de custos ambientais de ECO NorthWest em 1987 ............................................63

Tabela 6.2 - Estimativa de custos ambientais de Chernick e Caverhill em 1989........................................63

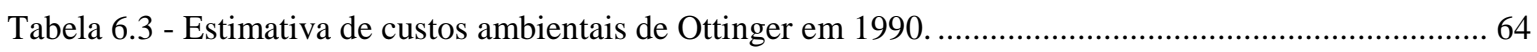

Tabela 6.4 - Estimativa de custos ambientais de Bernow em 1990 ........................................................65

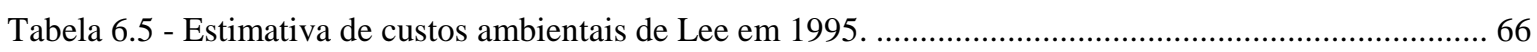

Tabela 6.6 - Estimativa de custos ambientais para RCG/Hagler/Baily em 1995 ....................................... 67

Tabela 6.7 - Estimativa de custos ambientais de Hohmeyer em 1988 .....................................................69

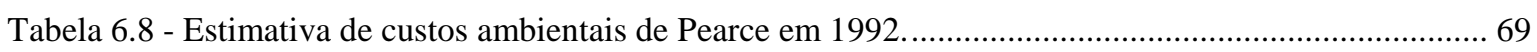

Tabela 6.9 - Estimativa de custos ambientais do projeto ExternE em 1995.............................................. 71

Tabela 6.10 - Estimativa de custos ambientais ExternE Portugal (ciclo da hidroeletricidade)...................... 73

Tabela 6.11 - Estimativa de custos ambientais ExternE Portugal (ciclo da biomassa)................................ 73

Tabela 6.12 - Estimativa de custos ambientais do setor elétrico português em 1995................................ 74

Tabela 6.13 - Custos externos da produção de eletricidade na Alemanha. .................................................. 75

Tabela 6.14 - Síntese dos estudos da primeira geração dos EUA............................................................... 76

Tabela 6.15 - Síntese dos estudos da segunda geração dos EUA. ......................................................... 77 
Tabela 6.16 - Síntese dos estudos europeus..

Tabela 6.17 - Estimativa atualizada de custos ambientais do diesel.......................................................... 80

Tabela 6.18 - Estimativa atualizada de custos ambientais da hidroeletricidade. ....................................... 81

Tabela 6.19 - Estimativa atualizada de custos ambientais da energia eólica............................................ 81

Tabela 6.20 - Estimativa atualizada de custos ambientais da biomassa. ................................................... 81

Tabela 6.21 - Estimativa atualizada de custos ambientais da energia solar fotovoltaica............................. 81

Tabela 7.1 - Simulação para 5.000 casos considerando externalidades...................................................... 84

Tabela 7.2 - Resultados da simulação para 5.000 casos com externalidades. .......................................... 85

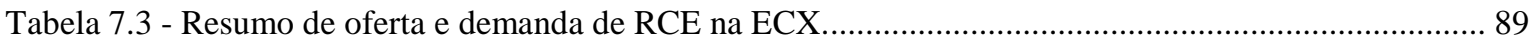

Tabela 7.4 - Resultados da Simulação para 5.000 casos com externalidades (positivas e negativas)............ 91

Tabela A I.1 - PROINFA resultados consolidados............................................................................... 102

Tabela A I.2 - Unidades consumidoras - variação 2006/2007............................................................... 109

Tabela A II.1 - Dados do IGP-M simplificado, 1995 até outubro de 2009. ............................................. 110

Tabela A II.2 - Correção do VETEF pelo IGP-M. ............................................................................ 111

Tabela A II.3 - Correção do VN pelo IGP-M............................................................................................ 112

Tabela A III.1 - Dados do IGP-M simplificados, 1995 até outubro de 2009........................................... 114

Tabela A III.2 - Taxa de câmbio anual média libra X real brasileiro. ........................................................ 114

Tabela A III.3 - Estimativa de custos ambientais de Pearce atualizada..................................................... 115

Tabela A III.4 - Cotação do real em relação ao dólar, 1995 até outubro de 2009...................................... 116

Tabela A III.5 - Estimativa de custos ambientais do ExternE Portugal atualizada, hidroeletricidade........... 116

Tabela A III.6 - Estimativa de custos ambientais ExternE Portugal atualizada, biomassa........................... 116

Tabela A III.7 - Estimativa de custos ambientais ExternE Alemanha atualizada...................................... 117 


\section{SUMÁRIO}

1 INTRODUÇÃ

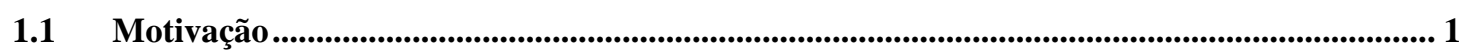

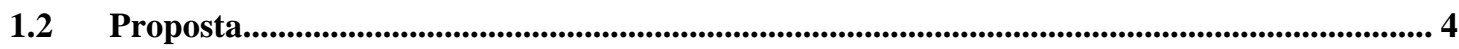

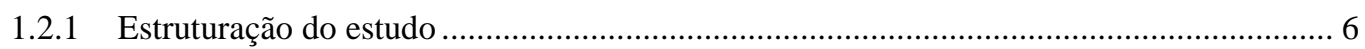

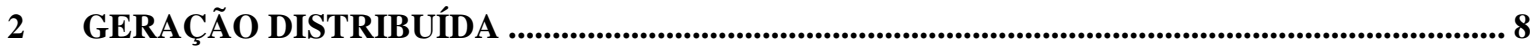

2.1 Fatores impulsionadores da geração distribuída ......................................................................... 9

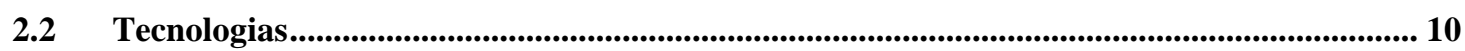

2.3 Vantagens e desvantagens................................................................................... 11

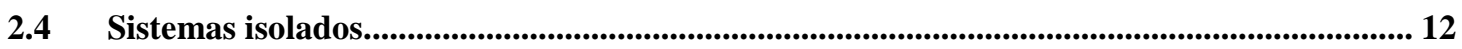

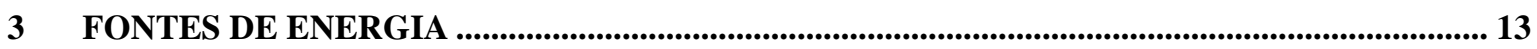

3.1 Energia hidroelétrica........................................................................................................................ 14

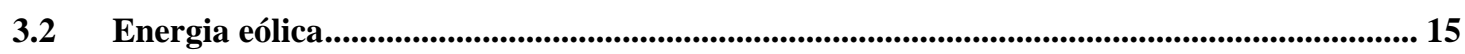

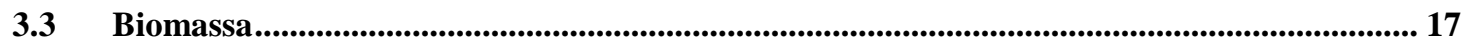

3.4 Fotovoltaica.............................................................................................................................. 19

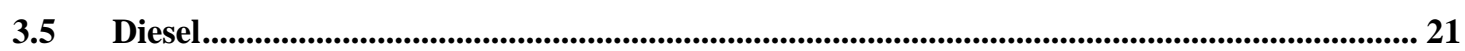

4 ABORDAGEM ECONÔMICA (ECONOMIA DA ENERGIA) ....................................................... 23

$4.1 \quad$ Estado-da-arte ............................................................................................................................... 23

4.2 Valor normativo e valor da tecnologia específica da fonte ................................................... 25

4.3 Levantamento de informações técnico-financeiras......................................................................... 31

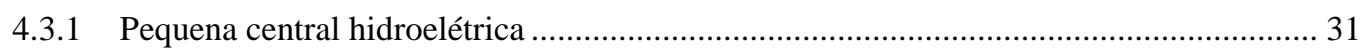

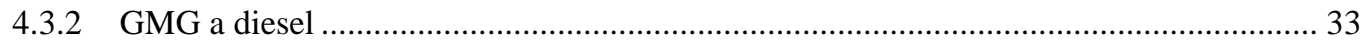

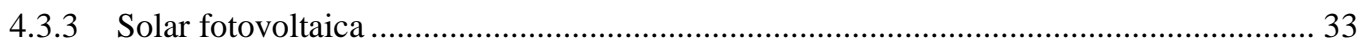

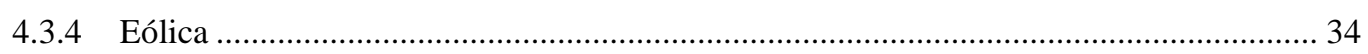

4.3.5 Biomassa de bagaço de cana ..................................................................................... 34

4.4 Modelagem matemática ........................................................................................................... 35

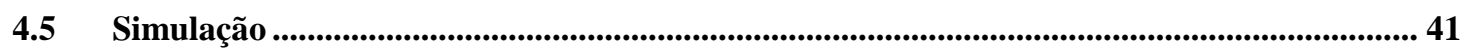

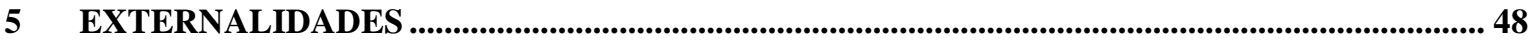

5.1 Externalidades ambientais das atividades do setor elétrico.......................................................50

5.2 Avaliação econômica das externalidades................................................................................... 54

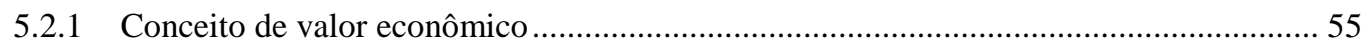

5.2.2 Metodologias de avaliação econômica........................................................................... 56

6 SÍNTESE DE ESTUDOS REALIZADOS PARA A AVALIAÇÃO ECONÔMICA DAS

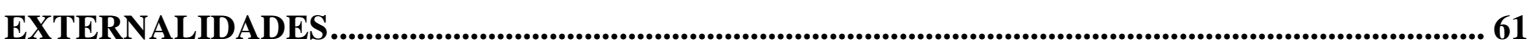

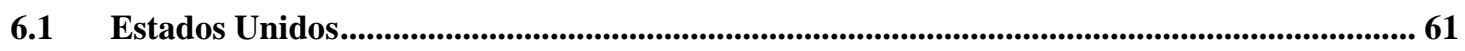

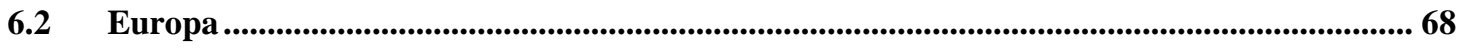

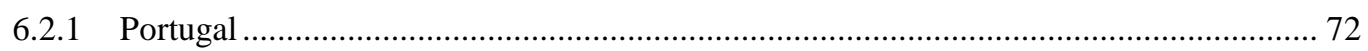

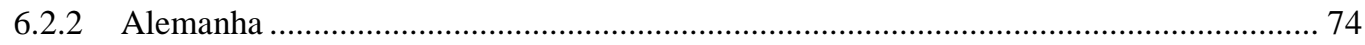

6.3 Transferência de resultados e análise de incerteza das estimativas ........................................... 75 
7 ANÁLISE DE CUSTOS EQUIVALENTES.

7.1 Avaliação de custos equivalentes com a inclusão de externalidades positivas (crédito de carbono)

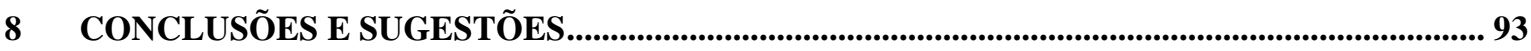

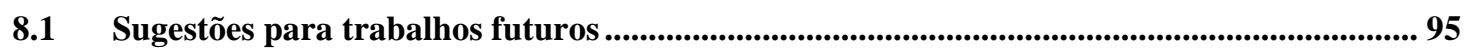

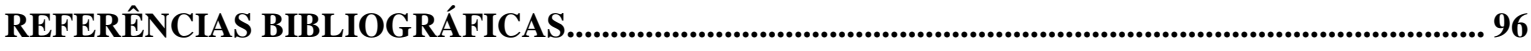

APÊNDICE I - PROGRAMAS GOVERNAMENTAIS.......................................................................... 100

Programa de Incentivo as Fontes Alternativas de Energia (PROINFA) ................................... 100

Programa Nacional de Universalização do Acesso e Uso da Energia Elétrica (LUZ PARA

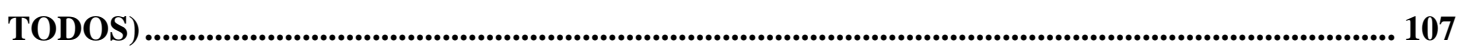

APÊNDICE II - CORREÇÕES DE VALORES PELO IGP-M .......................................................... 110

APÊNDICE III - ATUALIZAÇÃO DAS ESTIMATIVAS DE CUSTOS AMBIENTAIS.................... 113

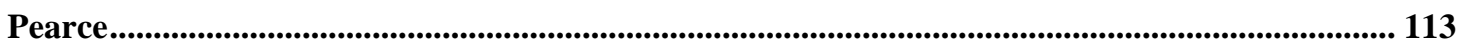

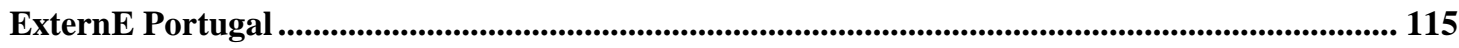

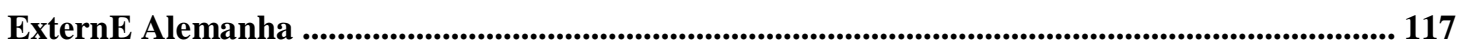




\section{INTRODUÇÃO}

\subsection{Motivação}

Questões relativas à energia podem ser visualizadas desde os primórdios, já que sua produção, transferência, distribuição e consumo têm por finalidade satisfazer às necessidades do ser humano. Desde o homem primitivo, que se utilizava dos fluxos energéticos naturais (sol, vento, água e alimentos) e tinha um consumo médio de $2.000 \mathrm{kcal} /$ dia (Lascio, 2007), até os dias atuais, constata-se também que a evolução humana está diretamente relacionada com o controle das fontes de energia.

Fatos marcantes, como a descoberta do fogo (400.000 AC a 250.000 AC), que impulsionou o consumo, ainda na pré-história, para aproximadas $5 \mathrm{kcal} / \mathrm{dia}$ (Lascio, 2007), a invenção da bicicleta, considerada por muitos a segunda maior invenção dos tempos pela sua eficiência, tendo em vista um consumo de $17 \mathrm{kcal} /(\mathrm{km}$.passageiro) (Lascio, 2007) com uma velocidade média de $24 \mathrm{~km} / \mathrm{h}$, confirmam a idéia de que o ser humano ao longo dos tempos vem tentando aprimorar o controle das fontes de energia, pois é do conhecimento atual que a energia agrega avanços tecnológicos, qualidade de vida e inclusão social.

Entre as conseqüências do desenvolvimento da humanidade citado, é preciso ressaltar o crescimento populacional, que acarreta em aumento do consumo de recursos e, segundo Di Lascio (2008), acelera o envenenamento do planeta; logo, existe a necessidade de se abordar energia de uma forma multidisciplinar, levando em conta além dos fatores tecnológicos, fatores ambientais, econômicos, políticos, sociais, entre outros.

Ultimamente, indagações vêm sendo feitas tendo em vista o tema em voga a respeito da escassez de alguns recursos não-renováveis que respondem por uma fatia considerável da matriz energética mundial. Entretanto, afirmações que ratificam a abundância dos recursos energéticos, e que indicam que algumas fontes sozinhas têm capacidade para suprir toda a demanda de energia da humanidade, tais como solar, carvão, geotérmica, nuclear, ventos e marés, não levam em conta fatos como a variação tecnológica e a quantidade de investimento e tempo que cada país atualmente despende no planejamento. 
Há de se levar em conta também a desigual repartição de recursos em torno do globo. Logo, não existe escassez de energia, porém esta prevalece ante a dificuldade de se adequar a geração às diferentes particularidades de cada localidade. Sabe-se que aproximadamente um terço da população mundial não tem acesso à energia elétrica (World Energy Assessment - WEA, 2000). No Brasil, este número chega a cerca de 10 milhões ${ }^{1}$, ou seja, mais de $5 \%$ da população nacional, em sua maioria habitante da área rural·(Agência Nacional de Energia Elétrica - ANEEL, 2008).

De fato o ser humano depende cada vez mais da energia para diversas finalidades entre elas a iluminação, aquecimento, resfriamento, comunicação, entre outras. Portanto comprova-se que a energia está diretamente relacionada ao desenvolvimento.

A energia pode ser considerada também como um forte indicador dos padrões de desenvolvimento e acesso a informação e qualidade de vida de um país, fato este comprovado pela relevância dos indicadores sócio-econômicos relacionados ao tema presentes no Atlas do Desenvolvimento Humano, que é elaborado pelo Programa das Nações Unidades para o Desenvolvimento (PNUD). Os indicadores de acesso a energia presentes na área de moradia estão relacionados abaixo.

Tabela 1.1 - Indicadores PNUD relativos à energia.

\begin{tabular}{|c|l|}
\hline INDICADOR & \multicolumn{1}{|c|}{ GLOSSÁRIO } \\
\hline $\begin{array}{c}\text { Percentual de pessoas que vivem em } \\
\text { domicílios com energia elétrica }\end{array}$ & $\begin{array}{l}\text { Percentual de pessoas que vivem em } \\
\text { domicílios com iluminação elétrica, } \\
\text { proveniente ou não de uma rede geral, com } \\
\text { ou sem medidor. }\end{array}$ \\
\hline $\begin{array}{c}\text { Percentual de pessoas que vivem em } \\
\text { domicílios com energia elétrica e TV }\end{array}$ & $\begin{array}{l}\text { Percentual de pessoas que vivem em } \\
\text { domicílios com energia elétrica e aparelho } \\
\text { de televisão em cores ou preto e branco que } \\
\text { esteja em condições de uso. }\end{array}$ \\
\hline $\begin{array}{l}\text { Percentual de pessoas que vivem em } \\
\text { domicílios com energia elétrica e geladeira }\end{array}$ \\
\hline $\begin{array}{l}\text { Percentual de pessoas que vivem em } \\
\text { domicílios com energia elétrica e com } \\
\text { geladeira ou freezer em condições de uso. }\end{array}$ \\
\hline
\end{tabular}

Fonte: (PNUD - Programa das Nações Unidas para o Desenvolvimento, 2009) - Atlas do Desenvolvimento Humano. Disponível em: 〈http://www.pnud.org.br〉

\footnotetext{
${ }^{1}$ Dados retirados do Atlas da Energia Elétrica do Brasil (ANEEL, 2008), onde se estima que 95\% da população já possuam acesso a energia elétrica. Tal estudo leva em consideração o último censo do Instituto Brasileiro de Geografia e Estatística (IBGE) em 2000, onde se estima uma população com quase 184 milhões de habitantes.
} 
Entretanto grande parte da energia gerada atualmente provém de combustíveis fósseis, e já se percebe que o consumo das reservas descobertas destes vem se esgotando a cada dia, o que os torna mais valiosos, devido à relação econômica entre oferta e demanda, estando os países que possuem grande parte de sua matriz energética voltada para a utilização destes combustíveis cada dia mais vulneráveis às suas oscilações de mercado.

Um bom exemplo diz respeito à escalada do petróleo que, no primeiro semestre de 2008, ultrapassou a barreira dos U\$ 140/barril, enquanto, em outubro de 2009, encerrou o referido mês cotado a US\$77,00/barril (ADVFN Portal Financeiro, 2009).

Porém observa-se que a demanda de energia cresce vertiginosamente ao longo dos anos, logo além de suplantar uma demanda reprimida existe a necessidade de um planejamento para o consumo do futuro. Por outro lado, os impactos ambientais causados pela geração e consumo de energia representam sérios problemas para a qualidade de vida atual e futura do ser humano.

Tais problemas são ressaltados e comprovados por estudos sobre o comportamento climático do planeta, tais como os estudos produzidos pelo Intergovernmental Panel on Climate Change (IPCC) ${ }^{2}$ que indicam conseqüências graves para as gerações futuras mesmo que seja implantada uma grande conscientização a respeito do desenvolvimento sustentável na geração atual. Tais informações servem de fomento para indicar a necessidade de mudança nas atuais estruturas de desenvolvimento energético, que não pode ser considerado sustentável em seus diversos prismas (ambiental, econômico, social, etc...).

Levando em conta que o acesso a energia é dificultado pelas distâncias a serem percorridas pelas linhas de transmissão, e pelos interesses dos produtores, começa a existir uma busca por tecnologias de geração que permitam a auto-suficiência energética da localidade por intermédio de fontes renováveis e ambientalmente limpas. Tais soluções seriam as

\footnotetext{
${ }^{2}$ Trata-se de um corpo intergovernamental criado pela World Meteorological Organization (WMO) e pelas Nações Unidas através do programa United Nations Environment Programme (UNEP), constituída pelos governos de países membros do UNEP e WMO, cientistas que fazem o trabalho de contribuição e revisão dos relatórios e pessoas envolvidas com as atividades das Nações Unidas. Tem por objetivo trazer informações sobre as causas das mudanças climáticas e a potencial consequiência ambiental e socioeconômica e as opções de adaptação e amenização para responder a tais alterações.
} 
responsáveis pelo acesso a energia, e conseqüente acesso a informação e melhoria da qualidade de vida.

De forma a tentar amenizar o problema do acesso a energia e melhorar os indicadores socioeconômicos municipais e conseqüentemente nacionais, o governo tem lançado programas no intuito de facilitar a geração e o acesso à energia, como o PROINFA (Lei n. ${ }^{\circ}$ 10.438/2002) e o LUZ PARA TODOS (Decreto $n .^{\circ} 4.873 / 2003$ ). Uma breve descrição de tais programas governamentais pode ser observada no APÊNCIDE I.

\subsection{Proposta}

Neste trabalho se desenvolve uma metodologia na tentativa de se estimar em valores monetários as externalidades advindas da geração de energia elétrica por variadas fontes de eletricidade, para que seja possível observar o quanto tais externalidades podem alterar as estimativas de custo de cunho técnico-financeiro.

Desta forma, pretende-se mostrar por intermédio de simulações e análises, uma estimativa de custo final da energia produzida por fontes alternativas, e sua eventual comparação com a solução convencional no atendimento a cargas isoladas no país, que atualmente é baseada na geração a diesel.

Entretanto, observa-se uma grande variação bibliográfica em relação às grandezas que compõem o custo da energia, sendo assim se entendeu como necessária a condução da avaliação considerando incertezas. Portanto se fará uso da técnica de Análise de Sensibilidade, que é baseada em uma análise de riscos onde a variação dos parâmetros de entrada é expressa por uma margem de erro percentual, ou uma faixa de valores possíveis.

Desta forma, para condução deste estudo foi confeccionada uma planilha utilizando o software Excel, onde são inseridos os parâmetros de entrada (dados técnicos, dados financeiros, estimativas econômicas das externalidades) que compõem a formulação matemática que será posteriormente apresentada. Tais parâmetros, em alguns casos, são considerados como uma faixa de valores devido à variação anteriormente citada. 
Sendo assim, foram utilizados os recursos do EXCEL para se desenvolver os cálculos propostos na formulação matemática deste estudo, e para se realizar a simulação de diversos resultados de estimativa de custo, de forma a se considerar as incertezas relacionadas às estimativas, considerando assim a análise de sensibilidade.

As simulações citadas são baseadas na geração de cinco mil casos distintos para a estimativa de custos, para cada tipo de solução de geração. A partir de tais simulações se torna possível determinar a média dos custos estimados e o desvio-padrão, de cada solução de geração. Sendo assim, consegue-se apresentar as curvas de distribuição de probabilidade dos valores estimados.

Tais curvas possibilitaram a análise de sensibilidade do projeto. Conhecendo-se tais resultados o estudo é conduzido para o acréscimo das estimativas de custos das externalidades, que serão introduzidos como diferenciais de custos (positivos ou negativos).

No intuito de se atender a realidade de atendimento a cargas isoladas, os aspectos técnicos relativos aos dados de entrada de simulação foram selecionados de forma a retratar tal realidade. Desta forma se optou por uma pequena carga a ser atendida, de potência nominal de $100 \mathrm{~kW}$, com funcionamento diário médio de 12 horas. Outro motivo pela escolha de tal carga diz respeito ao fato de que esta pode ser atendida por todas as soluções de geração a serem analisadas neste estudo.

Por exemplo, tal carga pode ser representada por uma pequena comunidade, ou algum pequeno empreendimento distante da rede elétrica. Com base em tal carga se determina a energia necessária para o atendimento e conseqüentemente a potência nominal de geração da fonte escolhida para o atendimento. Desta forma se apresentou uma modelagem matemática para o cálculo do custo da energia.

A premissa utilizada em todas as simulações que se seguem é a de que todas as fontes em questão possuem plena condição de atendimento à carga. Assim, não é utilizado nenhum método multicritério para eliminação de uma determinada fonte por não haver, por exemplo, o combustível ou a área necessária para a sua implantação. 
As fontes alternativas discutidas neste estudo, atualmente, tratam das soluções mais difundidas para a diversificação da matriz energética e por isso representam um grande leque de referências bibliográficas no intuito de subsidiar informações as considerações efetuadas por este estudo. Entende-se que para tais fontes se tem razoável domínio da tecnologia de geração, já que possuem fácil aplicação e manutenção, além do que, tratam de alternativas que com o passar dos tempos vem recebendo maior atenção em âmbito nacional, fato este que pode ser comprovado por intermédio dos projetos descritos no APÊNDICE I.

Desta forma, optou-se pela avaliação da geração eólica, solar fotovoltaica, biomassa e pequena central hidroelétrica (PCH), além da avaliação da geração convencional a diesel. É relevante observar que a geração por PCH deve ser entendida, para este estudo, como a designação para um simples aproveitamento hídrico, tal fato será melhor explanado no decorrer do estudo.

\subsubsection{Estruturação do estudo}

O seguinte estudo foi estruturado em sete capítulos que visam, de forma conjunta, explanar detalhadamente a metodologia desenvolvida até o alcance do objetivo final de se ter um custo associado à geração de cada uma das fontes analisadas, incluindo as externalidades.

No presente capítulo, é apresentada a motivação para tal estudo e a proposta de desenvolvimento do estudo, além da apresentação da estrutura adotada para o desenvolvimento do estudo.

O capítulo 2 apresenta uma breve discussão sobre geração distribuída (GD), onde são apresentadas as tecnologias mais utilizadas para GD, algumas vantagens e desvantagens da utilização prática deste conceito de geração e a aplicação em sistemas isolados da rede elétrica.

O capítulo 3 apresenta uma abordagem genérica a respeito das fontes de energia que serão analisadas, por intermédio de informações a respeito do desenvolvimento destas nos últimos anos, e como estas estão sendo utilizadas atualmente no Brasil e no mundo, além de algumas previsões futuras. 
Já no capítulo 4, é desenvolvida a metodologia para se estimar os valores econômicos da energia sem o adicional das externalidades. Para tanto, é efetuado um levantamento de parâmetros técnico-financeiros de cada tecnologia adotada, e se apresenta a modelagem matemática para a estimativa dos valores econômicos. Por fim, são apresentadas as análises relativas aos resultados das simulações propostas para a estimativa de custos considerando a análise de sensibilidade.

Os capítulos 5 e 6 contemplam os estudos relativos às externalidades ambientais relativas às atividades do setor elétrico. No quinto capítulo, estas são apresentadas e as principais metodologias existentes para a avaliação econômica destas são resumidamente apresentadas. Já no capítulo 6, são apresentados estudos desenvolvidos em outros países para a avaliação econômica de externalidades ambientais.

Tais estudos são então considerados, e seus resultados atualizados. Entretanto a consideração de tais resultados acarreta na introdução de incertezas relativas às metodologias de avaliação econômica. E, novamente se pode considerar a análise de sensibilidade, condizente com os objetivos propostos.

Por fim, no capítulo 7, têm-se a aplicação dos resultados das estimativas dos custos externos à análise de custos anteriormente desenvolvida. Assim, se torne possível estimar o custo equivalente da energia quando são considerados aspectos econômico-financeiros e aspectos externos ao processo de geração de energia. 


\section{GERAÇÃO DISTRIBUÍDA}

Será utilizada neste trabalho uma definição bastante genérica proposta por Severino (2008) na busca por uma diferenciação entre a geração distribuída (GD) e a geração convencional, dita centralizada que é utilizada como principal modelo de geração de energia ao redor do globo atualmente.

"Geração Distribuída é a denominação genérica de um tipo de geração de energia elétrica que se diferencia da realizada pela geração centralizada por ocorrer em locais em que não seria instalada uma usina geradora convencional, contribuindo para aumentar a distribuição geográfica da geração de energia elétrica em determinada região.”

Este tipo de geração vem sendo cada vez mais utilizada e é de notável destaque a aplicação de técnicas de geração distribuída no tocante ao suporte à rede de energia, co-geração (principalmente relacionada ao fornecimento de energia em horários de pico), corte de picos de carga e utilização para o fornecimento de energia a sistemas remotos e/ou isolados da rede convencional. Para este estudo será dado especial enfoque ao último caso citado.

$\mathrm{O}$ produto eletricidade tem como principal característica o fato de ter um fluxo não estocável, fruto da existência dos processos de geração e utilização, além do fluxo que os integra no tempo e espaço. Assim, quando estes processos não são contíguos no espaço, o sistema passa a contar com mais dois processos que são a transmissão e distribuição. Fica evidenciada assim a interdependência temporal e espacial entre estes quatro componentes.

Sendo assim, os atributos da eletricidade, não-estocabilidade e interdependência sistêmica, trouxeram algumas especificidades técnico-econômicas tais como: (i) a necessidade de antecipação do comportamento da demanda e (ii) a sobrecapacidade planejada, tanto de produção quanto de transporte, devido às características da demanda (Queiroz, 2007).

Devido aos elevados volumes de investimentos e longos prazos de maturação, tais especificidades justificavam a necessidade da coordenação dos operadores do sistema elétrico, visando à redução de custos e garantir a estabilidade e confiabilidade do mesmo. Este conjunto de fatores justificou por muito tempo a formação de um modo de 
organização industrial formado por empresas integradas verticalmente e operando em regime de monopólio.

É de conhecimento que ao longo dos tempos os sistemas elétricos têm atendido a demanda de consumo de energia se utilizando de geração centralizada, onde as usinas geradoras são geralmente de grande porte e localizadas em áreas onde exista alta ocorrência da fonte de geração, de forma a maximizar a produção e o controle do sistema, e tais usinas estão ligadas a extensas linhas de transmissão e distribuição.

Entretanto a indústria vem experimentando, desde o início da década de 1980, um amplo processo de reestruturação no modo de organização industrial, que vem caracterizando sua expansão, destacando-se o impacto das inovações tecnológicas sobre as estruturas de mercado.

Entretanto, no tocante ao fornecimento de energia, notamos que regiões distantes, com baixo Índice de Desenvolvimento Humano (IDH), e que conseqüentemente exijam uma demanda de consumo muito baixa não representam um alvo em potencial para o prisma econômico do negócio "fornecimento de energia", sendo assim por não se tratar de um investimento economicamente viável, que dirá lucrativo, ainda existem várias localidades não somente sem acesso a energia elétrica via extensão da rede convencional como também sem previsão ou planejamento para que tal fato ocorra.

O fornecimento de energia elétrica a usuários sem acesso a esta e o atual modelo de geração surgem como possíveis fatores para alavancar a expansão do mercado por soluções de Geração Distribuída, cada vez mais presentes na esfera da geração de energia. Outro fator importante a ser destacado é a possibilidade de um melhor aproveitamento na utilização de fontes de energia renováveis em comparação ao sistema elétrico de geração convencional, atualmente muito enraizado na utilização de tecnologias não-renováveis e altamente agressivas ao meio ambiente.

\subsection{Fatores impulsionadores da geração distribuída}

Atualmente, a GD possui como principais aliados fatores tais como a proteção ao meio ambiente, avanços tecnológicos, a iminente reestruturação do setor elétrico e o aumento da 
demanda por energia que vem acarretando na perda da qualidade da mesma ao redor do planeta.

Cada vez mais o desenvolvimento sustentável passa a fazer parte da realidade mundial, e existe uma gama de tecnologias de GD que se assenta em uma filosofia de geração sustentável e combustíveis renováveis, além das reformulações nas regulamentações ambientais que prezam cada vez mais pela utilização de recursos renováveis, o que causa uma alta exigência ambiental e de eficiência energética.

Mudanças no setor elétrico, em vários países, para a liberalização do setor, fez com que diversas empresas tivessem a oportunidade de entrar no mercado de produção de energia. Tais empresas têm a oportunidade de estudarem falhas de mercado de forma a oferecerem melhores soluções aos clientes afetados, permitindo uma gama maior de opções para suprir as necessidades de consumo dos clientes.

Estudos relativos às tecnologias permitiram a diminuição de custos, a mitigação do efeito dos impactos ambientais com certas tecnologias e fortaleceram a utilização no aspecto da confiabilidade em certas tecnologias de geração.

\subsection{Tecnologias}

Sabe-se que a GD é utilizada em conjunto com outras tecnologias de geração. Desta forma, destacam-se diversas tecnologias de GD que podem ser observadas através da Tabela 2.1 a seguir bem como a capacidade de geração associada a cada alternativa.

Tabela 2.1 - Tecnologias associadas à geração distribuída.

TECNOLOGIA

Pequena Central Hidroelétrica

Micro Hidroelétrica

Turbina Eólica

Fotovoltaica

Térmica Solar

Biomassa

Célula Combustível

Geotérmica

Energia das marés

Motor de Combustão Interna

Turbina a Gás (Ciclo Combinado)

Turbina a Combustão

Micro turbina

\section{CAPACIDADE DE GERAÇÃO} $1 \mathrm{MW}-100 \mathrm{MW}$

$25 \mathrm{~kW}-1 \mathrm{MW}$

$200 \mathrm{~W}-3 \mathrm{MW}$

$20 \mathrm{~W}-100 \mathrm{~kW}$

$1 \mathrm{MW}-80 \mathrm{MW}$

$100 \mathrm{~kW}-20 \mathrm{MW}$

$1 \mathrm{KW}-5 \mathrm{MW}$

$5 \mathrm{MW}-100 \mathrm{MW}$

$100 \mathrm{~kW}-1 \mathrm{MW}$

$5 \mathrm{KW}-10 \mathrm{MW}$

$35 \mathrm{MW}-400 \mathrm{MW}$

$1 \mathrm{MW}-250 \mathrm{MW}$

$35 \mathrm{~kW}-1 \mathrm{MW}$

Fonte: Severino (2008), adaptado. 


\subsection{Vantagens e desvantagens}

Sendo a geração distribuída aquela não considerada como centralizada e de grande porte, estando esta próxima do local de consumo, pode-se elencar as seguintes vantagens na utilização das técnicas de GD:

- Diminuição das perdas nas linhas de transmissão e distribuição.

- Diminuição de custos para implementação de novas centrais, já que com a GD novas unidades produtoras podem ser instaladas de forma modular à medida que aumenta a demanda de fornecimento.

- Diminuição de riscos com planejamento, tendo em vista o porte menor das soluções e a flexibilidade das mesmas.

- Aumento da qualidade do serviço para consumidores próximos a produção, já que tais sistemas implicam em uma redução do risco a falhas de transmissão e distribuição.

- Diminuição no tempo de implementação, devido ao porte menor, o que facilita uma resposta mais rápida ao crescimento da procura por fornecimento de energia.

- Personalização dos serviços para atendimento às particularidades de cada solução e cliente.

- Disponibilidade em locais remotos e de difícil acesso à energia convencional.

- Diminuição dos impactos ambientais, tendo em vista a utilização de fontes energéticas menos poluentes.

Entretanto, devem ser levadas em consideração algumas desvantagens produzidas pela inserção da GD no mundo atual, principalmente no que diz respeito ao aumento no número de entidades envolvidas e a separação das funções de distribuição e comercialização de energia. Desta forma, pode-se elencar as seguintes desvantagens:

- Maior complexidade para o planejamento e operação do sistema elétrico.

- Aumento na complexidade administrativa e comercial para a viabilização da concessão dos serviços.

- Tendência de aumento dos preços médios de fornecimento devido à diminuição do fator de utilização das instalações de transmissão/distribuição, bem como de centrais produtoras. 


\subsection{Sistemas isolados}

O termo "sistemas isolados", quando tratamos de energia elétrica, refere-se principalmente às regiões geográficas não atendidas pelos sistemas de transmissão convencionais. No Brasil são assim denominados por não estarem ligados ao Sistema Interligado Nacional (SIN) e por não permitirem o intercâmbio de energia com outras regiões, na maioria dos casos devido às peculiaridades geográficas da região em que estão instalados, sendo predominantemente abastecidos por usinas térmicas movidas a óleo diesel, embora também possam ser abastecidos por aproveitamentos hidroelétricos e termelétricas movidas a biomassa.

Tais sistemas estão localizados, no Brasil, principalmente na região Norte: nos estados do Acre, Amapá, Amazonas, Rondônia e Roraima. Segundo a Centrais Elétricas Brasileiras S.A. (ELETROBRÁS), tais sistemas atendem a $45 \%$ do território nacional, porém atingem somente $3 \%$ da população (aproximadamente 1,3 milhão de consumidores em 380 localidades). E, em 2008 representavam 3,4\% da energia elétrica produzida no país.

Devido à predominância térmica, no Brasil, tais sistemas apresentam custos superiores ao SIN. Principalmente devido às dificuldades com logística e abastecimento das localidades, que fazem com que o preço do frete de combustíveis seja elevado. Porém, para assegurar o atendimento da população aos benefícios do acesso a energia elétrica o Governo Federal criou a Conta de Consumo de Combustíveis Fósseis $(\mathrm{CCC})^{3}$, de forma a subsidiar a compra de combustíveis utilizados na geração de energia para atendimento das áreas isoladas.

\footnotetext{
${ }^{3}$ CCC: Encargo do setor elétrico cobrado nas tarifas de distribuição e de uso dos sistemas elétricos de distribuição e transmissão, para cobrir os custos anuais da geração térmica produzida no país através de sistemas isolados. Foi instituída através da Lei n. ${ }^{\circ}$ 5899/1973 e alterada através da Lei 8631/1993, que estabeleceu o rateio entre as sub-contas das respectivas regiões nacionais. Seus recursos são administrados pela Eletrobrás e as cotas anuais são fixadas pela ANEEL (ANEEL, 2008).
} 


\section{FONTES DE ENERGIA}

$\mathrm{O}$ aproveitamento das fontes de energia pelo homem pressupõe a identificação de necessidades, cuja dimensão determina a escolha da alternativa do recurso energético e a escala destinada a tirar partido deste recurso com vista à satisfação daquelas necessidades (Bermann, 2003).

Tal afirmação preconiza a existência de interesses cujo caráter é explicitado por intermédio da forma com a qual a sociedade participa do processo de decisão, seja este um perfil de desenvolvimento imposto pelo Estado ou levando em conta as considerações da mesma, principalmente no que diz respeito ao bem-estar da sociedade.

Quando o assunto é política energética, é notável sua dimensão econômica, tendo em vista sua identificação direta com o crescimento econômico. Além de o setor ser um importante arrecadador de impostos, desempenhando papel fundamental na formação de receitas para o Estado.

Pode-se observar esta forte correlação exemplificando o período de 1971 a 2002, quando a economia mundial cresceu 3,3\% a.a., em média, e o consumo da eletricidade 3,6\% a.a. Estima-se um crescimento de 2,5\% a.a., entre 2002 e 2030, para o consumo de eletricidade, enquanto a economia deve crescer 3,2\% a.a., segundo estimativas da International Energy Agency (IEA, 2009).

Sendo assim, é notável a necessidade da diversificação das fontes de suprimento em substituição ao petróleo, bem como a ampliação da participação de fontes renováveis na matriz energética.

Atualmente, existe uma percepção crescente para mudanças nas diretrizes das políticas energéticas de quase todos os países do mundo, devido às mudanças climáticas que estão a ocorrer principalmente pela emissão de Gases do Efeito Estufa (GEE). Assim, será realizada a Conferência das Partes sobre o Clima (COP - 15), em dezembro deste ano, em Copenhague na Dinamarca, que possui a pretensão de firmar um acordo global para a redução destas emissões. 
O Brasil tem como proposta reduzir 38,9\% das emissões até 2020 , o que custaria cerca de 10 bilhões de reais anuais ao longo de uma década, segundo o ministro do Meio Ambiente Carlos Minc Baumfeld.

No entanto, não é esperado que a reunião de Copenhague resulte em um acordo efetivo, visto os resultados da última Cúpula do Clima, em Nova York, e o último encontro do G20 ${ }^{4}$, em Pittsburgh. Como afirma Paulo Artaxo, físico e professor da USP, "é muito fácil dizer isso [redução das emissões] sem dizer como fazer e, principalmente, quem vai pagar por isso. Essa discussão restante vai acontecer na COP - 15 e nos próximos 50 anos".

Apesar da vasta gama de tecnologias utilizadas atualmente para o fornecimento de energia, entende-se como ideal uma análise mais aprofundada e focada na realidade do cenário brasileiro, levando-se em consideração a geração distribuída.

Portanto, este estudo explora as fontes predominantes dos programas de incentivo à diversificação da matriz energética brasileira e acesso a energia elétrica, sendo estas a geração eólica, $\mathrm{PCH}$, biomassa e solar fotovoltaica. Além da comparação com a geração a diesel, usualmente utilizada para o atendimento de cargas isoladas.

\subsection{Energia hidroelétrica}

No Brasil, a energia provinda da água é a mais utilizada na geração de eletricidade, isto se deve ao país possuir $8 \%$ do total de água doce existente no mundo, tendo esta fonte como a mais abundante e de menor custo de geração, além de ter o terceiro maior potencial hidrelétrico do mundo, cerca de 10\% (ANEEL, 2008).

A potência hidroelétrica instalada no país atualmente, é de aproximadamente 78,4 GW (UHE 75.250.127 $\mathrm{kW}^{5}$, CGH 171.354 $\mathrm{kW}^{6}, \mathrm{PCH} 2.941 .609 \mathrm{~kW}$ ), que corresponde a $72,3 \%$ da capacidade total instalada no país, considerando-se todas as fontes. Tal grandeza representa cerca de $30 \%$ do potencial total hídrico brasileiro, que é de $258.410 \mathrm{MW}$ (ELETROBRAS, 2009).

\footnotetext{
${ }^{4}$ Grupo das vinte maiores economias do planeta.

${ }^{5}$ Usina Hidroelétrica.

${ }^{6}$ Central de Geração Hidroelétrica.
} 
No atual cenário mundial, em que se buscam cada vez mais alternativas para produzir energia elétrica afetando o mínimo possível o meio ambiente, projetos de hidroelétricas de grande porte que requerem grandes reservatórios e conseqüentemente afetam o curso do rio, a flora, a fauna local e a população ribeirinha sofrem cada vez mais empecilhos para a sua concretização.

Por isso, espera-se que o aumento necessário na produção de energia hidroelétrica ocorra com a utilização de usinas de menor porte. Neste contexto as $\mathrm{PCH}$, que tem potencial estimado no país de 17 GW, segundo a Empresa de Pesquisa Energética (EPE), tomam força.

Por possuírem pequena área de reservatório, as $\mathrm{PCH}$, se não instaladas em grande número ao longo de um mesmo rio, possuem baixo impacto ambiental. Caso contrário, apresentam os mesmos impactos que os grandes aproveitamentos.

As PCH possuem uma vida útil longa e trata da solução de geração mais consolidada dentre as alternativas do PROINFA, podendo-se encontrar no mercado nacional quase todos os equipamentos e a mão-de-obra necessária para a sua implantação. Tendo ainda boa aceitação por parte dos movimentos sociais e ambientalistas.

\subsection{Energia eólica}

Uma das alternativas de geração com grande destaque no cenário nacional atualmente é a geração eólica. Sendo que esta possui uma vantagem frente às fontes convencionais de produção de energia, já que da área total reservada para cada unidade, apenas $1 \%$ é ocupada com a instalação da turbina, apesar dos aparatos mecânicos de tais construções serem enormes. O restante da área pode ser aproveitado para outros fins, como pastagem. Outra vantagem é obviamente a não necessidade de custeio de combustível (PETROBRÁS).

Como principal desvantagem, possui o custo, que embora decrescente, ainda é elevado. Em 2008, no Brasil, considerando-se os impostos embutidos, este era estimado em aproximadamente R\$230,00/MWh (ELETROBRÁS). 
Além disto, a energia que uma turbina produz em sua vida útil, chega a ser oito vezes maior que a energia usada para construí-la, mantê-la, operá-la, desmontá-la e recuperá-la totalmente.

Não existem muitos estudos integrados relativos ao potencial eólico, e na tentativa de se ter uma fonte consistente e confiável, elaborou-se o Atlas do Potencial Eólico Brasileiro, pelo Centro de Referência para Energia Solar e Eólica (CRESESB), que inclui condicionantes geográficas em uma simulação do potencial eólico em todo território brasileiro. $\mathrm{O}$ resultado da análise deste atlas para cada região brasileira pode ser visto na Tabela 3.1.

\begin{tabular}{|c|c|c|c|c|c|c|c|c|c|}
\hline \multirow[b]{2}{*}{ REGLAO } & \multicolumn{5}{|c|}{ INTEGRACAOO POR FAIXAS DE VELOCIDADES } & \multicolumn{4}{|c|}{ INTEGRAGAO CUMULATVA } \\
\hline & $\begin{array}{l}\text { VENTO } \\
\text { [m's] }\end{array}$ & $\begin{array}{l}\text { AREA } \\
\left|\mathrm{km}^{2}\right|\end{array}$ & $\begin{array}{l}\text { POTENCIA } \\
\text { INSTALAVEL } \\
\text { [GW] }\end{array}$ & $\begin{array}{l}\text { FATOR DE } \\
\text { CAPACIDADE }\end{array}$ & $\begin{array}{l}\text { ENERGIA } \\
\text { ANuAL } \\
\text { [TWhand }\end{array}$ & $\begin{array}{l}\text { VENTO } \\
\text { [m/s] }\end{array}$ & $\begin{array}{l}\text { AREA } \\
\text { (CUMULATIVA) } \\
\text { (km?) }\end{array}$ & $\begin{array}{l}\text { POTENCIA } \\
\text { INSTALAAVEL } \\
\text { [GW] }\end{array}$ & $\begin{array}{l}\text { ENERGIA } \\
\text { ANUAL. } \\
\text { (TWWVano) }\end{array}$ \\
\hline \multirow[t]{6}{*}{ NORTE } & $6.6,5$ & 11460 & 22,92 & 0.13 & 25.58 & $>6$ & 24206 & 48,41 & 70,49 \\
\hline & $6.5+7$ & 6326 & 12.65 & 0,17 & 18.46 & $\times 6.5$ & 12746 & 25.49 & 44,91 \\
\hline & $7=7.5$ & 3300 & 660 & 0.20 & 11,33 & $>7 \mathrm{mis}$ & 6420 & 12,84 & 26,45 \\
\hline & $7,5 \cdot 8$ & 1668 & 333 & 0.25 & 7.15 & $>7,5$ & 3120 & 8.24 & 15,11 \\
\hline & 8.85 & 903 & 181 & 0.30 & 4.65 & $>8$ & 1454 & 2.91 & 7,96 \\
\hline & $>8.5$ & 551 & 1,10 & 0,35 & 3,31 & $>8,5$ & 551 & 1,10 & 3,31 \\
\hline \multirow[t]{6}{*}{ NOROESTE } & $6-6.5$ & 246599 & 298,19 & 0.13 & 327.19 & 36 & 245105 & 490.21 & 649.50 \\
\hline & $6,5 \cdot 7$ & 60990 & 121,98 & 0.17 & 178.02 & $\times 6,5$ & 98516 & 197,03 & 322,35 \\
\hline & $x-7.5$ & 24383 & 48,77 & 0,20 & 83.73 & $>7 \mathrm{mis}$ & 37526 & 75,05 & 144,29 \\
\hline & $7,5 \cdot 8$ & 9185 & 18,37 & 0.25 & 39,43 & $>7,5$ & 13143 & 26,29 & 80,58 \\
\hline & 8.85 & 3089 & 618 & 030 & 15,91 & $>8$ & 3958 & 7.92 & 21,13 \\
\hline & $>8.5$ & 870 & 1,74 & 0.35 & 5.23 & $>8.5$ & 870 & 1,74 & 5,23 \\
\hline \multirow{6}{*}{ CENTRO.OESTE } & 6.65 & 41110 & 8222 & 0,03 & 91,76 & 36 & 50752 & 10150 & 12083 \\
\hline & 8.5 .7 & 8101 & 16.20 & 0.17 & 23,65 & $\times 6.5$ & 9642 & 18.28 & 29.07 \\
\hline & 7.7 .5 & 1395 & 279 & 0.20 & 4.79 & $>7 \mathrm{~m} / \mathrm{s}$ & 1541 & 3,08 & 5,42 \\
\hline & $7,5=8$ & 140 & 0.28 & 0.25 & 0,60 & $>7.5$ & 146 & 0,29 & 0.83 \\
\hline & 8.85 & 6 & 0,01 & 0.30 & 0,03 & $>8$ & 6 & 0,01 & 0,03 \\
\hline & -8.5 & $D$ & 0.00 & 0,35 & 0.00 & $>8,5$ & 0 & 0,00 & 0,00 \\
\hline \multirow[t]{6}{*}{ SUDESTE } & $6.6,5$ & 114688 & 2229,38 & 0,13 & 255,99 & $>8$ & 175859 & 351,72 & 446,07 \\
\hline & $6.5+7$ & 46302 & 92,60 & 0,17 & 135,15 & $\times 6.5$ & 61171 & 122,34 & 190,08 \\
\hline & 7.75 & 11545 & 23.09 & 0.20 & 39,64 & $>7 \mathrm{~m} / \mathrm{s}$ & 14869 & 20.74 & 54,93 \\
\hline & $7,5-8$ & 2433 & 4.87 & 025 & 10,44 & $>7.5$ & 3324 & 6.65 & 15.29 \\
\hline & 8.8 .5 & 694 & 1,19 & 0,30 & 3.06 & $>8$ & 895 & 1,78 & 4,84 \\
\hline & $>8.5$ & 297 & 0,59 & 0,35 & 1.78 & $>8,5$ & 297 & 0,59 & 1,78 \\
\hline & & & & & & & & & \\
\hline \multirow{6}{*}{ 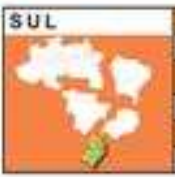 } & 6.6 .5 & 129798 & 243600 & 0.13 & 271,86 & $\$ 6$ & 171469 & 342,94 & 424.74 \\
\hline & 65.7 & 36292 & 76.58 & 0.17 & 111,77 & 76.5 & 49671 & 9934 & 152,88 \\
\hline & $7-7,5$ & 9436 & 18.87 & 020 & 32.40 & $37 \mathrm{~m} / \mathrm{s}$ & 11379 & 22,76 & 41,11 \\
\hline & 75.8 & 1573 & 3,15 & 0.25 & 6.75 & $>7.5$ & 1943 & 389 & 8.71 \\
\hline & 8.8 .5 & 323 & 0.63 & 0.30 & 1.61 & $>B$ & 370 & 0.74 & 1,95 \\
\hline & $>8.5$ & 57 & 0.11 & 0.36 & 0.34 & $>8.5$ & 37 & 0,11 & 0,34 \\
\hline & & & & & & $>6$ & 667391 & 1334.78 & 1711,62 \\
\hline & & & & & & 76,5 & 231746 & 463,49 & 739.24 \\
\hline & & & & & OTAL & $77 \mathrm{~m} / \mathrm{s}$ & 71735 & 143,47 & 272,20 \\
\hline & & & & & & $>7,5$ & 21676 & 43,35 & 100.30 \\
\hline & & & & & TIMAOU & 78 & 6679 & 13,36 & 35.93 \\
\hline & & & & & & $>8,5$ & 1775 & 3.55 & 10.67 \\
\hline
\end{tabular}

Fonte: Atlas do Potencial Eólico Brasileiro, (CRESESB, 2001).

Estimando-se um total de 143,47 GW de potencial de geração no país, em regiões que possuam ventos com velocidades médias maiores que $7 \mathrm{~m} / \mathrm{s}$. Estes dados não levam em conta o potencial off-shore ${ }^{7}$.

\footnotetext{
${ }^{7}$ Instalação de torres de geração no mar.
} 
A capacidade nacional instalada atualmente desta fonte é de $602.284 \mathrm{~kW}$. O Ceará ganha destaque em âmbito nacional, por ter sido um dos primeiros a fazer levantamentos sobre seu potencial eólico, e possuir $309.634 \mathrm{~kW}$ da capacidade instalada nacional, o que corresponde a 51,41\% do total, em novembro de 2009.

A dificuldade que esta solução encontra para se integrar a rede elétrica já existente se deve a necessidade de previsão de produção eólica e a utilização de investimentos e estratégias de armazenamento de energia. Já que a mesma possui uma intermitência maior que a solução hídrica, por exemplo, que trata da base do nosso sistema elétrico. Assim, as estratégias usualmente utilizadas são as de complementação da energia hídrica.

Outra grande dificuldade enfrentada por tal solução, diz respeito ao alto custo de implantação. Entretanto, com o rápido crescimento e investimento que esta solução vem recebendo, os custos tendem a baixar. $\mathrm{O}$ alto custo atual se deve a falta de uma indústria consolidada de geração, no Brasil, pois existe apenas uma única empresa de grande porte que produz equipamentos para geração eólica.

\subsection{Biomassa}

Dentre as alternativas de geração por biomassa será abordado por este estudo somente a biomassa de bagaço-de-cana, tendo em vista se tratar da solução mais consolidada e com maior investimento. Onde o bagaço originalmente era um rejeito nas usinas do setor sucroalcooleiro, sendo em parte já utilizado para geração de energia nas próprias usinas. Como tal setor já é bem desenvolvido e de grande porte no país, fica evidente a notoriedade desta solução em detrimento as demais opções.

Uma questão importante deve ser salientada a respeito desta fonte, haja vista que a geração de energia elétrica por meio desta, necessita de uma considerável área plantada com cana de açúcar, já que o transporte do bagaço da cana, devido o seu enorme volume, sai muito oneroso. Assim, só se torna atrativa a geração em áreas próximas as lavouras de cana, por exemplo, em uma colônia agrícola dentro de uma propriedade produtora.

Sabe-se que um hectare de cana produz 90 ton de bagaço em condições normais (Weingrill, 2007), e com o uso somente do bagaço se pode gerar 85,6 kWh para 
exportação, de acordo com a empresa Areva Koblitz. Com o uso adicional da ponta e da palha da cana, essa geração pode chegar a 199,9 kWh, com o uso de caldeiras de alta pressão. Assim, nessa última situação, necessita-se de uma área de aproximadamente 24 ha/ano, que é, por exemplo, em média o tamanho das propriedades destinadas a assentamentos do Paraterra ${ }^{8}$, programa de apoio à reforma agrária, em Minas Gerais.

Alguns fatores devem ser observados de forma a se efetuar a desconsideração das demais alternativas de geração por biomassa, tais como: (i) a biomassa de gás de lixo necessita de aterro sanitário, o que obviamente não há em regiões isoladas; (ii) considerando-se o abastecimento por matos de uma central de reduzidas dimensões, tal premissa ainda assim é insuficiente para a geração por biomassa a partir da madeira; e (iii) a biomassa de casca de arroz ainda trata de uma técnica pouco difundida e ainda estão em estudo as técnicas que viabilizam sua utilização para a geração de energia elétrica.

Outro fator a ser considerado diz respeito a um estudo realizado pela empresa Koblitz em 2004, onde se estimou que o maior potencial para termoelétricas brasileiras, considerando combustíveis não-fósseis, está no bagaço de cana, sendo tal potencial estimado em 12 GW.

Em 2008 a produção de energia elétrica baseada nessa fonte correspondia a 3\% da energia elétrica produzida no país, e estima-se que em 2011 chegue a 6\%. Das 405 usinas brasileiras a época, apenas 48 vendiam energia a distribuidoras ou outras empresas (Revista Exame, 2008).

O investimento inicial para produção de energia a partir do bagaço é alto, no entanto, possui um tempo de retorno de capital em torno de 5 a 7 anos, o que é menor do que em investimentos industriais, por exemplo, que são em torno de 12 anos (Areva Koblitz).

Outra vantagem desta solução de geração diz respeito à complementaridade com a produção por hidroelétricas, visto que a safra da cana corresponde ao período entre março e novembro, período de pouca chuva que afeta os níveis de reservatórios.

\footnotetext{
${ }^{8}$ Programa de Assentamento rural do Norte de Minas.
} 
Sem que haja as queimadas antes do corte da cana, pode-se efetuar o aproveitamento da palha e da ponta da cana, o que pode aumentar em 30\% a capacidade de produção de energia. É interessante salientar que a queima dessa palha é responsável por $10 \%$ de toda a emissão no Brasil (Areva Koblitz, 2009).

A maior produtora brasileira do ramo é a Equipav, que em 2008 conseguia abastecer sozinha uma cidade com dois milhões de habitantes, sendo a única no país a trabalhar com caldeiras de alta pressão (90 bar). Pois se sabe que a pressão está diretamente ligada à eficiência na geração, motivo pelo qual a maioria das usinas brasileiras, que normalmente trabalham com 22 bar, possui um terço do rendimento da Equipav, podendo fornecer energia apenas em um período do ano. Já a Equipav fornece energia durante o ano todo para a Companhia Paulista de Força e Luz (CPFL), Eletropaulo, Duratex e Unilever (Revista Exame, 2008).

\subsection{Fotovoltaica}

O crescimento desta tecnologia tem se dado de forma diferente da expectativa inicial, que era para abastecimento de regiões isoladas, hoje tal solução de geração de energia é ligada a rede de distribuição, como mostrado no Gráfico 3.1.

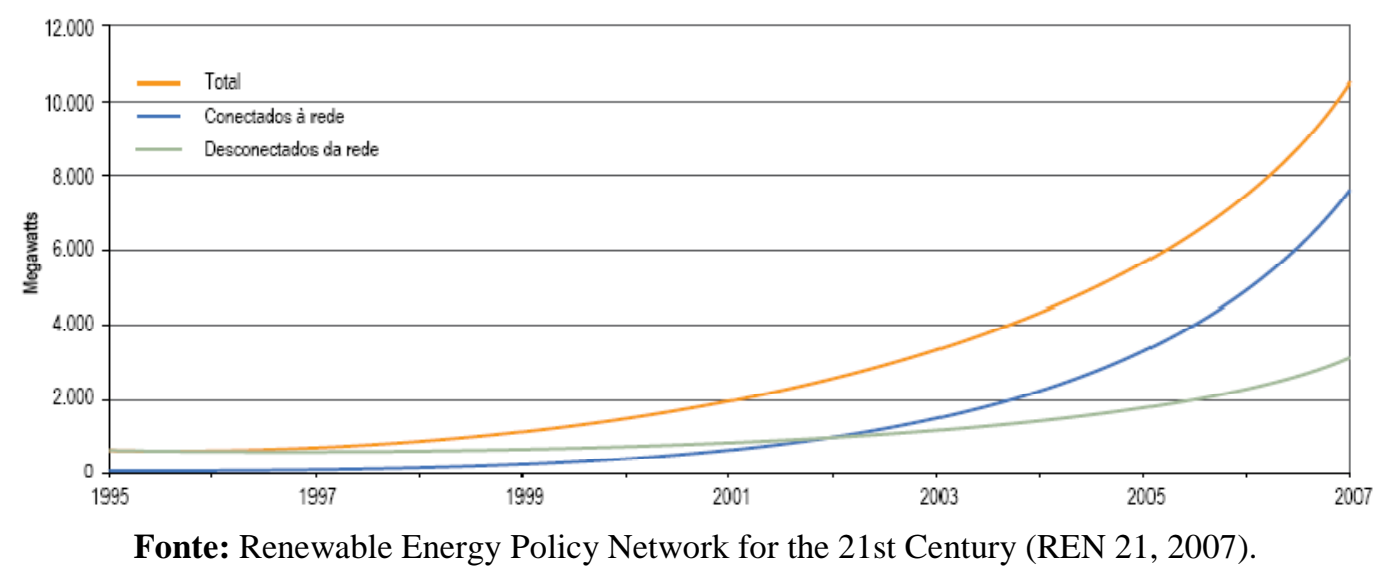

Gráfico 3.1 - Capacidade mundial instalada de fotovoltaica. 
Observa-se a seguir na Figura 3.1 o bom potencial que esta solução possui no Brasil.

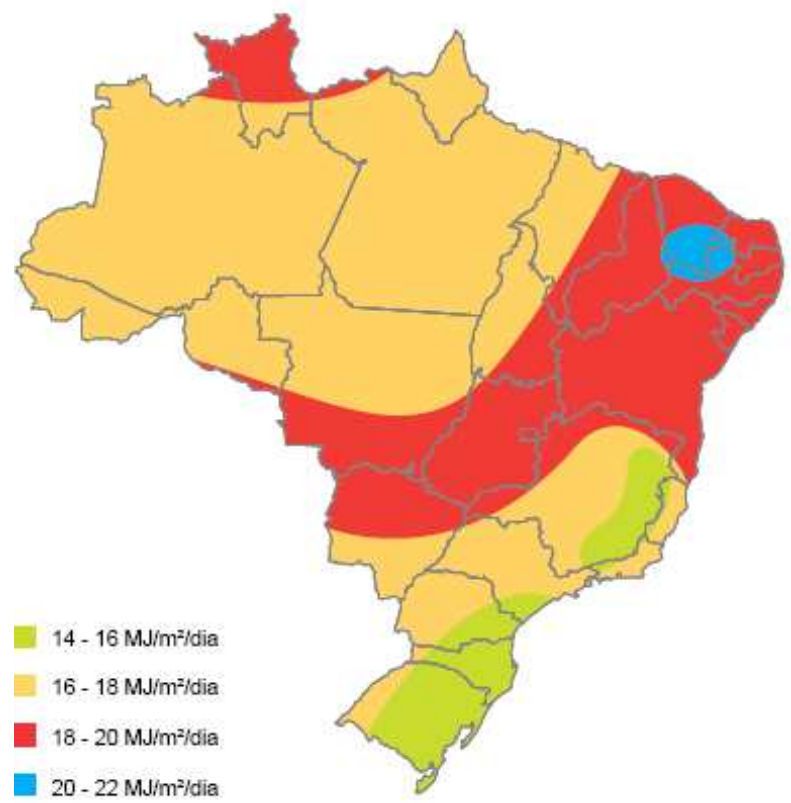

Fonte: Atlas da Energia Elétrica do Brasil, Edição 3 (EspaçoReservado1).

Figura 3.1 - Variação da radiação solar no Brasil.

O grande crescimento da utilização de tal solução pode ser explicado pelo decaimento que o preço dos painéis fotovoltaicos tem apresentado nos últimos anos, conforme pode ser observado no Gráfico 3.2. Apesar deste se referir aos custos do painel fotovoltaico no Japão, a mesma tendência é observada no resto do globo.

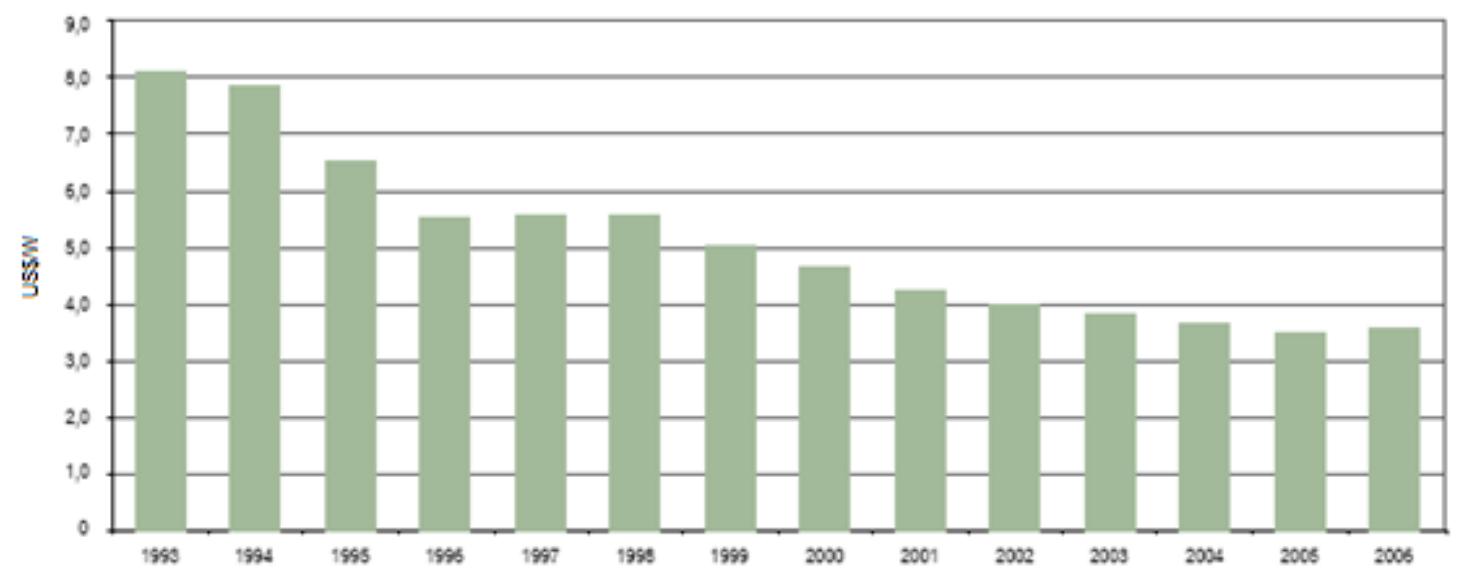

Fonte: Atlas da Energia Elétrica do Brasil, Edição 3.

Gráfico 3.2 - Custo do painel fotovoltaico no Japão. 
Portanto, fica evidente o potencial dessa energia em se consagrar como uma das grandes co-geradoras de energia nos próximos anos. Outro fator interessante a ser observado é a diminuição de $\mathrm{CO}_{2}$ pelo uso da geração fotovoltaica, estimado em 616 milhões de toneladas até 2030 pela European Photovoltaic Industry Association (EPIA).

Desta forma, percebe-se que o uso da solução fotovoltaica é um bom aliado na atual conjuntura mundial em prol da redução dos impactos ambientais causados pelo setor elétrico. Sendo assim, trata-se de uma ótima alternativa de geração a ser estimulada e estudada na tentativa de se obter melhor eficiência na produção e barateamento dos custos.

No Brasil, apesar do grande potencial, o uso da energia solar é predominantemente através da solução heliotérmica para aquecimento de água residencial. Já a utilização da solução fotovoltaica em cidades do interior e da zona rural é bem reduzida, não chegando sequer a compor o Balanço Energético Nacional (2008). Tal solução conta atualmente apenas com uma usina, em Rondônia, no Banco de Informações de Geração (BIG) da ANEEL.

\subsection{Diesel}

O óleo diesel para produção de eletricidade trata de um poluente atmosférico, na medida em que os produtos de sua combustão, que possuem grande volume de material particulado, fuligem, monóxido de carbono e compostos sulfídricos, como o $\mathrm{SO}_{2}$, são expelidos para o ambiente, em alguns casos na forma de fumaça negra.

Uma das mais modernas tecnologias para se tentar diminuir a quantidade de poluentes expelidos pela utilização de tal alternativa de geração é a dessulfurização (eliminação do enxofre) de gases (PETROBRÁS). No entanto, dado o elevado custo de sua implantação, tal tecnologia ainda é pouco utilizada.

No Brasil, trata-se da fonte mais utilizada no atendimento a comunidades isoladas, principalmente na região amazônica. Entretanto, o custo para o país se torna alto, não só pela questão ambiental, mas devido ao subsídio necessário a utilização de tal solução. Subsídio este que se refere principalmente a CCC, que está embutida na tarifa final de todos os consumidores de energia elétrica do país. Estima-se em 2009 um gasto de 
4,176 bilhões de reais para o subsídio ao consumo de combustíveis fósseis pela CCC (ANEEL, 2008).

As termelétricas movidas a diesel, óleo combustível e a gás de refinaria no país somavam 626 unidades em operação em 2008. Estas foram responsáveis pela geração de 13,5 TWh ou 2,8\% do total de energia elétrica produzida no país em 2007 (ANEEL, 2008).

É importante salientar que o diesel como sendo um derivado do petróleo, além de ter os problemas já citados na sua queima, ainda apresenta impactos ambientais ligados diretamente à extração do petróleo. Esta extração em terra provoca alterações e degradação do solo. Já no mar, além da interferência no ambiente, pode provocar grandes impactos na ocorrência de vazamentos do óleo, o que coloca em risco a fauna e a flora aquática. 


\section{ABORDAGEM ECONÔMICA (ECONOMIA DA ENERGIA)}

\subsection{Estado-da-arte}

É notável a essencialidade da energia para a organização econômica e social de todos os países, onde as variadas formas de produção e consumo de energia possuem uma gama de impactos sobre o desenvolvimento econômico, social e do meio ambiente. Sendo assim é justificável o papel de destaque da energia no processo de definição de estratégias de empreendimento e nas pautas de políticas governamentais.

Observa-se então que seria correto afirmar que o suprimento de energia é um grande catalisador do desenvolvimento econômico e social, afirmação esta comprovada pelo fato de que a economia foi constituída com base na disponibilidade de recursos energéticos desde a Revolução Industrial ${ }^{9}$, e isto influencia até hoje as condições de desenvolvimento de todas as nações.

Assim, a abordagem econômica se torna praticamente obrigatória para a análise de temas energéticos, pois estes requerem, quase sempre, além de conhecimento técnico uma abordagem multidisciplinar, englobando também temas sociais, culturais e ambientais. A Economia da Energia é um ramo da economia que busca conjugar a análise econômica com as demais dimensões abordadas em assuntos energéticos.

Apesar das dificuldades encontradas por economistas com o tema energia, devido principalmente aos aspectos técnicos, é evidente a necessidade de conhecimentos cada vez mais conjuntos no que é denominado de características técnico-econômicas, visando um maior apoio à progressão de estudos sobre problemas energéticos. Ressaltando que a teoria econômica dispõe de instrumentos de análise bem contundentes para tratar diversas questões energéticas, entre elas a formação de preços, condições de oferta e demanda, estruturas de mercado, comércio internacional das diversas fontes e as relações de causalidade entre crescimento econômico e consumo de energia (Queiroz, 2007).

\footnotetext{
${ }^{9}$ Iniciou-se no séc. XVIII na Inglaterra e se expandiu pelo mundo no séc. XIX. Abarca um conjunto de mudanças tecnológicas no processo produtivo tanto em nível econômico como social, englobando fatos tais como a substituição do homem pela máquina no processo produtivo, o estabelecimento de novas relações entre o capital e trabalho, o surgimento da cultura de massa, entre outros. Tudo isto somente foi possível graças à disseminação da cultura do liberalismo econômico, a acumulação de capitais e o surgimento de várias invenções tecnológicas, entre elas a máquina a vapor (Lascio, 2007).
} 
Destacando as condições de oferta e demanda de energia, é importante ressaltar a relevância destes atributos para o desempenho do sistema econômico, resultado de diversas interações entre as distintas abordagens relativas às dimensões econômicas que envolvem as questões do setor energético. Pode-se então destacar as seguintes dimensões econômicas no tocante ao envolvimento do setor energético (Queiroz, 2007):

\section{Dimensão Macroeconômica:}

Compreende uma série de aspectos, entre eles a relação entre energia e crescimento econômico, que constitui um indicador para o planejamento da oferta, a proporção dos investimentos na formação de capital, além do lugar de destaque ocupado no comércio internacional de energia, em decorrência da desigual distribuição de recursos. Sendo assim é notável que o equilíbrio da balança comercial seja muito sensível às oscilações nos preços de algumas fontes de energia, em especial o petróleo.

Por ser um ente imprescindível a todas as economias, o preço da energia exerce grande influência sobre as taxas de inflação, além do que a comercialização de energia é uma das principais fontes de arrecadação de tributos, garantindo assim receitas, dentro de uma visão econômica, e a utilização de tais receitas como instrumento de aspectos distributivos, em uma abordagem social.

\section{Dimensão Microeconômica}

Diz respeito às funções de custo e aos critérios de formação de preços, utilizando a análise de diferentes estruturas de mercado e de formas de organização industrial com o intuito de examinar a constituição e expansão da indústria de energia. Outro fato a ser considerado são os processos de tomada de decisão para investimentos e mecanismos financeiros, relativos à expansão de sistemas.

\section{Dimensão Tecnológica}

Aproveitar de forma econômica os recursos energéticos está diretamente vinculado ao avanço das inovações tecnológicas e às técnicas e equipamentos utilizados na produção e utilização das diferentes fontes de energia. Sendo assim, é notável que as decisões devam ser pautadas pela indissociável relação entre energia e tecnologia.

Um grande exemplo trata do desenvolvimento da capacitação tecnológica da indústria francesa com os incentivos à energia nuclear devido à crise com o petróleo. Outro assunto 
em voga trata do tema eficiência energética, que depende de políticas de pesquisa e desenvolvimento de novas tecnologias cada vez mais eficientes.

\section{Dimensão Política Internacional}

O tema energia gera relações comerciais e geopolíticas devido a problemas de distribuição de recursos e controle de reservas. Sendo assim, é notável a participação da energia no centro das relações econômicas, políticas e até militares.

\section{Dimensão Ambiental}

A dimensão ambiental está fundamentalmente ligada ao desenvolvimento sustentável, já que nenhuma fonte de energia deixa de gerar impactos negativos ao meio ambiente. Assim, existe um intenso debate sobre os efeitos e as formas de controle relacionadas aos problemas causados pela geração de energia.

Motivo pelo qual as restrições a fontes mais poluentes e incentivos dados as tecnologias limpas têm consequiência direta sobre os preços da energia, além do que este aspecto possui uma relação decisiva com as escolhas efetuadas pelas empresas em geral.

Tratada a relevância econômica do tema energia, nota-se que a produção, transporte, distribuição e comercialização tratam de atividades econômicas que necessitam de preços adequados para se remunerarem os investimentos realizados pelos agentes econômicos.

\subsection{Valor normativo e valor da tecnologia específica da fonte}

Nesta etapa foram utilizadas informações retiradas de consulta pública do Ministério de Minas e Energia (MME) para análise e valoração econômica da tecnologia específica, relativa ao PROINFA e valor normativo referente à Resolução 488/2002 ANEEL, de onde foram retiradas informações de valores do repasse da energia.

A modelagem utilizada em 2004 pelo PROINFA para a formulação dos preços se utilizava de parâmetros considerados de âmbito geral ou específico. Entre os parâmetros gerais, destacam-se o câmbio de dólar a 3,00R \$/US\$ e uma taxa de atratividade dos empreendimentos de $14,9 \%$ ao ano. 
Já os parâmetros específicos dizem respeito a custos relativos à fonte contemplada, entre tais parâmetros, destacam-se:

Fator de disponibilidade média anual: relação entre o tempo de disponibilidade total e a duração do período, considerando-se as paradas por indisponibilidade e manutenção.

Fator de capacidade bruto/Fator de utilização (\%): razão da potência média gerada durante um período pela potência elétrica total nominal bruta de um projeto padrão de geração a partir de uma determinada tecnologia.

Eficiência líquida: relação entre energia útil gerada a partir de determinada tecnologia e à energia total fornecida à entrada do projeto, em um dado período.

Investimento Total ( $R \$ / \mathrm{kW}$ instalado): montante de capital investido na construção do projeto a partir de determinada tecnologia.

Energia elétrica para consumo próprio $(R \$ / M W h)$ : valor indicado para aquisição da energia produzida para a utilização da própria planta, a partir do projeto de determinada tecnologia.

Operação e manutenção $(R \$ / k W h)$ : são despesas com operação e manutenção de um projeto de geração de energia elétrica, a partir de determinada tecnologia.

Arrendamento $(R \$ / \mathrm{kW})$ : despesas fundiárias fixas e anuais pagas pela instalação do projeto, a partir de determinada tecnologia.

Desmontagem e recultivação $(R \$ / \mathrm{kW})$ : são as reservas necessárias durante a operação do projeto que servirá para cobrir a recultivação do terreno e a desmontagem da planta após a conclusão do projeto. 
Sendo assim, após consulta pública realizada, foram divulgados pelo MME, em 30 de março de 2004, os valores econômicos da tecnologia específica da fonte $\left(\operatorname{VETEF}^{10}\right)$, que seriam corrigidos anualmente pelo IGP-M ${ }^{11}$, com base na data de assinatura dos contratos com a ELETROBRÁS. Tais custos de aquisição estão apresentados a seguir.

Tabela 4.1 - VETEF definidos pelo MME por intermédio de consulta pública.

\begin{tabular}{lr}
\hline & $R \$ / M W h$ \\
\cline { 2 - 2 } PCH & 117,02 \\
Eólica & entre $180,18 \times 204,35$ \\
Biomassa & 93,77 \\
Cana-de-açúcar & 103,20 \\
Casca de arroz & 101,35 \\
Resíduos de Madeira & 169,08 \\
\hline
\end{tabular}

Fonte: Ministério de Minas e Energia.

Alguns aspectos a se ressaltar da divulgação do resultado de consulta pública dizem respeito a custos com o investimento total $(\mathrm{R} \$ / \mathrm{kW}$ instalado) que foram estipulados levando em conta as perspectivas de gastos para se estabelecer as instalações para as respectivas fontes, e como resultado são disponibilizados os dados abaixo.

Tabela 4.2 - Parâmetros específicos - custo do investimento total.

\begin{tabular}{|c|c|c|c|c|c|c|}
\hline \multirow{2}{*}{ Parâmetros Padräo } & \multicolumn{4}{|c|}{ Biomassa } & \multirow[t]{2}{*}{ Eoblica } & \multirow[t]{2}{*}{ PCH } \\
\hline & Arroz & Bagaco-de-Cana & Biogás & Madeira & & \\
\hline Investimento total ( $R S / \mathrm{kW}$ instalado) & 2803,7 & $1.794,3$ & $2.371,4$ & $3.163,6$ & $3.061,2$ & $2.620,9$ \\
\hline Aquisiçăo de terrenos e benfeitorias (\%) & $1,1 \%$ & $1,8 \%$ & $1,8 \%$ & $1,0 \%$ & $0,0 \%$ & $5,1 \%$ \\
\hline Obras civis e outras benfeitorias (\%) & $5,7 \%$ & $8,9 \%$ & $8,9 \%$ & $5,1 \%$ & $7,5 \%$ & $39,9 \%$ \\
\hline Equipamentos e acessórios nacionais $(\%)$ & $36,5 \%$ & $57,1 \%$ & $56,7 \%$ & $32,4 \%$ & $35,2 \%$ & $29,0 \%$ \\
\hline Equipamentos e acessórios estrangeiros (\%) & $0,0 \%$ & $0,0 \%$ & $0,0 \%$ & $0,0 \%$ & $39,0 \%$ & $0,0 \%$ \\
\hline Seguros de construção (\%) & $0,6 \%$ & $0,9 \%$ & $0,9 \%$ & $0,5 \%$ & $0,9 \%$ & $0,40 \%$ \\
\hline Custo de conexão (\%) & $42,9 \%$ & $10,8 \%$ & $11,4 \%$ & $49,4 \%$ & $9,3 \%$ & $11,60 \%$ \\
\hline Outros custos (\%) & $9,1 \%$ & $14,3 \%$ & $14,2 \%$ & $8,1 \%$ & $5,8 \%$ & $6,90 \%$ \\
\hline Despesas pré-operacionais (\%) & $4,0 \%$ & $6,2 \%$ & $6,2 \%$ & $3,5 \%$ & $2,3 \%$ & $7,10 \%$ \\
\hline
\end{tabular}

Fonte: Ministério de Minas e Energia (MME).

\footnotetext{
${ }^{10}$ VETEF (Valor Econômico da Tecnologia Específica da Fonte): Trata-se do valor de venda da energia elétrica que, num determinado tempo e para determinado nível de eficiência, viabiliza economicamente o projeto utilizando a referida fonte.

${ }^{11}$ ÍNDICE GERAL DE PREÇOS DO MERCADO: é calculado mensalmente pela Fundação Getúlio Vargas (FGV) e é divulgado no final de cada mês de referência. Inicialmente concebido para ser um indicador para balizar as correções de alguns títulos emitidos pelo Tesouro Nacional e Depósitos Bancários com renda pósfixada acima de um ano. Posteriormente passou a ser utilizado para a correção de contratos de aluguel e como indexador de tarifas de energia.
} 
Nota-se que, para a energia eólica, existe uma parcela considerável de aporte de produtos importados, motivo pelo qual o VETEF desta fonte se encontra bem mais elevado que o das demais soluções. Entretanto, como um dólar, à época da consulta, estava cotado em aproximados $\mathrm{R} \$ 3,00$, deve-se levar em consideração a atual desvalorização da moeda norte-americana para a formulação do VETEF da energia eólica.

Para tanto se considera uma redução aproximada de $21 \%$ no VETEF da solução eólica. Tal consideração se baseia em fatores tais como: (i) a parcela de equipamentos e acessórios estrangeiros, que representa um percentual de 39\% do investimento; (ii) a redução aproximada de $41 \%$ do câmbio do dólar, que foi utilizado, à época, como parâmetro geral com o câmbio de R \$3,00/US\$, e em outubro de 2009 teve cotação média estimada em R \$ 1,74/US\$; e (iii) a queda do imposto de exportação incidente sobre turbinas eólicas a partir de 2006, que anteriormente era de $14 \%$.

Em virtude do tempo transcorrido desde a divulgação dos valores citados, faz-se necessária a correção destes pelo IGP-M, desde o período de abril de 2004 até outubro de 2009. As atualizações dos valores pelo IGP-M para o VETEF são alvo de discussão no APÊNDICE II deste estudo, e os respectivos resultados são apresentados a seguir.

Tabela 4.3 - Valor da tecnologia específica da fonte corrigido pelo IGP-M.

\begin{tabular}{|c|r|r|rr|r|}
\hline MOEDA & PCH & EÓLICA & EÓLICA C/ CORREÇÃO DE COTAÇÃO & BIO-CANA \\
& & & & \\
\hline VALOR (R\$/kWh) & $R \$ 156,73$ & $R \$ 273,70$ & R\$ 216,22 & $R \$ 125,59$ \\
\hline
\end{tabular}

Ressalta-se novamente que, de acordo com as premissas indicadas no capítulo anterior, são apresentadas somente as estimativas atualizadas para a biomassa de cana em detrimento às demais alternativas de geração desta fonte. E, evidencia-se o destaque da produção por PCH e biomassa pelo menor VETEF se utilizando de fontes renováveis para a diversificação da matriz energética nacional. 
Paralelo ao processo de formulação de preços do VETEF foi estipulado pela ANEEL o conceito de Valor Normativo $(\mathrm{VN})^{12}$, que trata do valor limite de repasse dos preços de energia elétrica para a tarifa de fornecimento dos consumidores. O VN foi criado em 1998, por intermédio da Resolução 266 ANEEL, e os valores tiveram sua última revisão em 2002, por meio da Resolução 488 ANEEL, onde se estipula o VN por fonte, com a ressalva da atualização dos valores pelo IGP-M de acordo com a data dos contratos de compra de energia.

A tabela a seguir demonstra os valores vigentes e a respectiva atualização para o período atual. As atualizações do valor normativo por intermédio do IGP-M são alvo de discussão no APÊNDICE II.

Tabela 4.4 - Valor normativo corrigido pelo IGP-M.

\begin{tabular}{|c|c|c|c|c|}
\hline FONTE & PCH & EÓLICA & BIOMASSA & SOLAR \\
\hline VN 2001 & $\mathrm{R} \$ \quad 79,29$ & $\mathrm{R} \$ 112,21$ & $\mathrm{R} \$ \quad 89,86$ & $\mathrm{R} \$ 264,12$ \\
\hline VN ATUAL & $\mathrm{R} \$ \quad 157,18$ & $\mathrm{R} \$ 222,44$ & 178,13 & $\mathrm{R} \$ \quad 523,58$ \\
\hline
\end{tabular}

Entretanto, há de se levar em consideração que, para a produção de energia por intermédio da fonte solar, existe a necessidade de importação de diversos componentes, destacando-se os inversores, controladores e painéis. Logo, cerca de $90 \%$ do investimento inicial é baseado na compra de insumos estrangeiros. Outro fato considerável diz respeito à cotação do dólar à época da referência do valor normativo citado na resolução, que era cotado em R\$2,3758/US\$. Desta forma a redução da cotação da moeda é estimada em aproximadamente $25,5 \%$.

Sendo assim, fica evidente a necessidade de se considerar uma redução no VN da fonte solar. E, segundo os fatores considerados, tal redução pode ser estimada em aproximadamente $23 \%$. Utilizando-se de tal argumento, teremos um novo $\mathrm{VN}$ em torno de $\mathrm{R} \$ 403,16$, para a referência outubro de 2009.

\footnotetext{
${ }^{12}$ Valor Normativo: Valor definido pela ANEEL, com base nos preços de compra de energia elétrica de curto prazo, realizadas no âmbito do Mercado Atacadista de Energia Elétrica, no período de referência. Expresso em R \$/MWh. Foi criado através da Resolução 266/98 ANEEL, e os primeiros valores foram estabelecidos e discriminados por fontes através da Resolução 233/99 ANEEL e teve seus preços reajustados através da Resolução 488/02 ANEEL, destacando que os valores seriam corrigidos pelo IGP-M do mês anterior, quando da assinatura dos contratos de compra de energia.
} 
Entende-se como de extrema importância se destacar as diferenças entre o VETEF e o VN. Tendo em vista que, o VN estipula o custo de referência para o cotejamento entre o preço de compra e o preço a ser repassado às tarifas. Enquanto o VETEF estipula um valor de compra de forma a tornar o projeto de determinada fonte economicamente viável dentro de certo período e nível de eficiência.

Para os casos em que houvesse diferenças entre o VETEF, a maior, e o VN, tal diferença seria coberta pelos recursos da Conta de Desenvolvimento Energético $(\mathrm{CDE})^{13}$. Entretanto de acordo com a metodologia de atualização dos valores se utilizando do IGP-M e taxas de câmbio para as fontes solar e eólica, nota-se que as projeções para o VETEF e VN apresentam valores muito semelhantes, demonstrando a coesão entre os resultados das consultas públicas do PROINFA e a metodologia utilizada pela ANEEL para estipular o $\mathrm{VN}$ das fontes de energia.

A tabela a seguir apresenta um resumo dos valores estipulados pelas referências citadas e os respectivos valores corrigidos de acordo com a metodologia de cálculo discutida no APÊNDICE II. Pode-se destacar a mínima disparidade apresentada entre a projeção para os valores referentes à utilização de $\mathrm{PCH}$ que chegam a ínfimos $0,29 \%$.

Já para a energia solar não há a possibilidade de efetuar tal comparação entre as estimativas pelo fato de existirem somente as referências de VN para o estudo de tal fonte. Tais valores poderão vir a ser utilizados na verificação do valor de subsídio necessário à produção de energia pelas fontes alternativas analisadas.

Tabela 4.5 - Comparação dos valores por fonte (data de referência e data atual).

\begin{tabular}{|c|c|c|c|c|}
\hline FONTE & $\mathrm{PCH}$ & EÓLICA & BIOMASSA & SOLAR \\
\hline VETEF 2004 & $\mathrm{R} \$ 117,02$ & $\mathrm{R} \$ 204,35$ & $\mathrm{R} \$ 93,77$ & \\
\hline VETEF CORRIGIDO & $\mathrm{R} \$ 156,73$ & $R \$ 216,22$ & $\mathrm{R} \$ \quad 125,59$ & \\
\hline VN 2001 & $\mathrm{R} \$ \quad 79,29$ & $\mathrm{R} \$ 112,21$ & 89,86 & $\mathrm{R} \$ 264,12$ \\
\hline VN CORRIGIDO & $\mathrm{R} \$ 157,18$ & $\mathrm{R} \$ 222,44$ & $\mathrm{R} \$ 178,13$ & $\mathrm{R} \$ \quad 403,16$ \\
\hline MARGEM DISPARIDADE & $0,29 \%$ & $3 \%$ & $30 \%$ & \\
\hline
\end{tabular}

\footnotetext{
${ }^{13}$ Fonte de subsídio criada para tornar competitivas fontes alternativas de energia, como eólica e biomassa, e promover a universalização dos serviços de energia elétrica. Além de fontes alternativas, a CDE cobre os custos de termelétricas a carvão que já haviam entrado em operação em 1998 e da instalação de transporte para gás natural. Os recursos virão de pagamentos anuais realizados a título de uso de bem público, multas aplicadas pela ANEEL e a partir de 2003, das cotas anuais pagas por agentes que vendam energia para o consumidor final. Terá duração de 25 anos e é considerada sucessora da CCC (ANEEL, 2008).
} 
Tendo em vista que a metodologia desenvolvida para o cálculo do custo da energia gerada por cada uma das fontes em análise requer uma vasta pesquisa em artigos publicados e organismos governamentais, tal metodologia será alvo de discussão nas seções seguintes deste capítulo, onde serão apresentadas as informações relativas ao levantamento de parâmetros objetivos e a modelagem matemática proposta para o cálculo do custo da energia. E caso tais custos sejam superiores ao $\mathrm{VN}$, indicado anteriormente para cada solução de geração, indica-se a necessidade de subsídios para a geração de energia.

\subsection{Levantamento de informações técnico-financeiras}

Para se viabilizar a análise de sensibilidade, determinando-se para cada tecnologia as faixas de valores que devem ser utilizadas para a condução da precificação da energia gerada por cada fonte estudada, faz-se necessário o levantamento dos parâmetros técnicofinanceiros das respectivas soluções de geração, que serão apresentados a seguir.

Ressalta-se que a maior parte das referências apresenta estimativa de custos em dólar americano. Sendo assim, faz-se necessária a conversão para a moeda nacional, e a metodologia de conversão utilizada se baseia na conversão da moeda a partir da taxa de câmbio média do dólar em outubro de 2009, cotada em R \$ 1,74935/US\$.

\subsubsection{Pequena central hidroelétrica}

Para a solução por pequena central hidroelétrica $(\mathrm{PCH})$ se apresentam faixas de valores para os custos de implantação e de operação e manutenção $(\mathrm{O} \& \mathrm{M})$, conforme tabela a seguir.

Tabela 4.6 - Custos de geração em pequenas centrais hidroelétricas.

\begin{tabular}{|c|c|c|}
\hline REFERÊNCIA & (MME, 2004) & (Veronese, 2004) \\
\hline Custo de Implantação (US\$/kW) & - & $900-1.500$ \\
\hline Custo de Implantação $(\mathrm{R} \$ / \mathrm{kW})$ & 2.620 & $1.574,42-2.624,03$ \\
\hline Custo O\&M (US\$/MWh) & - & $6-15$ \\
\hline Custo O\&M (R\$/MWh) & 7 & $10,49-26,24$ \\
\hline
\end{tabular}

Para tal fonte, devem-se considerar os custos com a inclusão de uma linha de transmissão, pois a carga pode se situar a certa distância do centro de geração, o que normalmente não 
ocorre com as demais fontes na situação analisada, pois estas podem ser instaladas de forma local.

Tal distância normalmente é pequena, e para este estudo será considerada da ordem de $300 \mathrm{~m}$ a $1 \mathrm{~km}$. O custo de implantação da linha pode ser bem variável, dependendo da localidade, e segundo dados oficiais da Companhia Energética de Brasília (CEB), tal custo é de aproximadamente $\mathrm{R} \$ 18.000,00 / \mathrm{km}$. Entretanto, de acordo com dados da Companhia de Energia Elétrica do Estado do Tocantins (CELTINS), este custo pode ser variável dentro do intervalo de US\$7.000,00/km a US\$10.000,00/km. Desta forma o intervalo a

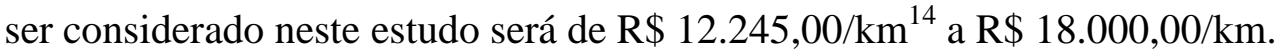

Já as perdas associadas às linhas, são estimadas em cerca de 7\% pela CELTINS. Entretanto, verifica-se que as perdas podem corresponder a 10,2\% (Araujo, 2007). Desta forma este estudo irá considerar que as perdas em linhas podem variar entre $7 \%$ a 10,2\%.

Sendo assim, para o cálculo do custo das perdas, há de se considerar um preço básico da energia, já que se desconhece momentaneamente o custo da energia para a solução em questão. Desta forma, consideram-se como o preço básico da energia as tarifas para consumidores do subgrupo B2 - Rural. Desta forma, o intervalo de preços estimados se encontram entre R\$163,15/MWh (Força e Luz do Oeste ${ }^{15}$ ) e R\$242,31/MWh (CELTINS), correspondendo aos valores mínimos e máximos praticados pelas distribuidoras de energia pesquisadas, conforme tabela a seguir.

Tabela 4.7 Taxas de distribuição subgrupo B2.

\begin{tabular}{|c|c|c|c|c|c|c|c|}
\hline DISTRIBUIDORA & CEB & CELPA & ENERSUL & $\begin{array}{c}\text { FORÇA E LUZ } \\
\text { DO OESTE }\end{array}$ & EDP & CEAL & CELTINS \\
\hline Tarifa sem ICMS (R\$/MWh) & 190,07 & 207,00 & 221,48 & 163,15 & 187,66 & 194,46 & 242,31 \\
\hline
\end{tabular}

Vale ressaltar que este estudo trata de um sistema gerador de porte bem pequeno, constituído basicamente por uma turbina hidráulica acoplada a um gerador, instalada em local adequado. Portanto, o termo PCH, de acordo com a nomenclatura e classificação tecnológica das soluções de GD pode não ser adequado para tal finalidade, já que se refere

\footnotetext{
${ }^{14}$ Tal estimativa é baseada na conversão de estimativa de US\$7.000,00/km para o respectivo valor em reais brasileiros, que corresponde a aproximadamente R\$12.245,00/km.

${ }^{15}$ Força e Luz do Oeste: Companhia Força e Luz do Oeste, presente nas localidades Guarapuava, Guará e Jordão no Paraná.
} 
a um sistema de maior porte. No entanto, por falta de dados para o caso proposto, faz-se uso de tal termo pela sua maior proximidade com relação aos dados objetivos mencionados anteriormente (custos, solução tecnológica proposta, perdas de transmissão, O\&M).

\subsubsection{GMG a diesel}

Para a geração a diesel, consideram-se os custos de implantação, O\&M e os custos relativos ao consumo de combustível, conforme tabela a seguir.

Tabela 4.8 - Custos da geração a óleo diesel.

\begin{tabular}{|l|c|c|}
\multicolumn{1}{|c|}{ REFERÊNCIA } & $\begin{array}{c}\text { ELETRONORTE } \\
(\mathbf{2 0 0 4 )}\end{array}$ & (Severino, 2008) \\
\hline Custo de Implantação (US\$/kW) & 700 & $586,24-616,19$ \\
\hline Custo de Implantação (R\$/kW) & $1.224,55$ & $1.025,54-1.077,93$ \\
\hline Custo O\&M (US\$MWh) & $44-72$ & - \\
\hline Custo O\&M (R\$/MWh) & $76,97-125,95$ & - \\
\hline Consumo Específico (litro/kWh) & 0,25 & 0,42 \\
\hline
\end{tabular}

Para a estimativa do custo de combustível, utiliza-se o preço médio de óleo diesel na região norte em novembro de 2009, já que esta região possui a maior concentração de sistemas isolados, com o preço do diesel aferido em R\$ 2,149/L (ANP, 2009). Sendo assim, devido a variação considerada para o consumo específico, o custo de combustível varia entre $\mathrm{R} \$ 0,537 / \mathrm{kWh}$ a R \$ 0,9026/kWh. Vale ressaltar que não é considerado o subsídio da CCC, já que tal subsídio atende somente à região Norte do país.

\subsubsection{Solar fotovoltaica}

Consideram-se os custos de implantação e de O\&M, e o parâmetro de fator de capacidade desta solução de geração, devido à intermitência desta fonte de energia. Segundo dados da IEA, o fator de capacidade para tal solução é da ordem de $22 \%$, enquanto para Severino (2008), este fator pode ser estimado em 30\%. Desta forma, este estudo considera a análise de sensibilidade, considerado que o fator de capacidade varie no intervalo de $22 \%$ a $30 \%$. A tabela a seguir apresenta os parâmetros pesquisados para a solução fotovoltaica. 
Tabela 4.9 - Custos de geração solar fotovoltaica.

\begin{tabular}{|l|c|c|c|c|}
\hline \multicolumn{1}{|c|}{ REFERÊNCIA } & (Tomalsquim, 2003) & (Souza, 2002) & (Severino, 2008) & (IEA) \\
\hline Custo de Implantação $(\mathrm{US} / \mathrm{kW})$ & 7.000 & $4.000-9.000$ & - & - \\
\hline Custo de Implantação $(\mathbf{R} \$ / \mathrm{kW})$ & $12.255,50$ & $6.997,40-$ & - & - \\
\hline O\&M (\% do Investimento) & - & $15.754,20$ & - & - \\
\hline Fator de Capacidade $(\%)$ & - & - & 30 & 22 \\
\hline
\end{tabular}

\subsubsection{Eólica}

Consideram-se os custos de implantação e O\&M. Tal solução, devido a sua intermitência, apresenta a necessidade de conhecimento do fator de capacidade. Desta forma, na tabela a seguir, são apresentados os parâmetros pesquisados para a solução eólica.

Tabela 4.10 - Custos de geração eólica.

\begin{tabular}{|l|c|c|c|}
\multicolumn{1}{|c|}{ REFERÊNCIA } & (MME, 2004) & (Veronese, 2004) & (Souza, 2002) \\
\hline Custo de Implantação (US\$/kW) & - & $800-1.400$ & $700-1.200$ \\
\hline Custo de Implantação $(\mathbf{R} \$ / k W)$ & 3.061 & $1.399,48-2.449,09$ & $1.224,55-2.099,22$ \\
\hline O\&M (US\$/MWh) & - & $4-12$ & $4-12$ \\
\hline O\&M (R\$MWh) & - & $7-21$ & $7-21$ \\
\hline Fator de Capacidade (\%) & $34-44$ & - & - \\
\hline
\end{tabular}

\subsubsection{Biomassa de bagaço de cana}

Para a geração por biomassa de cana, consideram-se os custos de implantação e O\&M, além das estimativas de preço da tonelada do bagaço de cana para que seja possível se efetuar o cálculo do custo com a utilização de combustíveis. Sendo assim, a tabela a seguir apresenta os parâmetros pesquisados para a biomassa de bagaço de cana.

Tabela 4.11 - Custos de geração por biomassa: bagaço de cana.

\begin{tabular}{|l|}
\hline \multicolumn{1}{|c|}{ REFERÊNCIA } \\
\hline Custo de Implantação (US\$/kW) \\
\hline Custo de Implantação (R\$/kW) \\
\hline O\&M (\% do investimento) \\
\hline Custo O\&M (R\$/kW) \\
\hline Custo do Bagaço (US\$/ton) \\
\hline Custo do Bagaço (R\$/ton) \\
\hline
\end{tabular}

\begin{tabular}{|c|c|}
\hline (MMI, 2004) & (Veronese, 2004) \\
\hline $1.794,00$ & $500-1.000$ \\
\hline- & $874,67-1.749,35$ \\
\hline $64-80$ & $2-4$ \\
\hline- & - \\
\hline 20 & $4-14$ \\
\hline
\end{tabular}

Para o cálculo do custo de combustível, em $\mathrm{R} \$ / \mathrm{kWh}$, é necessário o conhecimento do custo do bagaço (R $\$$ /ton) e da eficiência de conversão do processo (kWh/ton). Pois tal custo é 
resultado do produto entre tais parâmetros. E, segundo Veronese (2004), a taxa de conversão energética é da ordem de $126 \mathrm{kWh} /$ ton. Sendo assim, de acordo com os parâmetros do custo do bagaço presentes na tabela acima, considera-se que o custo do combustível varia entre as estimativas de $\mathrm{R} \$ 0,055 / \mathrm{kWh}$ e $\mathrm{R} \$ 0,194 / \mathrm{kWh}$.

\subsection{Modelagem matemática}

A modelagem matemática apresentada por este estudo é baseada na modelagem apresentada por Severino (2008), que têm como premissa básica a comparabilidade de propósito, logo, parte-se do pressuposto de que todas as soluções devam atender a necessidade de suprimento energético da carga. Ou seja, para a carga estipulada em $100 \mathrm{~kW}$ com um funcionamento médio diário de 12 horas, o consumo médio anual necessário é de $438.000 \mathrm{kWh}$, considerando-se um ano de 365 dias, tal estimativa pode se comprovada pela formulação abaixo.

$$
E c a=P t c \cdot t f m \cdot 365
$$

Em que:

- Eca é a energia anual média necessária [kWh/ano].

- Ptc é a potência nominal da carga [kW].

- tfm é o tempo de funcionamento médio diário [horas].

Já a potência nominal de geração, em kW, pode ser obtida por intermédio da razão entre a potência nominal da carga e o fator de capacidade, conforme formulação abaixo.

$$
P t g=P t c / f c
$$

Em que:

- Ptg é a potência nominal de geração [kW].

- Ptc é potência nominal da carga $[\mathrm{kW}]$.

- $f c$ é o fator de capacidade.

O fator de capacidade pode ser considerado unitário para a maioria das soluções, exceto para as soluções de geração eólica e fotovoltaica. Partindo-se da premissa de que o 
armazenamento ou a fonte primária de energia nos permite garantir o suprimento de energia média anual necessária, e de que não haja intermitência na produção desde que exista disponibilidade de combustível.

As informações relativas à vida útil dos sistemas, em anos, são estimativas apresentadas no estudo de Veronese (2004), exceto as informações relativas à solução fotovoltaica que provém dos estudos de Severino (2008). Tais estimativas podem ser observadas a partir da tabela abaixo.

Tabela 4.12 - Vida útil do sistema.

\begin{tabular}{|c|c|c|c|c|c|}
\hline FONTE & SOLAR FV & EÓLICA & BIOMASSA: CANA & PCH & DIESEL \\
\hline VIDA ÚTIL (ano) & 25 & 15 & 25 & 30 & 20 \\
\hline
\end{tabular}

Vale ressaltar que a possibilidade de utilização de linhas de transmissão/distribuição é considerada somente para o caso de geração por PCH. Sendo assim, a parcela de contribuição das perdas relativas a tais linhas, para o custo da energia, está relacionada a parâmetros, tais como: (i) distância da carga; (ii) custo de implantação da linha; (iii) perdas na linha; e (iv) perdas anuais. As perdas anuais, em kWh/ano são calculadas da seguinte forma.

$$
P a=P l \cdot E c a
$$

Em que:

- $P a$ são as perdas anuais [kWh/ano].

- $P l$ são as perdas na linha [\% da energia].

- Eca é a energia anual média necessária [kWh.ano].

Assim, o custo anual das perdas (CAP) pode ser estimado pelo produto entre as perdas anuais e o custo da energia perdida (CEP), conforme formulação a seguir.

$$
C A P=P a \cdot C E P
$$


Em que:

- CAP é o Custo Anual das Perdas [R \$ano].

- Pa são as Perdas Anuais [kWh/ano].

- CEP é o Custo da Energia Perdida $[\mathrm{R} \$ / \mathrm{kWh}]^{16}$.

O período de estudo considerado é de 15 anos, que corresponde à vida útil de um empreendimento utilizando a solução eólica. Porém, como as demais fontes possuem vida útil maior, há de se levar em consideração o valor residual dos demais empreendimentos após o período de estudo. Sendo assim, define-se o valor presente residual (VPR), como o valor econômico que o sistema terá ao final do período de estudo atualizado para o momento presente. O cálculo do valor presente residual é efetuado por intermédio da formulação a seguir.

$$
V P R=I I \cdot \frac{(V u-n)}{V u} \cdot\left(1+\frac{i}{100}\right)^{-n}
$$

Em que:

- VPR é o valor presente residual [R\$].

- II é o investimento inicial [R\$].

- Vu é a vida útil do empreendimento [em anos].

- $n$ é o período de estudo [em anos].

- $i$ é a taxa de juros [\% a.a.].

A taxa de juros considerada é a TJLP (Taxa de Juros de Longo Prazo), que representa a taxa de juros utilizada pelo Banco Nacional do Desenvolvimento (BNDES) na linha de financiamento de projetos de energia. Sendo utilizada a taxa vigente entre outubro e dezembro de 2009, que está fixada em 6\%.

Já o investimento inicial é estimado por intermédio de duas parcelas: (i) produto do custo de implantação pela potência nominal de geração; e (ii) produto do custo de implantação da linha pela distância da carga. Ressaltando que a segunda parcela estará presente somente para o caso de geração por PCH. A formulação está apresentada a seguir.

\footnotetext{
${ }^{16} \mathrm{O}$ custo da energia perdida é baseado no custo da energia para consumidores do subgrupo B2, conforme parâmetros técnico-financeiros anteriormente apresentados.
} 


$$
I I=C I \cdot P \operatorname{tg}+C I L \cdot d
$$

Em que:

- II é o investimento inicial [R\$].

- $C I$ é o custo de implantação [R $\$ / \mathrm{kW}]$.

- Ptg é a potência nominal de geração [kW].

- CIL é o custo de implantação da linha [R $\$ / \mathrm{km}]$.

- $d$ é a distância da carga $[\mathrm{km}]$.

Com o conhecimento do VPR e do investimento inicial, pode-se então calcular o custo anual de implantação (CAI), por intermédio da seguinte equação:

$$
C A I=\frac{(I I-V P R) \times F R C}{P \operatorname{Pg}}
$$

Em que:

- CAI é o custo anual de implantação [R $\$ /(\mathrm{kW} . \mathrm{ano})]$.

- II é o investimento inicial [R\$].

- VPR é o valor presente residual [R\$].

- FRC é o fator de recuperação de capital.

- Ptg é a potência nominal de geração [kW].

O fator de recuperação de capital (FRC) utiliza os juros anuais e fornece um coeficiente que permite, a partir do valor do investimento, se calcular o custo fixo anual referente ao investimento. Tal fator produz uma série de pagamentos periódicos que amortizam o investimento inicial e remuneram o investimento remanescente ao longo do período de estudo à taxa de juros definida. Seu cálculo é baseado na equação abaixo (Camargo, 1998).

$$
F R C=\frac{(1+i)^{n} \cdot i}{(1+i)^{n}-1}
$$

Em que:

- FRC é o fator de recuperação de capital.

- $n$ é o período de estudo [anos].

- $i$ é a taxa de juros [\% a.a.]. 
Os custos de O\&M e de combustíveis foram informados anteriormente, em discussão específica de cada solução, porém como algumas referências trazem o custo de O\&M como um percentual do investimento e outras referências como estimativa em $\mathrm{R} \$ / \mathrm{kWh}$, assim como o custo com combustível, faz-se necessário então o cálculo de tais custos em $\mathrm{R} \$ /(\mathrm{kW} . \mathrm{ano})$.

Desta forma para o caso do custo dado como percentual do investimento, denominado neste estudo de caso O\&M1, basta efetuar o produto entre o referido percentual e o CAI. Já para o caso do custo em $\mathrm{R} \$ / \mathrm{kWh}$, denominado neste estudo de caso O\&M2, o custo em $\mathrm{R} \$ /(\mathrm{kW}$.ano) é calculado por intermédio do produto do referido custo com a energia anual média necessária, dividindo-se tal resultado pela potência nominal de geração. As formulações matemáticas para os casos O\&M1 e O\&M2 são apresentadas abaixo.

\section{Caso O\&M1:}

$$
O \& M 1=C A I \cdot O \& M \%
$$

Em que:

- $O \& M 1$ representa o custo de $\mathrm{O} \& \mathrm{M}[\mathrm{R} \$ /(\mathrm{kW} . \mathrm{ano})]$.

- CAI é o custo anual de implantação.

- $O \& M \%$ representa o percentual de O\&M referente ao Custo de Implantação [\%].

\section{Caso O\&M2:}

$$
O \& M 2=\frac{C M \cdot E c a}{P t g}
$$

Em que:

- $O \& M 2$ representa o custo de O\&M [R $\$ /(\mathrm{kW} . a n o)]$.

- $C M$ é o Custo de O\&M da referência utilizada [R $\$ / \mathrm{kWh}]$.

- Eca é a energia anual média necessária [kWh.ano].

- Ptg é a potência nominal de geração [kW]. 
O custo de combustível, em $\mathrm{R} \$ /(\mathrm{kW} . \mathrm{ano})$ é estimado pelo produto do custo do combustível, em $\mathrm{R} \$ / \mathrm{kWh}$, com a energia anual média necessária, dividindo-se tal resultado pela potência nominal de geração, conforme explicitado a seguir.

$$
C C[R \$ /(k W . a n o)]=\frac{E C[R \$ / k W h] \cdot E c a}{P \operatorname{tg}}
$$

Em que:

- $C C$ é o custo de combustível [R \$/(kW.ano)].

- EC é a estimativa de custo de combustível em [R $\$ / \mathrm{kWh}]$.

- Eca é a energia anual média necessária [kWh x ano].

- Ptg é a potência nominal de geração [kW].

Desta forma, pode-se calcular o custo anual de O\&M por intermédio da soma entre as parcelas O\&M1 ou O\&M2 com a parcela relativa ao custo de combustível (CC).

$$
C A O \& M=O \& M 1+O \& M 2+C C
$$

Em que:

- $C A O \& M$ é o custo anual de $O \& \mathrm{M}[\mathrm{R} \$ /(\mathrm{kW} . \mathrm{ano})]$.

- $O \& M 1$ e $O \& M 2$ representam os custos de $O \& \mathrm{M}[\mathrm{R} \$(\mathrm{~kW}$. ano)].

- $C C$ é o custo de combustível [R \$(kW.ano)].

Já o custo anual total (CAT), em $\mathrm{R} \$ /(\mathrm{kW}$.ano), é composto pela soma de três parcelas: (i) CAI; (ii) CAO\&M; e (iii) a razão entre o custo anual das perdas (CAP) e potência nominal de geração. Conforme formulação a seguir.

$$
C A T=C A I+C A O \& M+C A P / P t g
$$

Já o custo da energia (CE), em R \$/kWh, pode ser estimado pela equação abaixo.

$$
C E=\frac{C A T \cdot P t g}{E c a}
$$

Em que:

- $C E$ é o custo da energia [R $\$ / \mathrm{kWh}]$.

- CAT é o custo anual total $[\mathrm{R} \$ /(\mathrm{kW} . \mathrm{ano})]$. 
- Ptg é a potência nominal de geração [kW].

- Eca é a energia anual média necessária [kWh.ano].

Os valores estimados de subsídio devem ser observados sempre que o CE for superior ao VN. Sendo assim, quando houver subsídio, este deve ser calculado por intermédio da seguinte formulação.

$$
S=C E-V N / 1000
$$

Em que:

- $S$ representa o valor do subsídio [R $\$ / \mathrm{kWh}]$.

- $C E$ é o custo da energia $[\mathrm{R} \$ / \mathrm{kWh}]$.

- VN é o valor normativo [R $\$ / M W h]$.

\subsection{Simulação}

Para a simulação se utiliza o software EXCEL, com o intuito de se estimar o CAT e o CE das várias soluções estudadas com variação aleatória de algumas grandezas, por intermédio da função “ALEATÓRIOENTRE”, seguindo-se a modelagem matemática da seção anterior. Para se obter os resultados possíveis foram confeccionadas duas macros.

Onde a primeira macro realiza: (i) a atribuição de valores aleatórios, para as grandezas assim definidas; (ii) os cálculos programados, segundo a modelagem matemática proposta; (iii) a gravação dos resultados de interesse em locais predefinidos; e (iv) repete os procedimentos anteriores para a quantidade de casos a serem simulados. Já a segunda macro realiza a cópia das informações geradas em outras colunas predefinidas, fazendo posteriormente a ordenação crescente dos valores simulados em cada coluna de interesse.

Segundo Severino (2008), a estratégia de simulação adotada apresenta melhores resultados quanto maior for o número de casos simulados, pois, com número pequeno de casos, a variação aleatória das grandezas pode gerar resultados inexpressivos do ponto de vista estatístico. As literaturas consultadas não indicam um número preciso de casos a serem simulados: em Veronese (2004), utiliza-se 500 casos como um bom resultado; em Severino (2008), utiliza-se 2.000 casos como adequado. 
Entretanto, devido à quantidade de grandezas aleatórias, realizaram-se 5 simulações com 500 e 2.000 casos, onde se verificou uma variação indesejável das grandezas de interesse. Sendo assim, de forma a diminuir a variação dos resultados, o número de casos foi incrementado para 5.000 e foram efetuadas 5 novas simulações. Onde se verificou que os resultados se apresentaram de forma menos variável, otimizando inclusive o desvio-padrão dos resultados simulados. Optou-se então pela utilização da simulação de 5.000 casos, pois apesar do incremento no custo computacional, tal opção se mostrou a mais adequada.

Os dados de entrada de uma simulação podem ser observados na tabela a seguir, onde as células amarelas com fonte vermelha representam dados de entrada aleatórios. As duas últimas linhas apresentam os valores de CAT e CE, que são considerados os resultados da simulação. Por apresentar dados aleatórios, os valores apresentados na tabela, que possuem esta natureza, caracterizam somente um exemplo de simulação.

Tabela 4.13 - Planilha com dados de entrada da simulação.

\begin{tabular}{|c|c|c|c|c|c|}
\hline ATRIBUTO & $\begin{array}{l}\text { SOLAR } \\
\text { FOIOVOLTAICA }\end{array}$ & EÓLICA & $\begin{array}{l}\text { BIOMASSA } \\
\text { CANA }\end{array}$ & PCH & GMG a DIESEL \\
\hline Potência Nominal de Carga $(\mathrm{kW})$ & 100 & 100 & 100 & 100 & 100 \\
\hline Funcionamento Diário Médio (h/dia) & 12 & 12 & 12 & 12 & 12 \\
\hline Energia Anual Média Necessária (kWh/ano) & $438.000,00$ & $438.000,00$ & $438.000,00$ & $438.000,00$ & $438.000,00$ \\
\hline Fator de Capacidade & 0,2693 & 0,3832 & 1 & 1 & 1 \\
\hline Potência Nominal de Geração (kW) & 371,33 & 260,96 & 100 & 100 & 100 \\
\hline Vida Útil do Sistema (ano) & 25 & 15 & 25 & 30 & 20 \\
\hline Distância da Carga $(\mathrm{km})$ & 0 & 0 & 0 & 0,38 & 0 \\
\hline Custo de Implantação da Linha $(\mathrm{R} \$ / \mathrm{km})$ & 0 & 0 & 0 & $12.297,00$ & 0 \\
\hline Perdas na Linha (\% da energia) & $0 \%$ & $0 \%$ & $0 \%$ & $8,69 \%$ & $0 \%$ \\
\hline Perdas Anuais (kWh/ano) & 0 & 0 & 0 & $38.062,20$ & 0 \\
\hline Custo da Energia Perdida (R\$/kWh) & 0 & 0 & 0 & 0,2070 & 0 \\
\hline Custo Anual das Perdas (R\$/ano) & 0 & 0 & 0 & $7.878,88$ & 0 \\
\hline Taxa de Juros (a.a.) & $6 \%$ & $6 \%$ & $6 \%$ & $6 \%$ & $6 \%$ \\
\hline Período de Estudo (ano) & 15 & 15 & 15 & 15 & 15 \\
\hline FRC de Todo o Período de Estudo & 0,1030 & 0,1030 & 0,1030 & 0,1030 & 0,1030 \\
\hline Custo de Implantaçao $(\mathrm{R} \$ \mathrm{~kW})$ & $10.954,00$ & $1.888,00$ & $1.735,00$ & $1.614,00$ & $1.156,00$ \\
\hline Investimento Inicial (R\$) & $4.067 .582,62$ & $492.693,11$ & $173.500,00$ & $166.060,56$ & $115.600,00$ \\
\hline Valor Residual (R\$) & $678.904,04$ & 0 & $28.958,20$ & $34.645,64$ & $12.058,96$ \\
\hline CA de Implantação (R\$/(kW.ano)) & 939,61 & 194,39 & 148,82 & 135,31 & 106,61 \\
\hline Custo de O\&M (\% do Investimento) & $1,62 \%$ & $0 \%$ & $2,23 \%$ & $0 \%$ & $0 \%$ \\
\hline Custo de O\&M (R\$/(kW.ano)) & 15,25 & 0 & 3,31 & 0 & 0 \\
\hline Custo de O\&M (R\$/kWh) & 0 & 0,0109 & 0 & 0,0200 & 0,1129 \\
\hline Custo de O\&M (R\$/(kW.ano)) & 0 & 18,30 & 0 & 87,65 & 494,33 \\
\hline Custo de Combustível (R\$/kWh) & 0 & 0 & 0,0985 & 0 & 0,912 \\
\hline Custo de Combustível (R \$/(kW.ano)) & 0 & 0 & 431,40 & 0 & $3.995,44$ \\
\hline CA de O\&M (R\$/(kW.ano)) & 15,25 & 18,30 & 434,71 & 87,65 & $4.489,76$ \\
\hline CA TOTAL (R\$/(kW.ano)) & 954,86 & 212,69 & 583,53 & 301,75 & $4.596,37$ \\
\hline Custo da Energia ( $\mathbf{R} \$ / \mathbf{k W h})$ & 0,8095 & 0,1267 & 0,1332 & 0,0689 & 1,0494 \\
\hline
\end{tabular}


No intuito de facilitar a visualização das variáveis aleatórias serão apresentadas por intermédio da Tabela 4.14 as faixas de valores utilizadas na simulação, conforme levantamento técnico-financeiro efetuado em seção anterior.

Tabela 4.14 - Faixa de valores da simulação.

\begin{tabular}{|c|c|c|}
\hline FONTE & ATRIBUTOS & FAIXAS UTILIZADAS \\
\hline \multirow{3}{*}{ FOTOVOLTAICA } & Fator de Capacidade (\%) & $22-30$ \\
\hline & Custo de Implantação (R\$̦/kW) & $6.997,40-15.754,20$ \\
\hline & Custo de O\&M (\% do Investimento) & $1,5-2$ \\
\hline \multirow{3}{*}{ EÓLICA } & Fator de Capacidade (\%) & $34-44$ \\
\hline & Custo de Implantação (R\$/kW) & $1.224,55-3.061,00$ \\
\hline & Custo de O\&M (R\$T/MWh) & $7-21$ \\
\hline \multirow{3}{*}{ BIOMASSA } & Custo de Implantação (R\$/kW) & $874,67-1.794,00$ \\
\hline & Custo de O\&M (\% do Investimento) & $2-4$ \\
\hline & Custo de Combustível (R\$̦/kWh) & $0,055-0,194$ \\
\hline \multirow{6}{*}{$\mathrm{PCH}$} & Distância da Carga $(\mathrm{km})$ & $0,3-1$ \\
\hline & Custo de Implantação da Linha ( $\mathrm{R} \$ \mathrm{~km})$ & $12.245,00-18.000,00$ \\
\hline & Perdas na Linha (\% da energia) & $7-10,2$ \\
\hline & Custo da Energia Perdida (R\$/kWh) & $163,15-242,31$ \\
\hline & Custo de Implantação (R\$/kW) & $1.574,42-2.624,03$ \\
\hline & Custo de O\&M (R\$/MWh) & $10,49-26,24$ \\
\hline \multirow{3}{*}{ GMG a Diesel } & Custo de Implantação (R\$/kW) & $1.025,54-1.224,55$ \\
\hline & Custo de O\&M (R\$/MWh) & $76,97-125,95$ \\
\hline & Custo de Combustível (R\$̣/kWh) & $0,537-0,9026$ \\
\hline
\end{tabular}

Os resultados da simulação são apresentados por intermédio dos gráficos e da tabela apresentada a seguir que demonstra os valores médios, desvio padrão e probabilidade de 95\% dos casos ocorrerem com valor inferior a determinado custo.

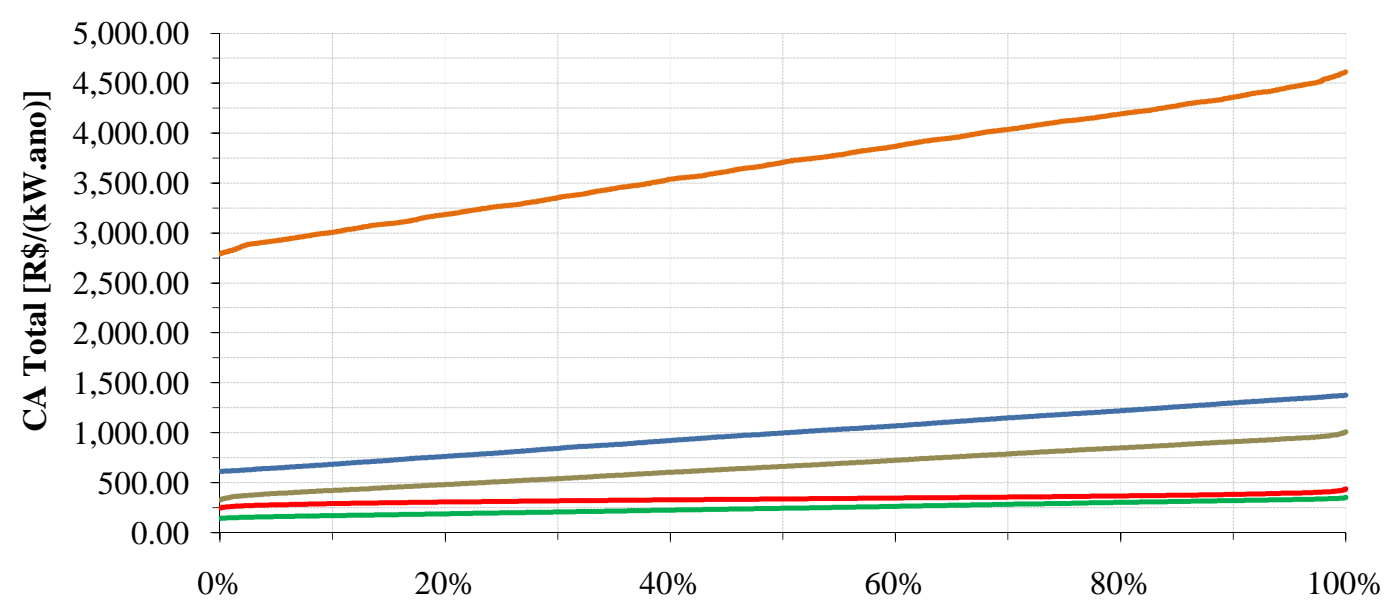

Distribuição Acumulada dos Valores Simulados

\begin{tabular}{ll|}
\hline GMG a Diesel & PCH \\
Solar Fotovotaica & Biomassa: Cana
\end{tabular}

Gráfico 4.1 - Valores de CAT da simulação para 5.000 casos. 


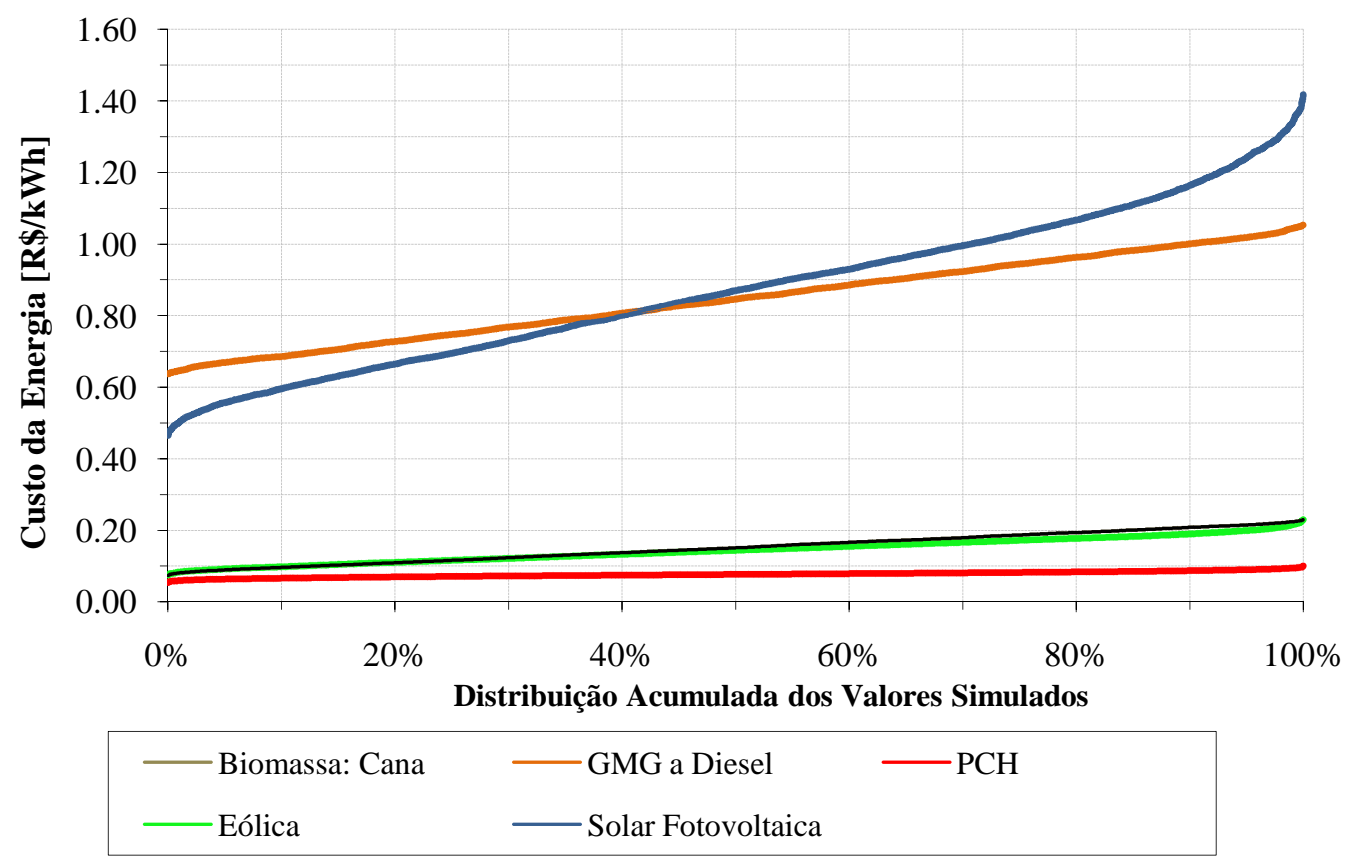

Gráfico 4.2 - Valores de CE da simulação para 5.000 casos.

Tabela 4.15 - Resultados da simulação para 5.000 casos.

\begin{tabular}{|l|r|r|r|r|r|}
\hline \multicolumn{1}{|c|}{ GRANDEZA } & \multicolumn{1}{c|}{$\begin{array}{c}\text { SOLAR } \\
\text { FOTOVOLTAICA }\end{array}$} & \multicolumn{1}{c|}{ EÓLICA } & \multicolumn{1}{c|}{ BIOMASSA } & \multicolumn{1}{c|}{ PCH } & \multicolumn{1}{c|}{$\begin{array}{c}\text { GMG a } \\
\text { DIESEL }\end{array}$} \\
\hline CAT Médio [R\$/(kW.ano)] & 993,98 & 244,54 & 662,57 & 335,91 & $3.694,48$ \\
\hline Desvio Padrão [R\$/(kW.ano)] & 221,30 & 55,66 & 177,81 & 34,26 & 493,18 \\
\hline P95\% [R\$(kW.ano)] & $1.337,30$ & 330,44 & 939,14 & 393,45 & $4.461,81$ \\
\hline CE Médio [R\$/kWh] & 0,87350 & 0,14402 & 0,15152 & 0,07669 & 0,84526 \\
\hline Desvio Padrão [R\$/kWh] & 0,21134 & 0,03402 & 0,04067 & 0,00776 & 0,11370 \\
\hline P95\% [R\$/kWh] & 1,24070 & 0,19871 & 0,21452 & 0,08971 & 1,01889 \\
\hline
\end{tabular}

A tabela acima, com os resultados da simulação, revela que a solução com o menor CAT é a geração eólica, com custo médio de $\mathrm{R} \$ 244,54 /(\mathrm{kW}$.ano), seguida da geração por PCH, com custo médio de R $\$ 335,91 /(\mathrm{kW}$.ano). Nota-se um elevado CAT para a utilização da geração a diesel, com custo médio de $\mathrm{R} \$ 3.694,48 /(\mathrm{kW}$.ano), o custo elevado se deve principalmente ao alto preço do combustível sem a inclusão de subsídios, e mesmo sendo a mais onerosa esta geração é a mais utilizada no atendimento a cargas isoladas.

A grande variação nos valores do CAT para a solução de geração com biomassa de cana deve-se a grande faixa de variação associada ao custo do bagaço [R $\$ /$ ton], fato que pode ser observado pelo alto desvio-padrão encontrado, cerca de $26,83 \%$ do valor médio. 
Segundo a tabela e o gráfico correspondente ao custo da energia, nota-se que a solução com o menor $\mathrm{CE}$ é a geração por $\mathrm{PCH}$, com custo médio de $\mathrm{R} \$ 76,69 / \mathrm{MWh}$, que se demonstrou inferior a todas as taxas de distribuição de energia para consumidores do subgrupo B2 (Rural) pesquisadas (Força e Luz do Oeste, com custo de R \$ 163,15/MWh) ${ }^{17}$. Em seguida aparecem os custos para a solução eólica (R \$ 144,02/MWh) e biomassa de cana $(\mathrm{R} \$ 151,52 / \mathrm{MWh})$.

A geração solar fotovoltaica se mostrou a mais onerosa, com custo médio de $\mathrm{R} \$ 873,50 / \mathrm{MWh}$, enquanto a segunda mais onerosa foi a solução de geração a diesel, com custo médio de R\$845,26/MWh.

Considerando a estimativa de resultados que indiquem grandezas situadas abaixo de $95 \%$ dos valores, nota-se que a solução eólica, com custo P95\% de R $\$ 198,71 / \mathrm{MWh}$, e a solução de biomassa de cana, com custo P95\% de R \$214,52/MWh, encontram-se abaixo da maior taxa de distribuição de energia a consumidores do subgrupo B2 (Rural) pesquisada ( $\mathrm{R} \$ 242,31 / \mathrm{MWh})$.

Analisando as curvas presentes nos dois gráficos, percebe-se que estas não aparecem na mesma ordem de custos, o que pode ser notado pelo fato de que a solução que apresenta o menor CE, geração por PCH, não apresenta o menor CAT. Segundo Severino (2008), tal fato tem sua justificativa na metodologia utilizada, onde a equivalência de produção energética implica no fato de que algumas soluções devam possuir uma potência nominal de geração maior. Conseqüentemente o CAT tende a diminuir, conforme modelagem matemática proposta, porém o CE não sofre alteração. Entretanto, a grandeza de maior importância para a avaliação econômica é o CE médio (Severino, 2008), em R\$/kWh ou $\mathrm{R} \$ \mathrm{MWh}$

Após verificação do CE de cada uma das soluções, nota-se que somente a solar fotovoltaica necessitaria do provimento de subsídios, pois é a única que possui CE maior que o VN corrigido, segundo estimativas apresentadas anteriormente que podem ser

\footnotetext{
${ }^{17}$ Considerando-se que o valor apresentado em simulação é tratado como estimativa para produção e consumo próprio, podendo assim ser comparado com a tarifa de distribuição (que agrega os custos de geração, transmissão e distribuição, além de encargos e impostos).
} 
observadas na Tabela 4.16. Portanto, tal subsídio será, de acordo com a modelagem matemática desenvolvida, de R \$ 470,34/MWh.

Tabela 4.16 - Comparação entre CE e VN para cálculo do subsídio.

\begin{tabular}{|l|c|c|c|c|}
\hline \multicolumn{1}{|c|}{ GRANDEZA } & $\begin{array}{c}\text { SOLAR } \\
\text { FOTOVOLTAICA }\end{array}$ & EÓLICA & BIOMASSA & PCH \\
\hline CE Médio $[\mathrm{R} \$ / \mathrm{MWh}]$ & 873,50 & 144,02 & 151,52 & 76,69 \\
\hline VN Corrigido $[\mathrm{R} \$ \mathrm{MWh}]$ & 403,16 & 222,44 & 178,13 & 157,18 \\
\hline Subsídio $[\mathrm{R} \$ \mathrm{MWh}]$ & 470,34 & - & - & - \\
\hline
\end{tabular}

Utilizando-se o benefício da CCC, e considerando um subsídio de $75 \%$ sobre o preço do diesel, verifica-se que a geração por esta fonte, torna-se mais competitiva, porém continua sendo mais onerosa que as soluções PCH, biomassa de cana e eólica, com custo de energia médio de $\mathrm{R} \$ 323,49 / \mathrm{MWh}$. Os resultados da simulação efetuada para o caso do subsídio da CCC ao diesel podem ser observados por intermédio do Gráfico 4.3 e da Tabela 4.17, a seguir.

Tabela 4.17 - Resultados da simulação utilizando a CCC.

\begin{tabular}{|l|r|r|r|r|}
\hline \multicolumn{1}{|c|}{ GRANDEZA } & \multicolumn{1}{c|}{ EÓLICA } & \multicolumn{1}{c|}{ BIOMASSA } & \multicolumn{1}{c|}{ PCH } & \multicolumn{1}{c|}{$\begin{array}{c}\text { GMG a } \\
\text { DIIESEL }\end{array}$} \\
\hline CE Médio $[\mathrm{R} \$ \mathrm{kWh}]$ & 0,14389 & 0,15174 & 0,07673 & 0,32349 \\
\hline Desvio Padrão $[\mathrm{R} \$ / \mathrm{kWh}]$ & 0,03399 & 0,04045 & 0,00778 & 0,03509 \\
\hline P95\% $[\mathrm{R} \$ \mathrm{kWh}]$ & 0,19998 & 0,21436 & 0,08932 & 0,38049 \\
\hline
\end{tabular}

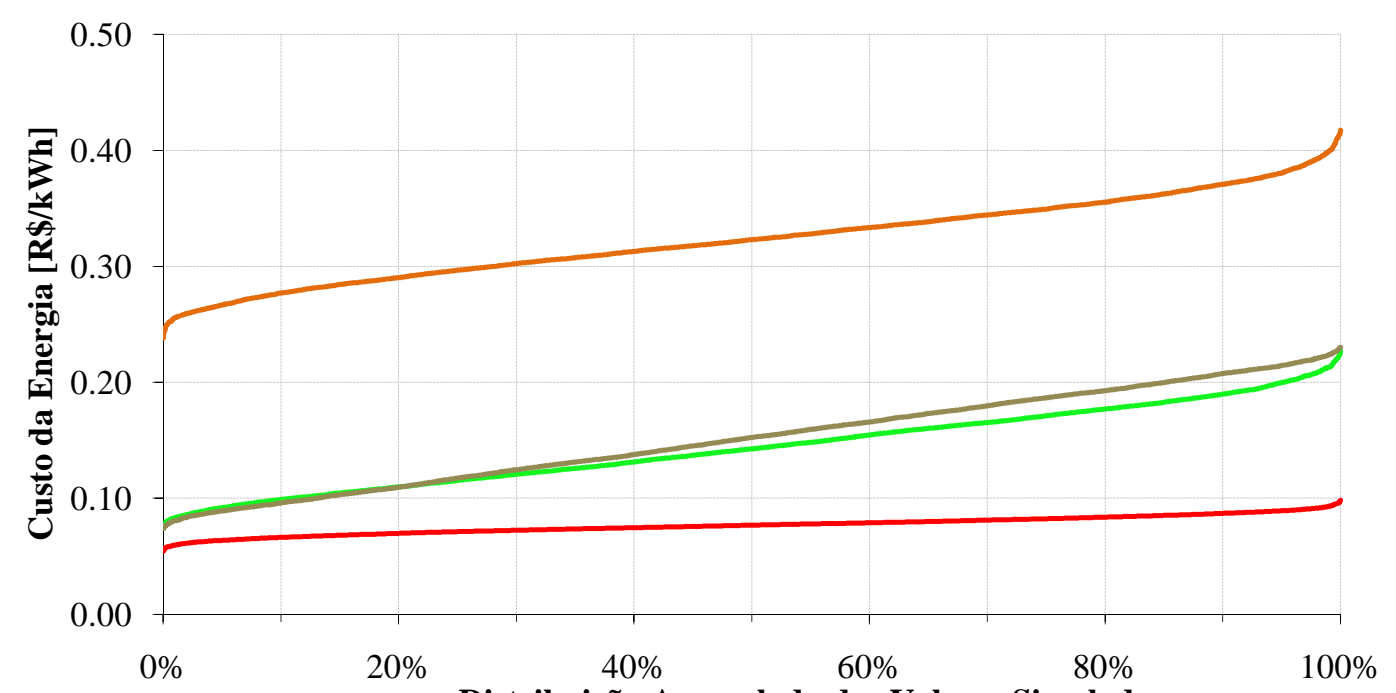

Distribuição Acumulada dos Valores Simulados

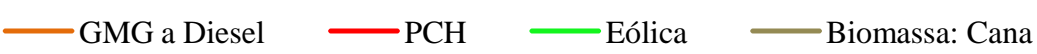

Gráfico 4.3 - Valores de CE com o subsídio da CCC. 
Verifica-se que com um subsídio de $75 \%$ no preço do combustível, foi possível reduzir o CE em 64,71\%, no caso da geração a diesel. Tal fato decorre de que o custo anual de O\&M corresponde a $90 \%$ do CAT desta solução.

Optou-se pela retirada dos valores relativos à solução fotovoltaica para a simulação, pois os valores de subsídio calculados tratam de dados meramente informativos para este estudo, que indicariam uma necessidade de cobertura de valores por parte da CDE. Enquanto o benefício da CCC não trata de uma indicação de necessidade de subsídio, e sim de uma prática suportada há tempos. Desta forma, pode-se verificar que apesar do aumento da atratividade da geração a diesel, esta ainda continua sendo mais onerosa que as demais soluções de geração por fontes alternativas. 


\section{EXTERNALIDADES}

Os economistas consideram que as atividades de produção e de consumo geram "exterioridades" positivas e negativas. Tais exterioridades são negativas quando a atividade de produção (ou de consumo) tem um efeito incidental ou não-intencional (isto é, não faz parte dos objetivos da produção ou do consumo) que prejudica outros agentes econômicos, sem que seu custo tenha reflexo no mercado, de tal sorte que esse prejuízo é ignorado nas contas (Gadrey \& Jany-Catrice, 2006).

A construção e operação de empreendimentos associados ao setor elétrico incorrem em custos econômicos diretos, conforme tratado anteriormente, que são pagos pelos agentes econômicos. Entretanto tais empreendimentos podem acarretar em consequiências favoráveis ou desfavoráveis para diversas dimensões de estudo, entre elas a dimensão ambiental, social, política e até mesmo econômica. A não-mitigação e não-contabilização de tais conseqüências podem acarretar em graves atenuantes tais como o uso predatório do meio ambiente e das relações sociais.

Externalidades políticas, apesar da difícil mensuração, são responsáveis por afetar a economia de países envolvidos, principalmente no que diz respeito ao investimento necessário a execução de conflitos armados no intuito de se efetuar o controle de reservas de recursos energéticos. Já externalidades econômicas são consideradas as mais complexas de serem expostas por tratarem de custos do processo de produção (ou consumo) que não são agregados por serem inseridas como benefícios por meio de subsídios, tais como obtenção de terrenos, isenções fiscais, ajudas diretas do governo (o qual às vezes aplica dinheiro a fundo perdido para viabilizar empreendimentos).

As externalidades sociais estão diretamente ligadas ao impacto causado em comunidades pela implantação de projetos de produção de energia, tais como desapropriação de terras, desalojamento de comunidades. Já as externalidades ambientais aparecem atualmente em voga devido a uma mudança de paradigma econômico em evolução na sociedade, pois os recursos naturais, antigamente tão fartos, têm se tornado cada vez mais escassos, e há de se levar em consideração ainda uma possível exaustão dos mesmos. 
A busca por sustentabilidade, entendida como a capacidade de as gerações presentes alcançarem suas necessidades, sem comprometer a capacidade das gerações futuras, aparece atualmente como um eixo reorganizador dos processos econômicos. No caso de políticas energéticas, da mesma forma, não se consegue deixar de aplicar a concepção de que esta deve ser coordenada e direcionada aos objetivos das políticas ambientais, com o intuito de assegurar a sustentabilidade das interações entre os sistemas econômicos e ecológicos.

Desta forma, nos encontramos inseridos num contexto de elevada complexidade técnica, que requer uma abordagem integrada e interdisciplinar entre as ciências do ambiente e econômica. Pois a contribuição da ciência econômica é uma componente essencial em processos de gestão ambiental e existem diversas razões que justificam uma abordagem econômica dos aspectos ambientais (Santos, 2001), tais como:

- A escassez de recursos ambientais, enquanto sistema de suporte à vida.

- A contribuição para identificar causas de problemas ambientais, principalmente às causas econômicas resultantes de externalidades ambientais.

- A contribuição para a solução e mitigação de problemas identificados, utilizando-se de recursos e metodologias de avaliação econômica, que sustentam o desenvolvimento e aplicação de instrumentos para a correção das distorções nos mercados.

Devido à ameaça da escassez de recursos naturais, buscam-se então alternativas para o desenvolvimento socioeconômico sustentável. E, como o impacto do setor elétrico na deterioração ambiental é significativo, faz-se fundamental considerar as externalidades provocadas pelo processo produtivo no meio ambiente e a internalização econômica dos efeitos sobre os recursos ambientais. Para que seja possível a promoção de uma aferição, eficiente, justa e sustentável dos recursos.

Existe então a necessidade de se fazer refletir nos preços dos bens e serviços a parcela proveniente das externalidades do processo produtivo, ou seja, a introdução do capital natural na análise econômica se faz necessária. Já que os custos da degradação ambiental e do consumo de recursos naturais não têm sido adicionados as estimativas de valores dos processos produtivos. 
Porém, quando os mercados não têm condições de fazer repercutir automaticamente nos preços os custos das externalidades ambientais e o custo da escassez de recursos, a concepção e aplicação de instrumentos de políticas ambientais e metodologias econômicas tornam-se fundamentais. Desta forma, surge a proposta da avaliação econômica do meio ambiente, que não tem como objetivo pura e simplesmente "dar um preço" a certo tipo de ambiente e sim mostrar o valor econômico que este pode oferecer e o prejuízo irrecuperável que pode haver caso seja destruído (Figueroa, 1996).

Não há dinheiro ou tecnologia capaz de substituir os serviços ambientais proporcionados pela biodiversidade, regulação climática, ciclo hidrológico, proteção da camada de ozônio e tantos outros (Merico, 1996). E sabemos que o setor elétrico gera externalidades ambientais associadas à extração de insumos, produção, transporte e distribuição de energia. E, no intuito de assegurar que as decisões de consumo e produção de eletricidade contribuam com o uso eficiente dos recursos ambientais, torna-se necessário encontrar formas de fazer repercutir os custos das externalidades ambientais no preço da eletricidade.

Logo o adequado gerenciamento econômico-ambiental é essencial para garantir que a degradação da natureza e a decadência da qualidade de vida cessem. Sendo que, a aplicação de instrumentos econômicos e a utilização dos mecanismos de mercado, tornamse uma via para internalizar as externalidades, e incentivar a adoção de medidas mais eficientes em termos de produção e consumo de energia elétrica.

\subsection{Externalidades ambientais das atividades do setor elétrico}

As atividades associadas ao setor elétrico geram diversos impactos ambientais importantes, e contribuem de forma significativa para problemas considerados prioritários na política ambiental. E, a análise de tais impactos não deve ser restrita somente aos problemas ambientais originados durante a produção da eletricidade, devendo sim considerar os impactos originados durante todo o ciclo de vida de uma determinada tecnologia de produção, sempre considerando, quando relevante, as demais etapas (Santos, 2001), tais como:

- extração de recursos;

- transporte; 
- refino/processamento de materiais;

- produção de equipamentos;

- construção de instalações;

- operação; e

- desativação.

Devido ao grau de consciência ainda imaturo da sociedade e a dificuldade de mensuração dos impactos ambientais, apesar do auxílio das metodologias da abordagem econômica, algumas externalidades ainda não são adequadamente agregadas ao custo convencional da energia. Entretanto, existe a capacidade de caracterizar a contribuição do setor elétrico para os principais problemas ambientais da atualidade. Sendo assim, apresentam-se alguns dos impactos mais significativos (Santos, 2001).

- Contribuição para as alterações climáticas devido à emissão de GEE, principalmente $\mathrm{CO}_{2}$, que está associada principalmente às atividades de extração, refino e principalmente devido à queima de combustíveis fósseis.

- Emissão de compostos acidificantes $\left(\mathrm{SO}_{2}\right.$ e $\left.\mathrm{NO}_{\mathrm{X}}\right)$ e a contribuição para a formação do ozônio troposférico, que está associada ao refino e queima de combustíveis fósseis.

- Redução de recursos não-renováveis, devido à utilização principalmente de combustíveis fósseis.

- Alteração de fluxos hidrológicos e degradação da qualidade da água, devido aos aproveitamentos hidrelétricos (barragens).

- Contribuição para a diminuição da biodiversidade. Por exemplo, devido aos efeitos provocados pelos aproveitamentos hidrelétricos nos ecossistemas aquáticos e terrestres.

- Degradação de zonas costeiras e ecossistemas marinhos, devido a atividades de extração e transporte de combustíveis fósseis.

- Ocupação do solo (desapropriação), principalmente devido à produção hidroelétrica e o aproveitamento de outras fontes renováveis, tais como solar e eólica.

- Riscos a saúde humana, devido a radiações associadas ao manuseio e utilização de combustíveis nucleares e dos efeitos dos campos eletromagnéticos associados às linhas de transmissão de eletricidade.

- Riscos a saúde humana decorrentes de problemas respiratórios associado às emissões de poluentes atmosféricos.

- Riscos químicos, devido à manipulação de substâncias perigosas. 
Focando os impactos mais significativos, pode-se então utilizar tais informações para categorizar os impactos ambientais e apresentar uma síntese das conseqüências ambientais por tecnologia específica. Destacam-se então as seguintes categorias de impacto (Santos, 2001):

- alterações climáticas;

- acidificação;

- poluição atmosférica;

- ozônio troposférico;

- fluxos hidrológicos;

- poluição das águas;

- perda de biodiversidade;

- degradação do solo;

- degradação de zonas costeiras e ecossistemas marinhos;

- redução de recursos não-renováveis;

- resíduos perigosos;

- saúde humana;

- insalubridade (riscos de acidentes graves);

- riscos químicos;

- poluição visual; e

- ruído;

A Tabela 5.1 a seguir apresenta uma síntese dos principais impactos ambientais das atividades do setor elétrico a serem observados neste estudo. 
Tabela 5.1 - Impactos ambientais das atividades do setor elétrico.

\begin{tabular}{|c|c|c|c|c|c|}
\hline CATEGORIA DO IMPACTO & DIESEL & PCH & BIOMASSA & EOLLICA & SOLAR \\
\hline ALTERAÇÕES CLIMÁTICAS & $\begin{array}{l}\text { A geração, refino e } \\
\text { queima de combustível } \\
\text { fóssil gera emissão de } \\
\text { GEE's }\end{array}$ & Pequenos lagos & Emissão de GEE's & $\begin{array}{l}\text { Processos } \\
\text { energéticos para } \\
\text { a produção de } \\
\text { equipamentos }\end{array}$ & $\begin{array}{l}\text { Intensivo } \\
\text { processo } \\
\text { energético para a } \\
\text { produção das } \\
\text { células }\end{array}$ \\
\hline ACIDIFICAÇÃO & $\begin{array}{l}\text { O refino e queima de } \\
\text { combustível fóssil gera } \\
\text { emissão de } \mathrm{SO}_{2} \text { e } \mathrm{NO}_{\mathrm{X}}\end{array}$ & & $\begin{array}{c}\text { Emissão de } \mathrm{SO}_{2} \mathrm{e} \\
\mathrm{NO}_{\mathrm{X}} \text { na queima }\end{array}$ & & \\
\hline POLUIÇÃO ATMOSFÉRICA & $\begin{array}{l}\text { A extração, transporte e } \\
\text { queima de combustível } \\
\text { fóssil gera a emissão de } \\
\text { partículas }\end{array}$ & & $\begin{array}{c}\text { Emissão de } \\
\text { partículas na queima }\end{array}$ & & \\
\hline OZÔNIO TROPOSFÉRICO & & & $\begin{array}{l}\text { Emissão de } \mathrm{NO}_{\mathrm{X}} \text { na } \\
\text { queima }\end{array}$ & & \\
\hline FLUXOS HIDROLÓGICOS & & $\begin{array}{l}\text { Alteração do } \\
\text { regime dos rios, } \\
\text { redução dos } \\
\text { caudais (água } \\
\text { em abundância) }\end{array}$ & $\begin{array}{c}\text { Remoção de } \\
\text { vegetação pode } \\
\text { causar alterações no } \\
\text { escoamento e } \\
\text { infiltração }\end{array}$ & & \\
\hline POLUIÇÃO DAS ÁGUAS & $\begin{array}{l}\text { Vazamento de } \\
\text { poluentes na extração, } \\
\text { transporte e refino, } \\
\text { além das águas de } \\
\text { refrigeração }\end{array}$ & & $\begin{array}{l}\text { Lixiviação }^{18} \text { para a } \\
\text { produção de } \\
\text { biomassa pode } \\
\text { causar contaminação } \\
\text { e eutrofização }\end{array}$ & & \\
\hline $\begin{array}{l}\text { ECOSSISTEMAS/PERDA DE } \\
\text { BIODIVERSIDADE/DANOS } \\
\text { EM FLORESTAS }\end{array}$ & $\begin{array}{l}\text { Vazamento de } \\
\text { poluentes na extração e } \\
\text { transporte pode } \\
\text { ocasionar a destruição } \\
\text { de vegetações }\end{array}$ & $\begin{array}{l}\text { Redução na } \\
\text { população de } \\
\text { peixes }\end{array}$ & $\begin{array}{c}\text { Destruição da } \\
\text { vegetação para a } \\
\text { cultura de insumos e } \\
\text { remoção de resíduos } \\
\text { florestais }\end{array}$ & $\begin{array}{l}\text { Risco de colisão } \\
\text { de aves com as } \\
\text { pás das turbinas }\end{array}$ & \\
\hline $\begin{array}{l}\text { DEGRADAÇÃO DO } \\
\text { SOLO/COLHEITAS }\end{array}$ & $\begin{array}{l}\text { A extração e } \\
\text { armazenamento de } \\
\text { combustíveis podem } \\
\text { causar degradação e } \\
\text { contaminação do solo }\end{array}$ & $\begin{array}{l}\text { Redução de } \\
\text { áreas de cultivo }\end{array}$ & $\begin{array}{l}\text { Degradação do solo } \\
\text { por cultura de } \\
\text { insumos e risco de } \\
\text { erosão }\end{array}$ & $\begin{array}{l}\text { Requer extensas } \\
\text { áreas, porém } \\
\text { sem ocupação } \\
\text { total }\end{array}$ & $\begin{array}{l}\text { Requer extensas } \\
\text { áreas, porém sem } \\
\text { ocupação total }\end{array}$ \\
\hline $\begin{array}{l}\text { DEGRADAÇÃO DE ZONAS } \\
\text { COSTEIRAS E } \\
\text { ECOSSISTEMAS MARINHOS }\end{array}$ & $\begin{array}{l}\text { O transporte de } \\
\text { combustíveis pode } \\
\text { causar contaminação de } \\
\text { ecossistemas marinhos }\end{array}$ & & & & \\
\hline $\begin{array}{l}\text { REDUÇÃO DE RECURSOS } \\
\text { NÃO RENOVÁVEIS }\end{array}$ & $\begin{array}{l}\text { O combustível fóssil é } \\
\text { um recurso não } \\
\text { renovável, passível de } \\
\text { escassez }\end{array}$ & & & & $\begin{array}{l}\text { Algumas células } \\
\text { utilizam material } \\
\text { não renovável }\end{array}$ \\
\hline RESÍDUOS PERIGOSOS & $\begin{array}{l}\text { O refino e queima de } \\
\text { combustível fóssil gera } \\
\text { cinzas e escórias }^{19}\end{array}$ & & $\begin{array}{l}\text { Produção de cinzas } \\
\text { resultantes da } \\
\text { combustão }\end{array}$ & & $\begin{array}{l}\text { Geração de } \\
\text { resíduos na } \\
\text { produção e } \\
\text { desmanche das } \\
\text { células }\end{array}$ \\
\hline SAÚDE HUMANA & $\begin{array}{l}\text { Danos indiretos à saúde } \\
\text { humana e do } \\
\text { trabalhador }\end{array}$ & $\begin{array}{l}\text { Danos indiretos } \\
\text { à saúde humana } \\
\text { e do trabalhador }\end{array}$ & $\begin{array}{l}\text { Danos indiretos à } \\
\text { saúde humana e do } \\
\text { trabalhador }\end{array}$ & $\begin{array}{l}\text { Danos indiretos } \\
\text { à saúde humana } \\
\text { e do trabalhador }\end{array}$ & $\begin{array}{l}\text { Danos indiretos à } \\
\text { saúde humana e } \\
\text { do trabalhador }\end{array}$ \\
\hline INSALUBRIDADE & $\begin{array}{l}\text { Perigo de Explosão e } \\
\text { incêndio em todas as } \\
\text { fases }\end{array}$ & & & & \\
\hline RISCOS QUÍMICOS & & & & & $\begin{array}{l}\text { Materiais } \\
\text { utilizados } \\
\text { possuem alguma } \\
\text { periculosidade }\end{array}$ \\
\hline POLUIÇÃO VISUAL & $\begin{array}{l}\text { As estruturas } \\
\text { associadas geram } \\
\text { alterações visuais }\end{array}$ & $\begin{array}{l}\text { Alteração } \\
\text { visual em áreas } \\
\text { não perturbadas }\end{array}$ & $\begin{array}{l}\text { Cultura de insumos } \\
\text { tem impactos na } \\
\text { paisagem }\end{array}$ & $\begin{array}{l}\text { As turbinas } \\
\text { causam } \\
\text { alterações na } \\
\text { paisagem }\end{array}$ & $\begin{array}{c}\text { Os painéis } \\
\text { causam alterações } \\
\text { na paisagem }\end{array}$ \\
\hline RUÍDO & $\begin{array}{l}\text { Utilização de motores } \\
\text { provoca aumento nos } \\
\text { níveis de ruído }\end{array}$ & & & $\begin{array}{l}\text { Ruído } \\
\text { provocado pela } \\
\text { operação das pás }\end{array}$ & \\
\hline
\end{tabular}

Fonte: Avaliação Econômica dos Impactos do Setor Elétrico, (Santos, Martinho, \& Antunes, 2001), Lisboa, Portugal, modificado.

\footnotetext{
${ }^{18}$ Lixiviação: Operação que consiste em fazer passar um solvente através de um material pulverizado (cinzas ou resíduos), para conseguir a separação de um ou mais constituintes solúveis.

${ }^{19}$ Escória: Matéria estranha, misturada com uma substância, e que resta como resíduo sólido, após a queima ou tratamento industrial desta.
} 


\subsection{Avaliação econômica das externalidades}

A avaliação econômica de externalidades ambientais está fundamentada na teoria do bem estar neoclássica (Santos, Martinho, \& Antunes, 2001), a qual prediz um conjunto de pressupostos, entre os quais podemos destacar:

- O bem estar da sociedade é igual à soma dos níveis de bem estar individuais;

- O bem estar de cada indivíduo pode ser medido, a partir de sua disposição para pagar pelos bens e serviços;

- Os indivíduos agem de forma a aumentar o seu bem estar, escolhendo os bens e serviços que lhes permita obter um nível máximo de utilidade, dado seu poder aquisitivo e o preço de mercado dos bens e serviços.

Assume-se então que um indivíduo está disposto a pagar pelo consumo de um bem na medida da utilidade que tal consumo irá lhe propiciar, isto traduz sua máxima "disposição para pagar" (willingness to pay, WTP). E, como a despesa efetuada pelo consumidor geralmente é inferior a sua máxima WTP, gera-se então uma diferença entre a despesa total realizada e os benefícios obtidos. Tal diferença é conhecida como excedente do consumidor (EC), e traduz o benefício líquido que o indivíduo está obtendo com o consumo de determinado bem, traduzindo-se então como uma medida de bem estar.

Como medidas de valores baseadas na definição teórica de bem estar não são observadas diretamente no mercado, justifica-se então o motivo pelo qual a maioria dos métodos de avaliação custo-benefício de recursos ambientais se baseia no conceito de curva de procura e na relação entre a preferência por determinado recurso e a disposição para pagar, de modo a assegurar a não escassez deste.

Dentre os métodos baseados em curva de procura, a determinação do valor econômico de ativos, funções e processos ambientais pode ser realizada baseada na avaliação de preferências observadas ou reveladas em mercados reais ou por comportamentos expressos em mercados hipotéticos. Notoriamente, a avaliação econômica requer muitas vezes o questionamento da disposição para pagar quando tratamos de bens, serviços ou recursos que não passam pelo mercado. Logo, mesmo quando não existe o mercado, a análise econômica busca estimar o valor econômico como se o mercado estivesse presente. 


\subsubsection{Conceito de valor econômico}

Para o caso de recursos ambientais, o conceito de valor econômico está direcionado na motivação individual para pagar pela utilização ou preservação destes. Tais motivações podem ter origem na defesa de interesses próprios ou no desejo de propiciar às gerações futuras o acesso aos recursos. Por esta razão, é usual decompor o valor econômico total (VET) de certo recurso ambiental em duas componentes básicas (Santos, Martinho, \& Antunes, 2001): o valor de uso (VU) e o valor de não uso (VNU).

O VU de um recurso ambiental representa o nível de bem estar ou utilidade que o indivíduo retira da utilização de tal recurso. O VU pode ser subdividido em valor de uso direto (VUD) e valor de uso indireto (VUI), onde o VUD representa a utilidade e a disposição para pagar que o indivíduo extrai do uso direto de um recurso ambiental, seja para a utilização com fins produtivos ou para o consumo final. Enquanto o VUI contempla benefícios que resultam de funções do meio ambiente e que se traduzem em valores produtivos, ou de consumo, indireto, tais como controle de erosão e controle de pragas, entre outros.

Já o valor de não uso (VNU), expressa um valor que o indivíduo retira de determinado recurso, porém por outras razões que não a da sua atual utilização. O VNU pode ser subdividido em valor de opção (VO), valor de quase opção (VQO), valor de legado (VL) e valor de existência (VE).

O valor de opção (VO), expressa o que o indivíduo está disposto a pagar pela preservação no presente, para posteriormente obter a possibilidade de usufruir futuramente. $\mathrm{O}$ valor de quase opção (VQO), trata do máximo que o indivíduo está disposto a pagar no presente de forma a assegurar a preservação de determinado recurso até que se possa tomar uma decisão mais informada sobre real necessidade de preservação ou não do recurso.

O valor de existência (VE), trata da opção do indivíduo em valorizar um recurso mesmo que não o utilize no presente, nem tenha uma expectativa acerca de seu uso potencial no futuro. Estando dispostos a pagar pela preservação do mesmo por reconhecer que exista um valor intrínseco para o recurso, limitado à existência de tal recurso, provavelmente derivado de sentimentos relacionados com a responsabilidade ambiental. 
Enquanto o valor de legado é considerado outra componente do VNU que está relacionada com o VE e o VO, expressando a disposição do indivíduo para pagar pela preservação do ambiente para que posteriormente seus descendentes possam usufruir deste.

Conclui-se então que o valor econômico total de um recurso ambiental resulta da agregação do valor de uso atual com os valores de opção, legado e existência. Logo, a figura abaixo resume a decomposição de um recurso ambiental em suas componentes base e subdivisões conforme explanado anteriormente.

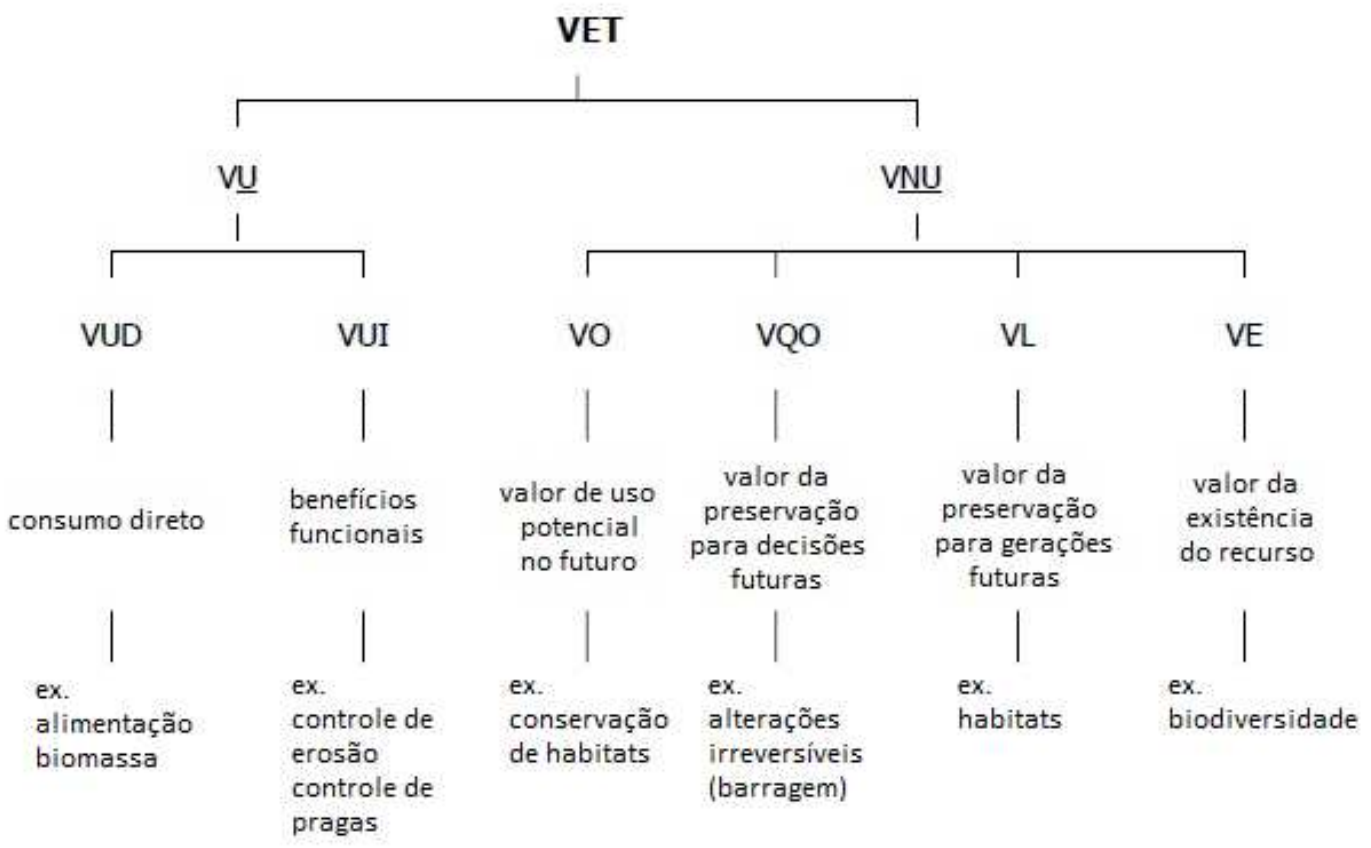

Fonte: Avaliação Econômica dos Impactos do Setor Elétrico (Santos, Martinho, \& Antunes, 2001), Lisboa, Portugal, modificado.

Figura 5.1 - Composição do valor econômico total.

\subsubsection{Metodologias de avaliação econômica}

As metodologias para avaliação econômica de recursos ambientais podem ser classificadas de acordo com diversos critérios. Uma das distinções diz respeito à utilização do conceito de curva de procura como base para a avaliação, e a outra distinção resulta da existência, ou não, de um mercado real para os bens ou serviços objeto da avaliação. Pois, quando existe um mercado real, a valoração monetária de um impacto ambiental pode ser estimada a preços de mercado, eventualmente corrigidos quando a análise é realizada com uma 
perspectiva social e o mercado não é competitivo, se não, faz-se necessária a utilização de preços substitutos ou valores contingenciais.

Segundo Dixon (1994), as metodologias de avaliação são subdivididas em dois grandes grupos: metodologias de avaliação objetiva ou subjetiva. Sendo que as metodologias de avaliação objetiva são baseadas em relações físicas, que descrevem formalmente relações de causa e efeito, oferecendo medidas objetivas do impacto ambiental de determinada ação. Tais relações são traduzidas por funções dose-resposta que são capazes de relacionar o nível da atividade agressora (ex.: emissão de poluentes) com a magnitude do impacto físico que isto originaria sobre a natureza, saúde humana, etc.

Tais funções são baseadas em dados provenientes de estudos de campo e ensaios experimentais. Posterior a caracterização dos aspectos físicos, quantitativos e qualitativos dos impactos, efetua-se a avaliação econômica por meio de preços de mercado ou das devidas correções levando-se em conta outras perspectivas além da econômica.

Já as metodologias de avaliação subjetiva são baseadas em preferências reveladas, relacionando-se diretamente com as funções de utilidade individual. Como o próprio nome já diz, tais metodologias são baseadas em avaliação subjetiva dos impactos ambientais por meio do comportamento revelado em mercados reais ou hipotéticos. Basicamente consiste na observação de mercados de bens ou serviços afetados por impactos ambientais, onde os indivíduos fazem escolhas entre o nível de qualidade do ambiente e outros bens. Mostrando assim uma medida aproximada da disposição para pagar por um bem estar relativo à qualidade ambiental.

As metodologias de avaliação subjetivas têm como premissa a utilização de comportamentos revelados em mercados reais como substitutos para bens e serviços ambientais que não são transacionados diretamente no mercado. Entretanto, existem casos em que impactos ambientais não podem ser avaliados, nem indiretamente, por intermédio da análise de mercados reais. Para tal a alternativa é a construção de um mercado hipotético para o bem ambiental em avaliação, que contemple diversos níveis de qualidade, e questione diretamente os indivíduos sobre a sua disponibilidade para pagar pela preservação de tal recurso. 
Como as metodologias subjetivas são embasadas em preferências do indivíduo, isto depende do nível de conhecimento e das informações disponíveis para este acerca dos recursos e impactos ambientais de determinada ação. Se tal informação for inadequada, a disposição para pagar pela preservação de um recurso ou evitar a ocorrência de um impacto pode ser sub ou superestimada, afetando o valor efetivo.

Ressalta-se que a escolha de uma metodologia em particular depende de vários fatores, tais como as características dos recursos e impactos a serem avaliados, além de sua magnitude e a disponibilidade de informações e recursos (financeiros, técnicos, humanos), além dos prazos para a realização dos estudos. Em certos casos tais fatores podem limitar a aplicação, principalmente das metodologias subjetivas. Logo, a utilização de resultados já existentes para o caso em análise pode se apresentar como a solução mais adequada.

Sendo assim, a avaliação econômica dos impactos ambientais do setor elétrico pode ser efetuada com o suporte de várias metodologias. Entretanto será dada ênfase a classificação adotada por Dixon (1994), utilizando-se a subdivisão entre metodologias objetivas e subjetivas, onde as análises podem ser agrupadas da seguinte forma: (1) análise de mercado; (2) análise de custos; (3) análise de mercados substitutos; e (4) análise de mercados hipotéticos. A Tabela 5.2 a seguir apresenta tal classificação.

Tabela 5.2 - Classificação de metodologias de avaliação econômica dos impactos ambientais.

\begin{tabular}{|c|c|c|c|}
\hline $\begin{array}{l}\text { METODOLOGIAS DE } \\
\text { AVALIAÇÃOO }\end{array}$ & $\begin{array}{c}\text { EFEITOS AMBIENTAIS } \\
\text { AVALIADOS }\end{array}$ & BASE DE APLICAÇÃO & BASE DE VALORAÇÃO \\
\hline \multicolumn{4}{|c|}{ METODOLOGIAS DE AVALIAÇÃO OBJETIVA } \\
\hline \multicolumn{4}{|l|}{ ANÁLISE DE MERCADO } \\
\hline Alterações na Produtividade & Produtividade & Técnica/Física & Preço de mercado \\
\hline Custo da Doença & Saúde Humana & Técnica/Física & Preço de mercado \\
\hline Capital Humano & Saúde Humana & Técnica/Física & Preço de mercado \\
\hline \multicolumn{4}{|l|}{ ANÁLISE DE CUSTOS } \\
\hline Custos de Realocação & Ativos Ambientais & Técnica/Física & Despesas Atuais ou Potenciais \\
\hline \multicolumn{4}{|c|}{ METODOLOGIAS DE AVALIAÇÃO SUBJETIVA } \\
\hline \multicolumn{4}{|l|}{ ANÁLISE DE CUSTOS } \\
\hline Despesas Preventivas & $\begin{array}{c}\text { Saúde Humana, Produtividade, } \\
\text { Ativos Ambientais }\end{array}$ & $\begin{array}{l}\text { Comportamentos } \\
\text { Revelados }\end{array}$ & Despesas Atuais ou Potenciais \\
\hline \multicolumn{4}{|c|}{ ANÁLISE DE MERCADOS SUBSTITUTOS } \\
\hline Valor da Propriedade & $\begin{array}{l}\text { Qualidade Ambiental, } \\
\text { Produtividade }\end{array}$ & Comportamentos Revelados & Preços de Mercado Substituto \\
\hline Diferencial de Salários & Saúde Humana & Comportamentos Revelados & Preços de Mercado Substituto \\
\hline Custo da Viagem & Ativos Ambientais & Comportamentos Revelados & Preços de Mercado Substituto \\
\hline \multicolumn{4}{|c|}{ ANÁLISE DE MERCADOS HIPOTÉTICOS } \\
\hline Avaliação Contingencial & $\begin{array}{l}\text { Saúde Humana, } \\
\text { Ativos Ambientais }\end{array}$ & Comportamentos Revelados & Valores Contingenciais \\
\hline
\end{tabular}

Fonte: Economic Analysis of Environmental Impacts, (Dixon, 1994), modificado. 
A existência de diversos métodos de avaliação econômica de recursos e impactos ambientais, que não são transacionados no mercado evidencia o significativo desenvolvimento teórico prestado por diversos colaboradores. Estão disponíveis atualmente diversas ferramentas, algumas contemplando várias opções metodológicas, que podem ser aplicadas à avaliação das externalidades ambientais do setor elétrico.

Entretanto, há de se ressaltar que alguns resultados obtidos até o presente não são satisfatórios, principalmente devido a algumas limitações metodológicas e requisitos de aplicação (Santos, 2001). Outros motivos podem ser elencados, tais como:

- A avaliação econômica das externalidades ambientais tem como base uma perspectiva antropocêntrica, onde a contribuição total das várias espécies e processos ecológicos para a função de sistema de suporte à vida providenciada por ecossistemas não é capturada de forma eficiente.

- A avaliação econômica ocorre posteriormente à avaliação física dos recursos ou impactos ambientais, sendo assim incorpora toda a incerteza que eventualmente exista na avaliação da magnitude dos impactos ou na caracterização dos sistemas ambientais. Levando em conta também a complexidade e dificuldade de abordagem científica dos processos e funções do ecossistema, associadas com as limitações na disponibilidade de informações, uma análise econômica e ambiental se vê limitada e conseqüentemente o interesse e a capacidade de desenvolver estudos para tal avaliação.

- A avaliação econômica encontra barreiras na atribuição de valores monetários aos recursos e danos ambientais. Tais dificuldades são conseqüência de metodologias, principalmente para contemplar os valores de não uso, e de restrições operacionais que condicionam a capacidade de mensurar os recursos necessários à realização de estudos que conduzam a resultados factíveis.

A Tabela 5.3 a seguir apresenta um resumo da sistematização dos métodos mencionados anteriormente, ressaltando os efeitos que podem ser avaliados no setor elétrico, bem como as vantagens e desvantagens na utilização das respectivas metodologias elencadas. 
Tabela 5.3 - Metodologia de avaliação e efeitos mensuráveis.

\begin{tabular}{|c|c|c|c|}
\hline $\begin{array}{c}\text { METODOLOGIAS } \\
\text { DE AVALIAÇÃOO }\end{array}$ & EFEITOS AMBIENTAIS AVALIADOS & & VANTAGENS/DESVANTAGENS \\
\hline \multicolumn{4}{|c|}{ ANÁLISE DE MERCADO } \\
\hline $\begin{array}{l}\text { Alterações na } \\
\text { Produtividade }\end{array}$ & $\begin{array}{c}\text { GERAL: } \\
\text { Efeitos da erosão do solo e desflorestamento, poluição } \\
\text { do ar e da água para agricultura e pesca } \\
\text { SETOR ELÉTRICO: } \\
\text { Impactos das emissões de produção de energia na } \\
\text { agricultura }\end{array}$ & $\Omega$ & $\begin{array}{l}\text { Baseia-se em dados que se observam diretamente no mercado } \\
\text { Dificuldades de implementação em situações de distorção dos } \\
\text { mercados } \\
\text { Dificuldade em garantir estimativas confiáveis dos efeitos } \\
\text { físicos }\end{array}$ \\
\hline $\begin{array}{l}\text { Custo da } \\
\text { Doença }\end{array}$ & $\begin{array}{l}\text { GERAL: } \\
\text { Efeitos da poluição do ar e da água e de acidentes com a } \\
\text { saúde humana }\end{array}$ & $\begin{array}{l}2 \\
x \\
x \\
x \\
x \\
x\end{array}$ & $\begin{array}{l}\text { Baseia-se em dados que se observam diretamente no mercado } \\
\text { Requisitos de Implementação de complexa verificação } \\
\text { Incerteza do impacto na saúde humana } \\
\text { Imprecisão das relações causa-efeito } \\
\text { Tratamento de indivíduos não produtivos } \\
\text { Exclusão de algumas componentes de custo } \\
\text { Não consideração da Vontade para pagar (WTP) pela redução } \\
\text { da exposição à doença }\end{array}$ \\
\hline $\begin{array}{c}\text { Capital } \\
\text { Humano }\end{array}$ & $\begin{array}{c}\text { GERAL: } \\
\text { Efeitos da poluição e de acidentes na vida humana }\end{array}$ & $x$ & $\begin{array}{l}\text { Certa controvérsia de abordagem (pois estima o valor da vida } \\
\text { humana na perda do potencial produtivo) }\end{array}$ \\
\hline \multicolumn{4}{|c|}{ ANÁLISE DE CUSTOS } \\
\hline $\begin{array}{l}\text { Custos de } \\
\text { Realocação e } \\
\text { Despesas } \\
\text { Preventivas }\end{array}$ & $\begin{array}{l}\text { SETOR ELÉTRICO: } \\
\text { Efeitos de emissões atmosféricas, tais como: custo para o } \\
\text { cumprimento da regulamentação; Efeitos das emissões } \\
\text { de GEE's: custo da manutenção de áreas florestais para } \\
\text { seqüestrar o carbono e custo de trabalhos para evitar } \\
\text { potenciais efeitos no aumento do nível das águas do mar }\end{array}$ & $x$ & $\begin{array}{l}\text { Dificuldade na verificação de alguns dos pressupostos de } \\
\text { implementação, tais como: evidência da disposição para } \\
\text { assumir despesas; informações sobre a alteração na qualidade } \\
\text { do ambiente; inexistência de benefícios secundários; } \\
\text { Constrangimentos impostos pela capacidade de pagar } \\
\text { Exigüidade da análise }\end{array}$ \\
\hline \multicolumn{4}{|c|}{ ANÁLISE DE MERCADOS SUBSTITUTOS } \\
\hline $\begin{array}{c}\text { Valor da } \\
\text { Propriedade }\end{array}$ & $\begin{array}{l}\text { GERAL: } \\
\text { Efeitos da poluição do ar, água, ruídos paisagem e } \\
\text { resíduos } \\
\text { SETOR ELÉTRICO: } \\
\text { Efeitos na paisagem para a produção de energia elétrica, } \\
\text { e análise de ruído nos estágios dos ciclos de combustível }\end{array}$ & $\boldsymbol{x}$ & $\begin{array}{l}\text { Exigência de alta disponibilidade de informações detalhadas } \\
\text { sobre diversos aspectos além da existência de situações de } \\
\text { distorção de mercados (principalmente especulação } \\
\text { imobiliária) } \\
\text { Condicionamento dos resultados pela robustez da análise } \\
\text { econômica }\end{array}$ \\
\hline $\begin{array}{l}\text { Diferencial } \\
\text { de Salários }\end{array}$ & $\begin{array}{c}\text { GERAL: } \\
\text { Riscos à perda de vidas e doença devido a emissões de } \\
\text { poluentes e acidentes profissionais } \\
\text { SETOR ELÉTRICO: } \\
\text { Mortalidade associada às emissões de poluentes e } \\
\text { acidentes de trabalho }\end{array}$ & $\mathbf{x}$ & $\begin{array}{l}\text { Impossibilidade do diferencial de salários refletirem os riscos } \\
\text { para os trabalhadores (informações incompletas, inexistência } \\
\text { de negociação salarial, barreiras a mobilidade no mercado de } \\
\text { trabalho) }\end{array}$ \\
\hline $\begin{array}{l}\text { Custo da } \\
\text { Viagem }\end{array}$ & $\begin{array}{l}\text { SETOR ELÉTRICO: } \\
\text { VUD dos recursos e bens que serão perdidos, por } \\
\text { exemplo, com a área a ser inundada por uma barragem }\end{array}$ & $x$ & $\begin{array}{l}\text { Reconhecimento científico quanto à avaliação dos benefícios de } \\
\text { áreas de lazer } \\
\text { Ausência de realismo nos pressupostos sobre comportamento } \\
\text { dos indivíduos na determinação da curva de procura } \\
\text { Nível de exigência de recursos alto (tempo, informação, verba, } \\
\text { etc...) } \\
\text { Dificuldades na abordagem e avaliação das alterações da } \\
\text { qualidade ambiental }\end{array}$ \\
\hline \multicolumn{4}{|c|}{ ANÁLISE DE MERCADOS HIPOTÉTICOS } \\
\hline $\begin{array}{c}\text { Avaliação } \\
\text { Contingencial }\end{array}$ & $\begin{array}{c}\text { GERAL: } \\
\text { VET da vida selvagem e proteção de ecossistemas e } \\
\text { habitats, e VUD do lazer e saúde humana } \\
\text { SETOR ELÉTRICO: } \\
\text { Impactos florestais para produção hidroelétrica, efeitos } \\
\text { da poluição atmosférica na saúde humana }\end{array}$ & $\mathscr{L}$ & $\begin{array}{l}\text { Única abordagem para estimar o Valor Econômico Total (VET) } \\
\text { Possibilidade de implementação em situações de inexistência, } \\
\text { distorção ou exigüidade de mercados reais ou ausência de } \\
\text { mercados substitutos } \\
\text { Ocorrência de excentricidade (diferença entre o valor estimado } \\
\text { e o verdadeiro valor do parâmetro a estimar) }\end{array}$ \\
\hline
\end{tabular}

Fonte: Avaliação Econômica dos Impactos do Setor Elétrico, (Santos, Martinho, \& Antunes, 2001), Lisboa, Portugal, modificado. 


\section{SÍNTESE DE ESTUdOS REALIZADOS PARA A AVALIAÇÃO ECONÔMICA DAS EXTERNALIDADES}

Ao final do século passado, foi desenvolvido um número significativo de estudos no domínio da avaliação econômica das externalidades ambientais do setor elétrico. Tais estudos foram desenvolvidos com o intuito de embasar diretivas da política energética e ambiental, enquadrando-se no planejamento da expansão do setor elétrico.

Estes estudos requeriam a adoção de abordagens exigentes quanto às metodologias a serem utilizadas, com elevado nível de informação, de forma a considerar a ampla diversidade dos impactos das atividades do setor. Entretanto, nota-se que muitos estudos, embora pretendam apresentar uma análise integrada de diversas externalidades, esbarram muitas vezes na limitação de reportar as diferentes opções de tecnologia de produção e seus respectivos impactos resultantes das emissões atmosféricas.

Sendo assim, os resultados obtidos devem ser utilizados com a ressalva de que as estimativas de valor econômico aferidas não devem ser interpretadas como resultados definitivos e sim como indicadores da magnitude dos impactos avaliados. Logo, tais publicações podem servir como ponto de partida para a realização de novos estudos com vistas a fomentar processos de decisões políticas.

A seguir, explicita-se de forma sintética alguns resultados de estudos de avaliação econômica das externalidades ambientais do setor elétrico, bem como os dificultadores para a comparação dos resultados e os cuidados na interpretação dos mesmos.

\subsection{Estados Unidos}

Desde a década de 80 do século passado os EUA têm desenvolvido diversos estudos a respeito do tema, embora com objetivos diversos e enquadrados por contextos de política energética e ambiental distintos, principalmente devido às distinções propostas pela legislação de cada estado. Sendo assim, tais estudos mostram diferenças relativas ao âmbito de aplicação (espacial, temporal, tecnologias estudadas), a abordagem metodológica e ao nível de complexidade de cada análise (Santos, 2001). 
Segundo Santos (2001), é possível também dividir tais estudos em duas gerações, principalmente devido à cronologia e a tendência de evolução das análises. Sendo assim, integram a primeira geração de estudos, os estudos desenvolvidos até o início da década de 90, onde o âmbito de análise é restrito aos impactos ambientais associados à fase de produção de energia elétrica. Já os estudos da segunda geração, compreendidos cronologicamente como aqueles desenvolvidos ao longo da década de 90, são caracterizados por apresentar maior nível de complexidade e rigor nas análises.

Entre os estudos da primeira geração desenvolvidos nos EUA, destacam-se os trabalhos de Chernick e Caverhill (1989), Ottinger (1990) e Bernow (1991), além do estudo desenvolvido pela ECO Northwest ${ }^{20}$ (1987). Já entre os estudos da segunda geração destacam-se os desenvolvidos por Lee (1995) e RGC/Hagler/Baily (1995).

Primeiramente ressaltando o estudo promovido pela Bonneville Power Administration ${ }^{21}$, e desenvolvido pelo consórcio ECO Northwest, Nero and Associates e Biosystems Analysis, em 1987, observa-se que tal estudo foi focado em uma avaliação econômica dos custos ambientais de diversas fontes de produção, para posteriormente integrar os resultados obtidos em uma análise de custo por eficácia no intuito de apoiar decisões políticas. Entre as opções de produção de energia elétrica, podemos ressaltar o diesel, biomassa e hidroelétrica.

As estimativas obtidas por tal estudo para as tecnologias específicas estão resumidas na tabela abaixo. Ressalta-se que o estudo produzido apresenta sua magnitude de custo em intervalos, devido a justificativas tais como as incertezas nos efeitos físicos dos impactos e sua conseqüente avaliação. A Tabela 6.1 a seguir apresenta os valores máximos do intervalo observado, para as soluções de geração de interesse.

\footnotetext{
${ }^{20}$ ECO Northwest: Maior e mais conceituada firma de consultoria econômica do Noroeste dos EUA, trabalhando para os setores privado e público desde 1974.

${ }^{21}$ Bonneville Power Administration (BPA): Agência Federal do Departamento de Energia dos Estados Unidos da América que opera o sistema de transmissão de eletricidade do Pacífico Noroeste dos EUA.
} 
Tabela 6.1 - Estimativa de custos ambientais de ECO NorthWest em 1987.

\begin{tabular}{cc}
\hline TECNOLOGIA DE PRODUÇÃO & CUSTO $\left(10^{-2} \mathrm{USD}_{90} / \mathrm{kWh}\right)$ \\
\hline Diesel & 0,04 \\
\hline Hidroelétrica & 1,465 \\
\hline Biomassa & 0,56 \\
\hline
\end{tabular}

Fonte: Office of Technology Assessment (OTA), 1994, modificado. Valores em centavos de dólar americano, 10² USD, preços de 1990.

Entretanto, a interpretação dos resultados, carece de certa atenção, pois apesar de o estudo adotar metodologias semelhantes para as diversas tecnologias de produção, a informação disponibilizada não nos permite conhecer com exatidão os aspectos avaliados nem eventuais fontes de incerteza no processo de avaliação. Nota-se também que os estudos das diferentes tecnologias de produção não se reportam a um mesmo momento no tempo. Tal fato pode ser evidenciado pelas estimativas para a geração hidroelétrica que datam de 1982.

Outro estudo foi desenvolvido em 1989 por Chernick e Caverhill, promovido pela Boston Gas Co e o Massachusetts Department of Public Utilities, realizado no âmbito do nordeste dos EUA. Sua análise foi baseada principalmente no estágio de produção de eletricidade, e abordou a produção por fontes não-renováveis.

A análise de Chernick e Caverhill ficou restrita a duas categorias de impacto, sendo estas a emissão atmosférica $\left(\mathrm{SO}_{2}, \mathrm{NO}_{\mathrm{X}}, \mathrm{CO}_{2}\right.$ e $\left.\mathrm{CH}_{4}\right)$ e o derrame de crude marinho. Outras fontes de custos externos foram identificadas, porém não fizeram parte da avaliação econômica.

Desta forma, as estimativas apresentadas devem ser interpretadas como subestimativas das externalidades ambientais, pois traduzem apenas uma parte dos custos associados à produção de eletricidade. A Tabela 6.2 a seguir representa a estimativa dos custos ambientais apresentados por Chernick e Caverhill com relação à geração a diesel.

Tabela 6.2 - Estimativa de custos ambientais de Chernick e Caverhill em 1989.

\begin{tabular}{cc}
\hline TECNOLOGIA DE PRODUÇÃO & CUSTO $\left(10^{-2} \mathrm{USD}_{90} / \mathrm{kWh}\right)$ \\
\hline Diesel & 5,1 \\
\hline
\end{tabular}

Fonte: Office of Technology Assessment (OTA), 1994, modificado. Valores em centavos de dólar americano, 10-2 USD, preços de 1990. 
O estudo efetuado por Ottinger (1990) é um dos documentos mais mencionados quando o assunto é a avaliação econômica dos impactos ambientais do setor elétrico, pois avalia diversos efeitos ambientais (poluição atmosférica e da água, alterações climáticas, acidificação, uso do solo, etc...). Entretanto tal análise está restrita às fases de produção e descomissionamento ${ }^{22}$. Entre as opções de produção estudadas podemos destacar a geração a diesel, solar, eólica, biomassa.

Tabela 6.3 - Estimativa de custos ambientais de Ottinger em 1990.

\begin{tabular}{cc}
\hline TECNOLOGIA DE PRODUÇÃO & CUSTO $\left(10^{-2} \mathrm{USD}_{90} / \mathrm{kWh}\right)$ \\
\hline Diesel & 4,85 \\
\hline Solar & 0,4 \\
\hline Eólica & 0,1 \\
\hline Biomassa & 0,7 \\
\hline
\end{tabular}

Fonte: Office of Technology Assessment (OTA), 1994, modificado.

Valores em centavos de dólar americano, 10²USD, preços de 1990.

Destaca-se dos resultados obtidos o fato de os próprios autores entenderem que alguns valores estariam provavelmente subestimados, tendo em vista que não foram incorporados alguns tipos de custos ambientais devido a incertezas ou ausência de informações.

Já o estudo desenvolvido por Bernow, Marron e Biewald (1990), adota uma abordagem distinta da utilizada pela maioria dos estudos, pois analisa exclusivamente a quantificação dos custos de controle e cumprimento da legislação, ou custos da reposição dos impactos ambientais para estimar o valor econômico das externalidades. Os autores consideram que as metodologias de avaliação dos danos trazem um grau de incerteza muito elevado, preferindo basear a estimativa na avaliação dos custos de reposição. A grande vantagem na abordagem resulta de as estimativas poderem ser obtidas se recorrendo à informação e dados facilmente acessíveis, objetivos e pouco controversos.

Tal estudo foi centrado na estimativa de custos associados à poluição atmosférica resultante da queima de combustíveis fósseis, excluindo os custos de outros tipos de emissões e demais impactos (acidentes e transporte). Os resultados obtidos para o diesel estão apresentados na Tabela 6.4 a seguir.

\footnotetext{
22 Conjunto de providências necessárias para a desativação de uma instalação ao final de sua vida útil, observando-se todos os cuidados necessários para se proteger a saúde e segurança de trabalhadores e da população, e ao mesmo tempo, o meio ambiente (International Atomic Energy Agency - IAEA, 2009).
} 
Tabela 6.4 - Estimativa de custos ambientais de Bernow em 1990.

\begin{tabular}{cc} 
TECNOLOGIA DE PRODUÇÃO & CUSTO $\left(10^{-2} \mathrm{USD}_{9_{0}} / \mathrm{kWh}\right)$ \\
\hline Diesel & 4,49 \\
\hline
\end{tabular}

Fonte: Office of Technology Assessment (OTA), 1994, modificado. Valores em centavos de dólar americano, 10²USD, preços de 1990.

A abordagem adotada no referido estudo foi alvo de muitas críticas, pois a premissa de que os custos de regulação representam os custos externos das emissões atmosféricas para a sociedade implica em considerar que os reguladores possuem a informação perfeita a respeito dos danos ambientais e que implicam sempre na melhor política de controle. Entretanto, constata-se que, usualmente, os reguladores não conhecem tais custos e que o processo de decisão não permite aplicar políticas ótimas de controle. Além do que a abordagem metodológica utilizada limita a dimensão espacial da análise, tendo em vista que diferentes localidades possuirão diferentes regulamentações, sendo inviável a utilização de tal estudo para a transferência de resultados.

Observa-se então que os estudos considerados da primeira geração utilizam metodologias e âmbitos de análise distintos, efetuando a análise de diferentes categorias de custos ambientais, o que dificulta a comparação entre os resultados apresentados. Pois não foram desenvolvidas linhas de investigação ou abordagens originais, pois os estudos em sua maioria baseiam-se na compilação e integração de trabalhos já desenvolvidos. Logo, podese concluir que a literatura disponível até o início dos anos 90 não reporta as estimativas de valores originais e independentes, mas sim a um conjunto de valores inter-relacionados de diversas maneiras.

Uma questão importante na contribuição da primeira geração de estudos diz respeito ao nível de coerência e rigor do processo de integração dos estudos originais, pois apesar dos esforços dos estudos para integrarem a dimensão espacial na avaliação, as transferências de benefícios ${ }^{23}$ podem ser consideradas como inadequadas.

Tal afirmação é baseada na utilização de estudos que não permitem a obtenção de estimativas consistentes para os locais de avaliação, ou seja, os autores podem ter ignorado o fato de alguns custos já estarem internalizados e utilizaram estudos cujo contexto é

\footnotetext{
${ }^{23}$ Transferência de Benefício: Abordagem que se baseia na utilização de estimativas disponíveis do valor econômico de recursos que não possuem um mercado real, em local de estudo distinto daquele para o qual o valor foi originalmente estimado.
} 
distinto e cuja estimativa de dano é apresentada de forma genérica sem especificar as contribuições de cada categoria de impacto, incorrendo assim na duplicação de custos ou a simples não inclusão de determinados impactos.

Nota-se pela simples comparação entre as estimativas de valor econômico a existência de grande variabilidade, evidenciando a falta de consenso acerca dos custos externos associados à produção de energia elétrica apresentados por esta primeira geração.

Já os estudos da segunda geração que foram desenvolvidos por Lee (1995) e RCG/Hagler/Baily (1995) envolveram equipes multidisciplinares, incorporando modelos de qualidade do ar, avaliação de efeitos epidemiológicos e econômicos associados às emissões resultantes das diversas etapas do ciclo de combustíveis (extração, refino, transporte) utilizado na produção de energia elétrica. Acomodando assim a dimensão espacial e temporal no cálculo do dano.

As metodologias utilizadas se caracterizam por identificar e quantificar as cargas ambientais (poluentes, resíduos, risco de acidentes) associadas aos diferentes estágios no ciclo de cada combustível analisado. Posteriormente foram identificados e quantificados, em termos físicos, os impactos e em seguida foi efetuada a quantificação em termos monetários dos impactos analisados, obtendo-se assim as estimativas do valor dos danos ambientais e custos externos de cada ciclo de combustível.

O estudo de Lee (1995) foi efetuado essencialmente para investigar e desenvolver métodos para estimar custos externos associados ao ciclo completo de combustíveis. Em sua fase inicial foram considerados todos os estágios do ciclo dos combustíveis e todos os poluentes, mas por intermédio de um processo de triagem foram eliminadas muitas cadeias de impactos. A Tabela 6.5 abaixo apresenta as estimativas de custo para os ciclos de combustível de interesse.

Tabela 6.5 - Estimativa de custos ambientais de Lee em 1995.

\begin{tabular}{cc}
\hline TECNOLOGIA DE PRODUÇÃO & CUSTO $\left(10^{-2} \mathrm{USD}_{95} / \mathrm{kWh}\right)$ \\
\hline Diesel & 1,2 \\
\hline Biomassa & 1,7 \\
\hline
\end{tabular}

Fonte: (Krupnick \& Burtraw, 1997), modificado.

Valores em centavos de dólar americano, 10² USD, preços de 1995. 
Já o estudo desenvolvido por RCG/Hagler, Baily, Inc. (1995) é considerado como um dos principais estudos desenvolvidos nos EUA. Sendo o âmbito de estudo semelhante ao de Lee, porém há de se ressaltar que ambos os estudos negligenciaram os danos associados ao efeito do aquecimento global. A Tabela 6.6 abaixo apresenta as estimativas de custo para os ciclos de combustível de interesse.

Tabela 6.6 - Estimativa de custos ambientais para RCG/Hagler/Baily em 1995.
\begin{tabular}{cc}
\hline TECNOLOGIA DE PRODUÇÃO & CUSTO $\left.\left(10^{-2} \mathrm{USD}_{95} / \mathrm{kWh}\right)\right)$ \\
\hline Diesel & 1,7 \\
\hline Biomassa & 4,2 \\
\hline
\end{tabular}

Fonte: (Krupnick \& Burtraw, 1997), modificado.

Valores em centavos de dólar americano, 10-2 USD, preços de 1995.

Observa-se então que os estudos apresentaram para algumas tecnologias valores semelhantes, e para outras tecnologias, valores bem distintos. Isto se deve ao fato de que as estimativas e funções utilizadas para estimar o valor físico do dano foram definidas e ajustadas para os respectivos locais de estudo. Destaca-se que a maioria das funções utilizadas para estimar os efeitos físicos sobre a saúde humana foram linearizadas.

Outro fato notável diz respeito à diminuição dos valores obtidos quando comparados com os valores da primeira geração. A justificativa para tal fato é baseada na utilização de centrais mais novas, como objeto de análise, sendo assim, estão sujeitas a regulamentação mais rigorosa (evolutiva ao longo dos tempos) e exigências de licenciamento e desempenho ambiental mais restritivo. Logo as emissões consideradas foram menores quando comparadas com as centrais mais antigas que foram objeto de estudo da primeira geração, o que fez com que o valor do dano diminuísse.

Como não são consideradas estimativas para os danos associados ao aquecimento global, nota-se que os custos externos dos combustíveis fósseis são inferiores aos da biomassa. Por outro lado, os custos externos da biomassa incorporam níveis de emissão atmosférica elevada que integram a contabilização de danos associados à erosão e outros efeitos decorrentes do processo de reflorestamento.

Nos EUA, vários estados consideram as externalidades ambientais no processo de planejamento do setor elétrico, entretanto nem todos utilizam a estimação de valores 
monetários para as externalidades ambientais resultantes das emissões atmosféricas. Contudo, a internalização total dos custos afeta as decisões de planejamento das diferentes tecnologias utilizadas em todo o país.

\subsection{Europa}

$\mathrm{Na}$ Europa, têm-se realizado estudos para a avaliação econômica das externalidades do setor elétrico desde o fim da década de 80. Em destaque estão os estudos de Hohmeyer (1988) e de Pearce (1992) e principalmente os estudos realizados no âmbito do projeto ExternE ${ }^{24}$.

O estudo de Hohmeyer (1988) foi baseado em avaliações das externalidades ambientais do setor elétrico da Alemanha. A análise envolve comparações entre diferentes tecnologias de produção, avaliando as externalidades ambientais associadas à produção se utilizando de fontes renováveis (eólica e solar) e fontes não-renováveis.

Tal estudo estimou os custos ambientais se utilizando de diversas fontes de informação e a maioria das estimativas monetárias é resultado da transferência de benefícios direta. A dimensão espacial não foi muito respeitada, porém foi adotada uma adaptação dos dados quanto à disponibilidade de informação e as características dos impactos.

Hohmeyer (1988) reconhece de forma explícita a exclusão de várias categorias de impacto em sua análise, tais como os custos da doença ou morte, perda de biodiversidade, intrusão visual e efeitos sobre o uso do solo. E também não considera todos os estágios dos ciclos dos combustíveis. Logo, conclui-se que, apesar da grande contribuição do estudo de Hohmeyer, não foram consideradas importantes fontes de custos externos. Os resultados obtidos pelo estudo de Hohmeyer podem ser visualizados na Tabela 6.7 a seguir, para as soluções de interesse.

\footnotetext{
${ }^{24}$ ExternE (Externalities of Energy): Projeto de pesquisa da Comissão Européia lançado em 1991. Já envolveu mais de 50 equipes de pesquisa de mais de 20 países, no intuito de evoluir as análises dos custos dos danos ambientais.
} 
Tabela 6.7 - Estimativa de custos ambientais de Hohmeyer em 1988.

\begin{tabular}{cc}
\hline TECNOLOGIA DE PRODUÇÃO & CUSTO $\left.\left(10^{-2} \mathrm{USD}_{90} / \mathrm{kWh}\right)\right)$ \\
\hline Solar & 0,3 \\
\hline Eólica & 0,007 \\
\hline
\end{tabular}

Fonte: Office of Technology Assessment (OTA), 1994, modificado.

Valores em centavos de dólar americano, 10²USD, preços de 1995.

O estudo desenvolvido por Pearce (1992), no Reino Unido, adota uma abordagem similar a de Ottinger (1990) para a avaliação das externalidades ambientais dos ciclos de combustíveis, porém considera um número maior de impactos ambientais. Os resultados obtidos podem ser observados na Tabela 6.8 abaixo, para as soluções de interesse. E, notoriamente, as fontes de combustível fóssil são responsáveis por uma parcela mais significativa quando tratados os danos ambientais.

Tabela 6.8 - Estimativa de custos ambientais de Pearce em 1992.

\begin{tabular}{ccccc}
\hline $\begin{array}{c}\text { TECNOLOGIA DE } \\
\text { PRODUÇÃO }\end{array}$ & DIESEL & SOLAR & EÓLICA & HIDRO \\
\hline CATEGORIA DE IMPACTO & & CUSTO $\left(10^{-2} \mathrm{GBP}_{90} / \mathrm{kWh}\right)$ & \\
\hline $\begin{array}{c}\text { Saúde Humana } \\
\text { Mortalidade } \\
\text { Doença }\end{array}$ & 0,29 & 0,07 & 0,04 & 0,03 \\
\hline Danos sobre a Colheita & 0,12 & $\mathrm{NE}$ & $\mathrm{NE}$ & $\mathrm{NE}$ \\
\hline Danos sobre Floresta & 0,05 & 0 & 0 & 0 \\
\hline Redução da Biodiversidade & $\mathrm{NE}$ & $\mathrm{NE}$ & $\mathrm{NE}$ & $\mathrm{NE}$ \\
\hline Ruído & $\mathrm{NE}$ & $\mathrm{NE}$ & $\mathrm{NE}$ & $\mathrm{NE}$ \\
\hline Aquecimento Global & 0,35 & 0 & 0 & 0,01 \\
\hline Impacto Visual & $\mathrm{NE}$ & $\mathrm{NE}$ & $\mathrm{NE}$ & $\mathrm{NE}$ \\
\hline Poluição das Águas & 0,049 & 0 & 0 & 0 \\
\hline Contaminação dos Solos & $\mathrm{NE}$ & $\mathrm{NE}$ & $\mathrm{NE}$ & $\mathrm{NE}$ \\
\hline TOTAL & 1,839 & 0,07 & 0,04 & 0,04 \\
\hline
\end{tabular}

Fonte: (Boyle, 2000), modificado.

Valores em centavos de libra esterlina britânica, $10^{-2} \mathrm{GBP}$, preços de 1990. NE: Não Estimado.

Já o projeto ExternE (Externalities of Energy) resulta de uma iniciativa de cooperação entre Comissão Européia e o Departamento de Energia dos EUA, posteriormente desenvolvido pela Comissão Européia sob tal denominação. Seus objetivos enquadram-se nas preocupações de várias organizações internacionais quanto à necessidade de internalizar as externalidades ambientais nas análises e decisões políticas e econômicas. Tenta-se o desenvolvimento e aplicação de um sistema comunitário de contabilização das 
externalidades (metodologia ExternE) para a avaliação dos custos externos gerados pelos ciclos dos combustíveis utilizados na produção de energia elétrica.

Tal estudo segue uma abordagem compreendida pelos seguintes estágios:

1) Identificação dos impactos ambientais prioritários da tecnologia de produção a ser analisada.

2) Quantificação das cargas ambientais (resíduos sólidos, poluentes gasosos e partículas, ruído, risco de acidente) resultantes de cada uma das atividades do ciclo de combustível a ser analisado.

3) Descrição do meio receptor (local, idade, áreas agrícolas) e identificação das áreas abrangidas por diferentes estados da qualidade do ambiente.

4) Quantificação física dos impactos sobre os receptores (ecológicos, humanos).

5) Avaliação econômica das externalidades ambientais associadas aos impactos quantificados.

6) Análise da incerteza associada a cada estágio de impacto.

Quanto a incertezas, é importante frisar que geralmente estão associadas à quantificação de impactos e sua respectiva avaliação econômica, e não à quantificação das cargas ambientais. Tais incertezas podem ser resultado de fatores como:

- variabilidade devido aos dados disponíveis para análise;

- extrapolação de dados de laboratório para casos de estudo concretos;

- ausência de informações detalhadas sobre comportamentos e preferências individuais;

- seleção incorreta de taxas de atualização;

- necessidade de projeção futura para impactos de longo prazo; e

- impossibilidade de quantificação de certos tipos de danos.

A abordagem descrita foi aplicada, em cada um dos países, a casos de estudo que ilustram os ciclos de combustível de forma a representar os respectivos sistemas de produção de cada nação. Uma vez estimadas as externalidades ambientais para os casos de estudo apresentados, por cada país, efetuou-se então a extrapolação dos dados para os demais subsistemas elétricos nacionais. 
Importante ressaltar que muitos países efetuaram a transferência de resultados obtidos em outros países, o que deve ser levado em consideração na análise das estimativas obtidas. Além do que, distintos interesses nacionais levaram os países a analisarem diferentes tecnologias e combustíveis, o que somado a fatores como a especificidade dos locais e qualidade do meio ambiente de cada região tornam os resultados estimados incomparáveis.

De forma geral, observa-se que as estimativas de custo ambiental são significativas, principalmente quando são considerados os danos associados ao aquecimento global. Prova da relevância de tais custos é que ao agregar os resultados de todas as tecnologias, temos custos externos, em alguns países, maiores que 1\% do PIB, em 1994, o que justificaria a integração de tal indicador na tomada de decisões sobre políticas energéticas (Santos, Martinho, \& Antunes, 2001). A Tabela 6.9 a seguir demonstra a relação entre o custo externo total e o percentual do PIB para alguns países da Comunidade Européia que foram objeto de estudo.

Tabela 6.9 - Estimativa de custos ambientais do projeto ExternE em 1995.

\begin{tabular}{ccc}
\hline PAÍS & CUSTO EXTERNO (MECU $\left.{ }_{95} / \mathrm{ano}\right)^{25}$ & $\%$ PIB (1994) \\
\hline Bélgica (1995) & $2,05-5,41$ & $1,2-3,1$ \\
\hline Dinamarca (1995) & $1,78-2,53$ & $2,0-2,9$ \\
\hline Espanha (1995) & $7,39-9,36$ & $1,6-2,1$ \\
\hline Grécia (1995) & $3,72-5,00$ & $3,9-5,2$ \\
\hline Holanda (1994) & $1,52-2,70$ & $0,6-1,1$ \\
\hline Portugal (1995) & $1,28-1,79$ & $1,3-1,8$ \\
\hline
\end{tabular}

Fonte: (Comissão Européia, 2001), ExternE Information System.

Valores em milhões de ECU (MECU), preços de 1995, modificado.

Há de se levar em consideração o grau ainda elevado quanto a incertezas na metodologia utilizada, o que tornaria necessário o desenvolvimento de mais investigações para se integrar os custos externos a tomada de decisões, entretanto a simples desconsideração da dimensão espacial e a transferência de resultados já obtidos tratam de indicadores coesos na avaliação de tecnologias de produção de eletricidade.

\footnotetext{
${ }^{25}$ MECU (Milhões de European Currency Unit): Unidade de Conta Européia, que funcionava como um cesto de moedas, onde todas estavam ligadas de forma a que nenhuma taxa de câmbio bilateral pudesse variar acima de 2,55\% relativamente a cada uma das demais. Posteriormente as taxas de câmbio bilaterais foram definitivamente fixadas, culminando na introdução do Euro.
} 
Para os casos de estudo no âmbito do projeto ExternE, destacam-se os projetos de implementação nacional em Portugal e Alemanha, onde foram investigadas algumas das soluções de interesse. Uma breve discussão sobre tais projetos de implementação será apresentada nas seções 6.2.1e 6.2.2.

\subsubsection{Portugal}

No caso português, destaca-se que a estimativa do valor econômico das externalidades ambientais encontrou algumas limitações, tais como a ausência de estudos para o ciclo do diesel, sendo assim foi necessária a estimativa dos impactos das emissões atmosféricas de poluentes primários, tais como $\mathrm{SO}_{2}, \mathrm{NO}_{\mathrm{X}}$ e partículas, e os respectivos danos resultantes de tais emissões foram calculados transferindo as estimativas de valor econômico.

Para o caso da hidroeletricidade foram consideradas as etapas de extração de recursos, operação e descomissionamento, sendo identificados e considerados os seguintes impactos prioritários (Martins, 1998):

- impactos no ecossistema aquático e terrestre;

- impactos na qualidade da água;

- impactos nas atividades de lazer;

- impactos na acessibilidade do local;

- impactos na saúde humana; e

- efeitos na saúde pública e em profissionais, resultante de acidentes.

Ressalta-se também que os resultados apresentados para o empreendimento hídrico representam apenas uma fração dos custos externos totais, tendo em vista que os impactos ecológicos não foram quantificados monetariamente. A Tabela 6.10 a seguir demonstra uma estimativa para o custo da externalidade ambiental para a PCH de Lourizela (capacidade instalada: 5,2 MW). Observa-se que a maior parte dos custos externos está associada a impactos relativos a acidentes envolvendo profissionais e a população (acima de $80 \%$ ). 
Tabela 6.10 - Estimativa de custos ambientais ExternE Portugal (ciclo da hidroeletricidade).

\begin{tabular}{|c|c|}
\hline CICLO DA HIDROELETRICIDADE & CUSTO $\left(10^{-2} \mathrm{ECU}_{95} / \mathrm{kWh}\right)$ \\
\hline Saúde Humana & $13,06 \mathrm{E}^{-4}$ \\
\hline Mortalidade & $4,71 \mathrm{E}^{-4}$ \\
\hline Doença & $8,35 \mathrm{E}^{-4}$ \\
\hline Saúde Pública e dos Trabalhadores & $2,20 \mathrm{E}^{-2}$ \\
\hline Danos sobre Colheitas & $64,98 \mathrm{E}^{-4}$ \\
\hline Ecossistemas & NQ \\
\hline Ruído & NG \\
\hline Impacto Visual & NG \\
\hline Ozônio na Saúde & $20,1 \mathrm{E}^{-4}$ \\
\hline Aquecimento Global & $127,89 \mathrm{E}^{-4}$ \\
\hline TOTAL & $0,44-0,45$ \\
\hline
\end{tabular}

Fonte: (Martins, Fernandes, Rodrigues, \& Ramos, 1998), CEETA $^{26}$, Lisboa. Caso Lourizela. Valores em centavos de ECU, preços de 1995, modificado. NQ: Não Quantificado. NG: Negligenciável.

Para o caso da biomassa foram consideradas todas as etapas, desde a produção dos insumos e transporte, além da produção de eletricidade, o tratamento de resíduos e o descomissionamento. Foram considerados como objeto de estudo os impactos relativos principalmente às etapas de produção de eletricidade e transporte de insumos, tais como os impactos relacionados à saúde pública e dos trabalhadores, efeitos nas colheitas, danos sobre estradas, erosão do solo, uso de fertilizantes e aquecimento global. Impactos como ruídos e intrusão visual foram negligenciados. A Tabela 6.11 a seguir apresenta as estimativas de custo externo obtidas para o caso da biomassa.

Tabela 6.11 - Estimativa de custos ambientais ExternE Portugal (ciclo da biomassa).

\begin{tabular}{cc}
\hline CICLO DA BIOMASSA & CUSTO $\left(\mathbf{1 0}^{-3} \mathbf{E C U}_{\mathbf{9 5}} \mathbf{/ k W h}\right)$ \\
\hline Saúde Humana & 10,67 \\
\hline Mortalidade & 4,21 \\
Doença & 2,15 \\
\hline Danos sobre Colheitas & 0,56 \\
\hline Ecossistemas & $\mathrm{NQ}$ \\
\hline Ruído & $\mathrm{NG}$ \\
\hline Impacto Visual & $\mathrm{NG}$ \\
\hline Danos sobre Estradas & 0,15 \\
\hline Aquecimento Global & 1,35 \\
\hline TOTAL & $\mathbf{1 2 , 6 - 1 2 , 8}$
\end{tabular}

Fonte: (Martins, Fernandes, Rodrigues, \& Ramos, 1998), Lisboa. Caso Figueira da Foz. Valores em ECU, preços de 1995, modificado. NQ: Não Quantificado. NG: Negligenciável.

\footnotetext{
${ }^{26}$ Centro de Estudos de Economia, Energia, Transportes e Ambiente de Lisboa (CEEETA): Consultora dos agentes de mercado português, trabalhando na avaliação do potencial técnico, econômico e ambiental de empreendimentos, e na elaboração de estudos no domínio da energia, transportes e ambiente.
} 
Observa-se que mais de $60 \%$ dos custos externos estão associados à saúde pública e cerca de $30 \%$ a acidentes profissionais e da população. O efeito do custo externo do aquecimento global representa menos de $10 \%$ do custo total, porém tal resultado é decorrente da não contabilização do $\mathrm{CO}_{2}$ emitido na fase de produção.

Sendo assim, resumem-se os resultados apresentados para o caso português por intermédio da Tabela 6.12 abaixo, que apresenta a estimativa dos custos ambientais do aquecimento global e os custos externos totais por tecnologia de produção. Porém é importante salientar que os processos de extrapolação e agregação de resultados sempre possuem alguma incerteza, dada a especificidade da dimensão espacial, que não deve ser desconsiderada na análise dos resultados finais (Santos, Martinho, \& Antunes, 2001).

Tabela 6.12 - Estimativa de custos ambientais do setor elétrico português em 1995.

\begin{tabular}{ccc}
\hline TECNOLOGIA DE PRODUÇÃO & $\begin{array}{c}\text { CUSTO AQUECIMENTO GLOBAL } \\
\left(\mathbf{1 0}^{-\mathbf{3}} \mathbf{E} \mathbf{U U}_{\mathbf{9 5}} / \mathbf{k W h}\right)\end{array}$ & $\begin{array}{c}\text { CUSTO EXTERNO TOTAL } \\
\left(\mathbf{1 0}^{-\mathbf{3}} \mathbf{E C U} \mathbf{~ U}_{\mathbf{5}} / \mathbf{k W h}\right)\end{array}$ \\
\hline Diesel & 3,36 & 42,1 \\
\hline Hidroelétrica & $1,28 \mathrm{E}^{-2}$ & $4,4-4,5$ \\
\hline Biomassa & 1,35 & $12,6-12,8$ \\
\hline
\end{tabular}

Fonte: (Martins, Fernandes, Rodrigues, \& Ramos, 1998), Lisboa.

Valores em ECU, preços de 1995, modificado.

De fato, considerando os diferentes cenários de avaliação, aproximadamente $30 \%$ do custo externo agregado ao aquecimento global é imputável às emissões atmosféricas do ciclo do diesel, enquanto menos de $1 \%$ é imputado ao ciclo da produção hidroelétrica. Demonstrando que apesar de tratarem de estimativas, a utilização da avaliação econômica da externalidade evidencia que a utilização de combustíveis fósseis continua sendo uma alternativa mais onerosa para o meio ambiente, quando comparada com a utilização de fontes alternativas.

\subsubsection{Alemanha}

O caso alemão é baseado em estudos desenvolvidos por Friedrich e Bickel (2000), professores da Universidade de Stuttgart, que se utilizaram da metodologia impact pathway proposta pelo ExternE. 
A Tabela 6.13 a seguir apresenta as estimativas previstas para os custos externos da produção de diferentes tecnologias, baseadas em casos de estudos alemães, desenvolvidos por Friedrich (1997). Além das estimativas dos custos de impactos, é possível observar a presença de custos para se evitar impactos no ecossistema e impactos sobre o aquecimento global, porém tais estimativas demonstram alto índice de incerteza.

Os custos com ecossistema são baseados nas diretivas políticas para a redução de áreas na União Européia onde cargas críticas são excedidas em 50\%. Para o aquecimento global, tal estudo se utilizou de um preço sombra ${ }^{27}$, para se atingir as metas estabelecidas pelo Protocolo de Kyoto ${ }^{28}$.

Tabela 6.13 - Custos externos da produção de eletricidade na Alemanha.

\begin{tabular}{|c|c|c|c|}
\hline TECNOLOGIA DE PRODUÇÃO & SOLAR & EÓLICA & HIDRO \\
\hline \multicolumn{4}{|c|}{ CUSTOS $\left(10^{-2} \mathrm{EURO}_{2000} / \mathrm{kWh}\right)$} \\
\hline & \multicolumn{3}{|c|}{ Custo dos Danos } \\
\hline Ruído & 0 & 0,005 & 0 \\
\hline Saúde & 0,45 & 0,072 & 0,051 \\
\hline Danos sobre a Colheita & 0 & 0,0007 & 0,0002 \\
\hline & \multicolumn{3}{|c|}{ Custos da Precaução } \\
\hline Ecossistema & 0,04 & 0,04 & 0,03 \\
\hline Aquecimento Global & 0,33 & 0,04 & 0,03 \\
\hline TOTAL & $\mathbf{0 , 8 2}$ & 0,1577 & 0,1112 \\
\hline
\end{tabular}

Fonte: (Friedrich \& Bickel, 2001). Estimation of external costs using the impact-pathway-approach, modificado. Valores em centavos de Euro/kWh, preços de 2000.

\subsection{Transferência de resultados e análise de incerteza das estimativas}

Os estudos de avaliação econômica das externalidades do setor elétrico elencados apresentam características diferenciadas quanto ao enquadramento político, dimensão de aplicação (espacial, temporal, tecnologias), pressupostos assumidos, abordagem metodológica, categorização dos impactos e nível de detalhe das análises. Tornando evidente a dificuldade em se efetuar uma comparação direta dos resultados obtidos e a extrapolação para outros casos de estudo.

\footnotetext{
${ }^{27}$ Preço Sombra: Preço de Mercado eventualmente corrigido quando a análise se realiza com perspectiva social e o mercado não é competitivo.

${ }^{28}$ Instrumento internacional, ratificado em 1999, para se reduzir as emissões de GEEs, causadores do aquecimento global. Tal instrumento propõe um calendário pelo qual os países-membros têm a obrigação de reduzir as emissões, em pelo menos 5,2\%, em relação aos níveis de 1990, no período de 2008 a 2012.
} 
Krupnick e Burtraw (1997), ao efetuarem uma comparação entre os estudos da segunda geração dos EUA (Lee em 1995 e RCG/Hagler/Baily em 1995) e o estudo do projeto ExternE, chegaram a conclusão de que a comparação direta era praticamente inviável. Pois se verifica que a identificação dos aspectos em que incide a avaliação são distintas, já que o estudo norte americano dá maior ênfase a paisagem e visibilidade deixando de lado os danos sobre florestas e o capital construído, contrastando com o estudo europeu. Além da dimensão espacial distinta entre as análises, existem outros fatores, tais como, as distintas modelagens de qualidade do ar, taxa de atualização, abordagem de incertezas entre outros aspectos.

Logo mesmo quando trata de um mesmo pathway ${ }^{29}$ de um mesmo ciclo de combustível com tecnologia e localização geográfica semelhante, a diversidade entre os estudos dificulta a realização de comparações. As tabelas a seguir foram elaboradas no intuito de se apresentar uma síntese dos estudos mencionados, de forma a facilitar a visualização de aspectos tais como, tecnologias estudadas, estágios do ciclo de combustível, impactos avaliados, impactos negligenciados e metodologia de avaliação utilizada.

Tabela 6.14 - Síntese dos estudos da primeira geração dos EUA.

\begin{tabular}{|c|c|c|c|c|}
\hline \multicolumn{5}{|c|}{ ESTUDOS DA PRIMEIRA GERAÇÃO EUA } \\
\hline ESTUDOS & ECO NORTHWEST & CHERNICK E CAVERHILL & OTTINGER & BERNOW \\
\hline $\begin{array}{c}\text { Tecnologias de } \\
\text { Produção/Recursos } \\
\text { Objeto de Avaliação }\end{array}$ & $\begin{array}{c}\text { Carvão, Diesel, Gás Natural, } \\
\text { Nuclear, Biomassa, } \\
\text { Geotérmica, Solar, Eólica, } \\
\text { Hidroelétrica }\end{array}$ & Carvão, Diesel, Gás Natural & $\begin{array}{c}\text { Carvão, Diesel, Gás Natural, } \\
\text { Nuclear, Solar, Eólica, } \\
\text { Biomassa }\end{array}$ & $\begin{array}{c}\text { Carvão, Diesel, Gás } \\
\text { Natural }\end{array}$ \\
\hline $\begin{array}{l}\text { Tecnologias/Recursos } \\
\text { Utilizados neste Estudo }\end{array}$ & $\begin{array}{c}\text { Diesel, Biomassa, Eólica, } \\
\text { Hidroelétrica }\end{array}$ & Diesel & $\begin{array}{c}\text { Diesel, Solar, Eólica, } \\
\text { Biomassa }\end{array}$ & Diesel \\
\hline $\begin{array}{l}\text { Estágios do Ciclo de } \\
\text { Combustível }\end{array}$ & Vários & Produção & $\begin{array}{c}\text { Produção e } \\
\text { Descomissionamento }\end{array}$ & Produção \\
\hline $\begin{array}{l}\text { Emissões Objeto de } \\
\text { Avaliação Econômica }\end{array}$ & Várias & $\begin{array}{l}\mathrm{SO}_{2}, \mathrm{NO}_{x}, \mathrm{CO}_{2}, \mathrm{CH}_{4} \text {, } \\
\text { derrame de crude no mar }\end{array}$ & $\begin{array}{c}\mathrm{SO}_{2}, \mathrm{NO}_{x}, \mathrm{CO}_{2} \text {, e partículas, } \\
\text { radiação, acidentes } \\
\text { nucleares e ruído }\end{array}$ & $\begin{array}{c}\mathrm{SO}_{2}, \mathrm{NO}_{x}, \mathrm{CO}_{2}, \mathrm{CH}_{4}, \\
\text { e partículas }\end{array}$ \\
\hline $\begin{array}{l}\text { Impactos/Efeitos } \\
\text { Ambientais Objeto de } \\
\text { Avaliação Econômica }\end{array}$ & Vários & $\begin{array}{c}\text { Saúde Humana, Danos em } \\
\text { Propriedades, } \\
\text { Aquecimento Global, } \\
\text { Danos nos Ecossistemas, } \\
\text { Colheitas, Intrusão Visual }\end{array}$ & $\begin{array}{c}\text { Saúde Humana, Danos em } \\
\text { Propriedades, } \\
\text { Aquecimento Global, } \\
\text { Danos em Colheitas, } \\
\text { Intrusão Visual }\end{array}$ & \\
\hline $\begin{array}{c}\text { Impactos/Efeitos } \\
\text { Ambientais } \\
\text { Quantificados que não } \\
\text { foram Alvo de Avaliação } \\
\text { Econômica }\end{array}$ & & $\begin{array}{l}\text { Tóxicos Atmosféricos, } \\
\text { Ozônio, Uso do Solo, } \\
\text { Deposição de Resíduos, } \\
\text { Poluição da Água, Poluição } \\
\text { Atmosférica }\end{array}$ & $\begin{array}{l}\text { Efeitos no Ecossistema, } \\
\text { Efeitos na Saúde Pública, } \\
\text { Danos sobre Florestas }\end{array}$ & $\begin{array}{l}\text { Poluição da Água, } \\
\text { Ruído }\end{array}$ \\
\hline $\begin{array}{l}\text { Métodos de Avaliação } \\
\text { Econômica }\end{array}$ & Vários & $\begin{array}{l}\text { Análise de Mercados Reais, } \\
\text { Custos de Reposição }\end{array}$ & $\begin{array}{l}\text { Análise de Mercados Reais, } \\
\text { Avaliação Contingencial, } \\
\text { Métodos Hedônicos }\end{array}$ & $\begin{array}{l}\text { Custos de } \\
\text { Reposição }\end{array}$ \\
\hline
\end{tabular}

\footnotetext{
${ }^{29}$ Pathway: Neste caso pode ser interpretado como o caminho do impacto a ser analisado durante todo o ciclo do combustível.
} 
Tabela 6.15 - Síntese dos estudos da segunda geração dos EUA.

\begin{tabular}{|c|c|c|}
\hline \multicolumn{3}{|c|}{ ESTUDOS DA SEGUNDA GERAÇÃO EUA } \\
\hline ESTUDOS & LEE & RCG/HAGLER/BAILY \\
\hline $\begin{array}{l}\text { Tecnologias de Produção/Recursos } \\
\text { Objeto de Avaliação }\end{array}$ & $\begin{array}{c}\text { Carvão, Diesel, Gás Natural, Nuclear, } \\
\text { Biomassa }\end{array}$ & $\begin{array}{c}\text { Carvão, Diesel, Gás Natural, Nuclear, } \\
\text { Biomassa }\end{array}$ \\
\hline $\begin{array}{c}\text { Tecnologias/Recursos Utilizados } \\
\text { neste Estudo }\end{array}$ & Diesel, Biomassa & Diesel, Biomassa \\
\hline Estágios do Ciclo de Combustível & $\begin{array}{c}\text { Inicialmente todos, posteriormente } \\
\text { PRODUÇÃO }\end{array}$ & Vários \\
\hline $\begin{array}{c}\text { Emissões Objeto de Avaliação } \\
\text { Econômica }\end{array}$ & $\mathrm{SO}_{2}, \mathrm{NO}_{x}$, partículas & $\begin{array}{c}\mathrm{SO}_{2}, \mathrm{NO}_{x}, \mathrm{CO}_{2}, \mathrm{CH}_{4} \text {, e derrame de } \\
\text { crude no mar }\end{array}$ \\
\hline $\begin{array}{l}\text { Impactos/Efeitos Ambientais Objeto } \\
\text { de Avaliação Econômica }\end{array}$ & $\begin{array}{l}\text { Ozônio, Saúde Humana, Intrusão } \\
\text { Visual, Impacto em Colheitas, }\end{array}$ & $\begin{array}{c}\text { Saúde Humana, Danos em } \\
\text { Propriedades, Danos nos } \\
\text { Ecossistemas, Colheitas, Intrusão } \\
\text { Visual }\end{array}$ \\
\hline $\begin{array}{c}\text { Impactos/Efeitos Ambientais } \\
\text { Quantificados que não foram Alvo } \\
\text { de Avaliação Econômica }\end{array}$ & Aquecimento Global & Aquecimento Global \\
\hline Métodos de Avaliação Econômica & $\begin{array}{l}\text { Análise de Mercados Reais, Avaliação } \\
\text { Contingencial, Custos de Reposição }\end{array}$ & $\begin{array}{l}\text { Análise de Mercados Reais, Avaliação } \\
\text { Contingencial, Custos de Reposição }\end{array}$ \\
\hline
\end{tabular}

Tabela 6.16 - Síntese dos estudos europeus.

\begin{tabular}{|c|c|c|c|}
\hline \multicolumn{4}{|c|}{ ESTUDOS EUROPEUS } \\
\hline ESTUDOS & HOHMEYER & PEARCE & EXTERNE \\
\hline $\begin{array}{c}\text { Tecnologias de } \\
\text { Produção/Recursos Objeto de } \\
\text { Avaliação }\end{array}$ & Diesel, Nuclear, Solar, Eólica & $\begin{array}{c}\text { Carvão, Diesel, Gás Natural, } \\
\text { Nuclear, Solar, Eólica, } \\
\text { Hidroelétrica }\end{array}$ & $\begin{array}{c}\text { Carvão, Diesel, Nuclear, Gás } \\
\text { Natural, Hidroelétrica, Biomassa, } \\
\text { Solar, Eólica }\end{array}$ \\
\hline $\begin{array}{l}\text { Tecnologias/Recursos } \\
\text { Utilizados neste Estudo }\end{array}$ & Diesel, Biomassa & $\begin{array}{l}\text { Diesel, Solar, Eólica, } \\
\text { Hidroelétrica }\end{array}$ & $\begin{array}{c}\text { Diesel, Biomassa, Solar, Eólica, } \\
\text { Hidroelétrica }\end{array}$ \\
\hline $\begin{array}{l}\text { Estágios do Ciclo de } \\
\text { Combustível }\end{array}$ & Produção & Produção & Transporte e Produção \\
\hline $\begin{array}{c}\text { Emissões Objeto de Avaliação } \\
\text { Econômica }\end{array}$ & $\mathrm{SO}_{2}, \mathrm{NO}_{x}$, partículas & $\mathrm{SO}_{2}, \mathrm{NO}_{\mathrm{x}}, \mathrm{CO}_{2}$, partículas & $\mathrm{SO}_{2}, \mathrm{NO}_{x}, \mathrm{CO}_{2}$, partículas \\
\hline $\begin{array}{l}\text { Impactos/Efeitos Ambientais } \\
\text { Objeto de Avaliação Econômica }\end{array}$ & Vários & Vários & $\begin{array}{l}\text { Saúde Humana, Danos sobre } \\
\text { Colheitas, Perda de Biodiversidade, } \\
\text { Ruído, Intrusão Visual, Ozônio, } \\
\text { Aquecimento Global, Danos sobre } \\
\text { Estradas, }\end{array}$ \\
\hline $\begin{array}{l}\text { Impactos/Efeitos Ambientais } \\
\text { Quantificados que não foram } \\
\text { Alvo de Avaliação Econômica }\end{array}$ & $\begin{array}{c}\text { Saúde Humana, Perda de } \\
\text { Biodiversidade, Intrusão Visual, } \\
\text { Degradação do Solo }\end{array}$ & $\begin{array}{l}\text { Ruídos, Redução da } \\
\text { Biodiversidade, Intrusão Visual, } \\
\text { Contaminação do Solo }\end{array}$ & \\
\hline $\begin{array}{l}\text { Métodos de Avaliação } \\
\text { Econômica }\end{array}$ & $\begin{array}{l}\text { Transferência de Benefícios, } \\
\text { Custo da Reposição }\end{array}$ & $\begin{array}{l}\text { Análise de Mercados Reais, } \\
\text { Avaliação Contingencial, } \\
\text { Métodos Hedônicos }\end{array}$ & Avaliação Contingencial \\
\hline
\end{tabular}

Conclui-se então que existem diversas fontes de incerteza associadas aos estudos de avaliação econômica: incerteza estatística a respeito dos valores médios estimados para cada pathway, incerteza qualitativa a respeito dos modelos selecionados para obter as estimativas, incerteza a respeito dos pathway negligenciados no processo de avaliação (como é o caso da maioria dos estudos que negligenciam as emissões atmosféricas aquecimento global). Exemplo claro da omissão de impactos é a ausência da análise dos efeitos no aquecimento global nos estudos norte-americanos da segunda geração, ao contrário do projeto ExternE, o que justifica as variações de valores observadas entre tais estudos. 
Segundo Martins (1998), as técnicas tradicionais de estatística poderiam, idealmente, ser utilizadas para descrever as incertezas associadas a cada uma das estimativas, no intuito de nos proporcionar um relatório de estimativa mediana dos danos com uma distribuição de probabilidade associada. Infelizmente, isso raramente é possível, sem excluir algum aspecto significativo de erro, ou sem fazer alguma suposição ousada sobre a forma de distribuição de probabilidade.

Ou seja, métodos alternativos são, portanto, necessários, tais como análise de sensibilidade, julgamento de especialistas e análise de decisão. Sendo que nesta área as incertezas tendem a ser tão grandes que os intervalos de confiança geralmente não fazem sentido, logo, devese especificar um intervalo de confiança (Martins, 1998). As incertezas de cada etapa de um pathway devem ser avaliadas e os erros quantificados. Os desvios individuais de cada etapa devem ser então combinados de forma a gerar uma indicação do limite de confiança para o impacto em investigação.

O próprio Martins (1998) classificou cada etapa do dano em A, B ou C de acordo com o nível de incerteza associado: onde A corresponde a resultados com elevado nível de confiança, B corresponde a resultados com médio nível de confiança e C corresponde a resultados com baixo nível de confiança. Seguindo as premissas de Martins (1998) este estudo se utilizará da mesma classificação para interpretar os níveis de confiança das estimativas dos estudos (A, B e C), definindo um intervalo de confiança entre 5 e $20 \%$ da estimativa dos custos das externalidades ambientais, onde:

- A: Elevado Nível de Confiança, correspondendo a uma variação de 5\% da estimativa.

- B: Médio Nível de Confiança, correspondendo a uma variação de 12,5\% da estimativa.

- C: Baixo Nível de Confiança, correspondendo a uma variação de $20 \%$ da estimativa.

Entre as metodologias elencadas, a escolha de uma em particular para a avaliação econômica das externalidades ambientais depende de vários fatores, nomeadamente das características dos recursos e dos impactos a serem avaliados, e da disponibilidade de informação e recursos (financeiros, técnicos, pessoas), além dos prazos para realização de pesquisas. Sendo que em determinados casos tais fatores podem limitar a aplicação prática de determinadas metodologias, nomeadamente de avaliação subjetiva. Logo, a transferência de resultados já existentes pode se apresentar como uma solução adequada. 
Entretanto, sabe-se que a transferência direta de resultados, em $\mathrm{R} \$ \mathrm{MWh}$, entre localizações geográficas distintas possui limitações, quer no que se refere a danos ambientais, quer no que se refere à externalidades não-ambientais, que variam com a especificidade da economia do local. A única exceção diz respeito aos danos associados ao aquecimento global, uma vez que estes, apesar de em muitos estudos ter sido negligenciado, não dependem da localização geográfica das fontes emissoras, embora os custos de cumprimento das metas de emissão sejam diferenciados entre as localidades.

Apesar das dificuldades apontadas, os resultados obtidos se utilizando de metodologias de avaliação dos custos externos têm contribuído para a análise da importância dos danos associados aos diferentes ciclos de combustíveis, bem como tornado possível correlacionar tais estimativas com os custos de produção e preço de venda da eletricidade. Tais aspectos podem ser relevantes para suportar políticas de incentivo e apoiar decisões de planejamento estratégico.

Logo, a transferência de resultados associada à análise de incertezas pode gerar estimativas de custos das externalidades ambientais relacionadas às tecnologias de produção objeto de estudo, de forma a podermos efetuar as devidas comparações com os custos de produção da energia. Entretanto, a transferência de resultados dos estudos realizados em outras localidades deve levar em conta as correções monetárias e dos índices econômicos de forma a tornar a estimativa fiel à valorização dos bens até o período atual bem como as variações do câmbio entre as moedas envolvidas. Para tanto foi elaborado o APÊNDICE III, que trata toda a metodologia de atualização monetária das estimativas apresentadas pelos estudos a serem considerados.

Conforme já explicitado, os estudos da primeira geração dos EUA podem ser negligenciados para a transferência de resultados devido a fatores, tais como: (i) a falta de consenso entre os autores; (ii) as variações de resultados apresentados; (iii) o tempo transcorrido até então, que pode resultar na desativação das plantas avaliadas à época e na melhora das tecnologias de produção, impactando na diminuição das cargas ambientais provenientes da geração de energia elétrica das unidades objeto de estudo à época; e (iv) a evolução da legislação e exigências ambientais. 
Os estudos da segunda geração dos EUA também podem ser negligenciados, pois não abarcam os efeitos do aquecimento global, sendo que esta categoria de impacto sempre possui uma das maiores estimativas de custos externos entre as cargas ambientais avaliadas, quando levada em consideração nas avaliações. Observam-se em tais estudos que a biomassa apresenta maiores custos externos totais do que tecnologias de combustíveis fósseis, pois para a biomassa foram incorporadas também as emissões atmosféricas que contabilizam danos associados à erosão e outros efeitos decorrentes do reflorestamento.

Para se utilizar da transferência de resultados da avaliação econômica das externalidades, este estudo fará uso dos estudos de Pearce (1992) e os projetos de implementação nacional do ExternE em Portugal e na Alemanha. Tais estudos foram selecionados por abarcar uma maior quantidade de categorias de impacto na avaliação econômica, além de utilizarem semelhantes metodologias de avaliação econômica das externalidades.

As tabelas a seguir foram elaboradas no intuito de se apresentar a transferência de resultados das avaliações econômicas das externalidades ambientais do setor elétrico para as soluções de interesse, bem como efetuar a consideração das incertezas associadas a tais avaliações. Os custos apresentados, em $\mathrm{R} \$_{09} / \mathrm{MWh}$, são resultado das correções propostas no APÊNDICE III, considerando-se o custo máximo de cada categoria de impacto entre os estudos considerados.

Ressalta-se que tais resultados devem ser considerados apenas como indicadores que possam suportar políticas de incentivos e apoiar decisões de planejamento energético. As atualizações monetárias realizadas são alvo de discussão no APÊNDICE III deste estudo.

Tabela 6.17 - Estimativa atualizada de custos ambientais do diesel.

\begin{tabular}{ccccc}
\hline CATEGORIA DE IMPACTO & $\begin{array}{c}\text { CUSTO } \\
\left(\mathbf{R} \mathbf{\$}_{\mathbf{0} 9} / \mathbf{M W h}\right)\end{array}$ & $\begin{array}{c}\text { GRAU DE } \\
\text { INCERTEZA }\end{array}$ & $\begin{array}{c}\text { CUSTO MÍNIMO } \\
\left(\mathbf{R} \mathbf{\$}_{\mathbf{0}} / \mathbf{M W h}\right)\end{array}$ & $\begin{array}{c}\text { CUSTO MÁXIMO } \\
\left(\mathbf{R} \mathbf{\$}_{\mathbf{0}} / \mathbf{M W h}\right)\end{array}$ \\
\hline Saúde Humana & 14,89 & $\mathrm{~B}$ & 13,03 & 16,75 \\
\hline $\begin{array}{c}\text { Ecossistemas/Perda de } \\
\text { Biodiversidade/Danos em Florestas }\end{array}$ & 35,58 & $\mathrm{~B}$ & 31,13 & 40,03 \\
\hline Degradação dos Solos/Colheitas & 1,82 & $\mathrm{~B}$ & 1,59 & 2,05 \\
\hline $\begin{array}{c}\text { Alterações Climáticas/Poluição } \\
\text { Atmosférica }\end{array}$ & 12,71 & $\mathrm{~B}$ & 11,12 & 14,30 \\
\hline Poluição das Águas & 1,78 & $\mathrm{~B}$ & 1,56 & 2,00 \\
\hline TOTAL & $\mathbf{6 6 , 7 8}$ & & $\mathbf{5 8 , 4 3}$ & $\mathbf{7 5 , 1 3}$ \\
\hline
\end{tabular}


Tabela 6.18 - Estimativa atualizada de custos ambientais da hidroeletricidade.

\begin{tabular}{ccccc}
\hline CATEGORIA DE IMPACTO & $\begin{array}{c}\text { CUSTO } \\
\left(\mathbf{R} \mathbf{\$}_{\mathbf{0 9}} / \mathbf{M W h}\right)\end{array}$ & $\begin{array}{c}\text { GRAU DE } \\
\text { INCERTEZA }\end{array}$ & $\begin{array}{c}\text { CUSTO MíNIMO } \\
\left(\mathbf{R} \mathbf{\$}_{\mathbf{0}} / \mathbf{M W h}\right)\end{array}$ & $\begin{array}{c}\text { CUSTO MÁXIMO } \\
\left(\mathbf{R} \mathbf{\$}_{\mathbf{0}} / \mathbf{M W h}\right)\end{array}$ \\
\hline Saúde Humana & 1,09 & $\mathrm{~B}$ & 0,95 & 1,23 \\
\hline $\begin{array}{c}\text { Ecossistemas/Perda de } \\
\text { Biodiversidade/Danos em Florestas }\end{array}$ & 0,12 & $\mathrm{~B}$ & 0,11 & 0,14 \\
\hline Degradação dos Solos/Colheitas & 0,28 & $\mathrm{~B}$ & 0,25 & 0,32 \\
\hline $\begin{array}{c}\text { Alterações Climáticas/Poluição } \\
\text { Atmosférica }\end{array}$ & 0,55 & $\mathrm{C}$ & 0,44 & 0,66 \\
\hline TOTAL & $\mathbf{2 , 0 4}$ & & $\mathbf{1 , 7 4}$ & $\mathbf{2 , 3 4}$ \\
\hline
\end{tabular}

Tabela 6.19 - Estimativa atualizada de custos ambientais da energia eólica.

\begin{tabular}{ccccc}
\hline CATEGORIA DE IMPACTO & $\begin{array}{c}\text { CUSTO } \\
\left(\mathbf{R} \mathbf{\$}_{\mathbf{0}} / \mathbf{M W h}\right)\end{array}$ & $\begin{array}{c}\text { GRAU DE } \\
\text { INCERTEZA }\end{array}$ & $\begin{array}{c}\text { CUSTO MíNIMO } \\
\left(\mathbf{R} \mathbf{\$}_{\mathbf{0}} / \mathbf{M W h}\right)\end{array}$ & $\begin{array}{c}\text { CUSTO MÁXIMO } \\
\left(\mathbf{R} \mathbf{\$}_{\mathbf{0}} / \mathbf{M W h}\right)\end{array}$ \\
\hline Saúde Humana & 2,77 & $\mathrm{~A}$ & 2,63 & 2,91 \\
\hline $\begin{array}{c}\text { Ecossistemas/Perda de } \\
\text { Biodiversidade/Danos em Florestas }\end{array}$ & 1,54 & $\mathrm{~B}$ & 1,35 & 1,73 \\
\hline Degradação dos Solos/Colheitas & 0,03 & $\mathrm{~A}$ & 0,03 & 0,03 \\
\hline $\begin{array}{c}\text { Alterações Climáticas/Poluição } \\
\text { Atmosférica }\end{array}$ & 1,54 & $\mathrm{~B}$ & 1,35 & 1,73 \\
\hline Ruído & 0,19 & $\mathrm{~A}$ & 0,18 & 0,20 \\
\hline TOTAL & $\mathbf{6 , 0 7}$ & & $\mathbf{5 , 5 4}$ & $\mathbf{6 , 6 0}$
\end{tabular}

Tabela 6.20 - Estimativa atualizada de custos ambientais da biomassa.

\begin{tabular}{ccccc}
\hline CATEGORIA DE IMPACTO & $\begin{array}{c}\text { CUSTO } \\
\left(\mathbf{R} \mathbf{\$}_{\mathbf{0}} / \mathbf{M W h}\right)\end{array}$ & $\begin{array}{c}\text { GRAU DE } \\
\text { INCERTEZA }\end{array}$ & $\begin{array}{c}\text { CUSTO MÍNIMO } \\
\left(\mathbf{R} \mathbf{\$}_{\mathbf{0} 9} / \mathbf{M W h}\right)\end{array}$ & $\begin{array}{c}\text { CUSTO MÁXIMO } \\
\left(\mathbf{R} \mathbf{9}_{\mathbf{0}} / \mathbf{M W h}\right)\end{array}$ \\
\hline Saúde Humana & 27,45 & $\mathrm{~A}$ & 26,08 & 28,82 \\
\hline Danos sobre Estradas & 0,65 & $\mathrm{~A}$ & 0,62 & 0,68 \\
\hline Degradação dos Solos/Colheitas & 2,42 & $\mathrm{~B}$ & 2,12 & 2,72 \\
\hline $\begin{array}{c}\text { Alterações Climáticas/Poluição } \\
\text { Atmosférica }\end{array}$ & 5,83 & $\mathrm{C}$ & 4,66 & 7,00 \\
\hline TOTAL & $\mathbf{3 6 , 3 5}$ & & $\mathbf{3 3 , 4 8}$ & $\mathbf{3 9 , 2 2}$ \\
\hline
\end{tabular}

Tabela 6.21 - Estimativa atualizada de custos ambientais da energia solar fotovoltaica.

\begin{tabular}{ccccc}
\hline CATEGORIA DE IMPACTO & $\begin{array}{c}\text { CUSTO } \\
\left(\mathbf{R} \mathbf{\$}_{\mathbf{0} 9} / \mathbf{M W h}\right)\end{array}$ & $\begin{array}{c}\text { GRAU DE } \\
\text { INCERTEZA }\end{array}$ & $\begin{array}{c}\text { CUSTO MÍNIMO } \\
\left(\mathbf{R} \mathbf{\$}_{\mathbf{0}} / \mathbf{M W h}\right)\end{array}$ & $\begin{array}{c}\text { CUSTO MÁXIMO } \\
\left(\mathbf{R} \mathbf{\$}_{\mathbf{0}} / \mathbf{M W h}\right)\end{array}$ \\
\hline Saúde Humana & 17,35 & $\mathrm{~B}$ & 15,18 & 19,52 \\
\hline $\begin{array}{c}\text { Ecossistemas/Perda de } \\
\text { Biodiversidade/Danos em Florestas }\end{array}$ & 1,54 & $\mathrm{~B}$ & 1,35 & 1,73 \\
\hline Degradação dos Solos/Colheitas & 0,03 & $\mathrm{C}$ & 0,02 & 0,04 \\
\hline $\begin{array}{c}\text { Alterações Climáticas/Poluição } \\
\text { Atmosférica }\end{array}$ & 12,71 & $\mathrm{~B}$ & 11,12 & 14,30 \\
\hline TOTAL & $\mathbf{3 1 , 6 3}$ & & $\mathbf{2 7 , 6 7}$ & $\mathbf{3 5 , 5 9}$ \\
\hline
\end{tabular}


Por intermédio dos resultados apresentados, observa-se que algumas das categorias de impacto não possuem sua respectiva estimativa de custo de acordo com a fonte utilizada, isto se deve ao fato de que tais impactos não foram considerados nos diversos estudos considerados, ou simplesmente foram considerados como negligenciáveis por tais estudos.

Para o diesel, nota-se a ausência das estimativas para os impactos visuais, ruído e degradação de zonas costeiras. Para a hidroeletricidade nota-se a ausência de estimativas para os impactos visuais e alteração dos fluxos hidrológicos. No caso da energia eólica a ausência de estimativas está restrita aos impactos visuais. E para a energia solar existe a ausência de estimativas para o impacto visual e danos sobre colheitas.

Apesar da ausência de estimativas para as categorias elencadas anteriormente, é possível notar que as principais categorias de impacto foram consideradas, tais como os efeitos sobre as alterações climáticas, os danos a saúde, efeitos sobre colheitas, degradação dos solos, perda de biodiversidade, danos em florestas e efeitos sobre o ecossistema. Tais categorias são as responsáveis pelas maiores cargas de impactos e respectivos danos a natureza, sendo assim as categorias de impacto elencadas representam uma estimativa de custos externos do setor elétrico de forma confiável.

A segregação das estimativas por categoria de impacto tem por finalidade apresentar a parcela de contribuição de cada dano da respectiva fonte e pode ser utilizada como indicador específico dos impactos causados pela produção de energia elétrica e auxiliar a tomada de decisões e o planejamento do setor. Pois dá a flexibilidade ao avaliador de incluir ou retirar as cargas que este entenda como necessárias ao processo de avaliação, ou seja, cabe ao avaliador incluir ou negligenciar no processo de avaliação as categorias de impactos que este entenda como pertinentes para se obter a estimativa dos custos externos totais da respectiva fonte. 


\section{ANÁLISE DE CUSTOS EQUIVALENTES}

Os custos apresentados na abordagem econômica deste estudo são notavelmente de cunho técnico-financeiro, e foram estimados segundo as considerações efetuadas anteriormente. No intuito de se levar em consideração a expectativa de sustentabilidade ambiental dos projetos de geração estudados, faz-se necessária a inclusão das variáveis externas a avaliação econômica das soluções na forma de diferenciais de custo, constituindo assim o custo da externalidade (CEX), em R\$/kWh.

O CEX é representado por custos adicionados ou evitados para o caso em estudo, porém como foram avaliadas somente externalidades ambientais negativas do setor elétrico, tal custo é composto pela soma dos custos de cada categoria de impacto discutida anteriormente para cada solução de geração, sendo considerado um adicional ao custo da energia (CE), gerando assim o conceito de custo equivalente da energia (CEE), em $\mathrm{R} \$ / \mathrm{kWh}$, que pode ser obtido pela formulação a seguir.

$$
C E E=C E+C E X
$$

Em que:

- $C E$ é o custo da energia [R $\$ / \mathrm{kWh}]$.

- $C E X$ é o custo da externalidade $[\mathrm{R} \$ / \mathrm{kWh}]$.

Em posse das informações de energia anual média necessária, pode-se também calcular o custo anual equivalente total (CAET), em $\mathrm{R} \$ /(\mathrm{kW} . \mathrm{ano})$, conforme formulação abaixo.

$$
C A E T=C E E \cdot E c a / P t g
$$

Em que:

- CAET é o custo anual equivalente total [R $\$(\mathrm{~kW} . \mathrm{ano})]$.

- CEE é o custo equivalente da energia [R $\$ / \mathrm{kWh}]$.

- Eca é a energia anual média necessária [kWh/ano].

- Ptg é a potência nominal de geração [kW]. 
Para se estimar o CEE e o CAET, foi realizada nova simulação utilizando o software EXCEL, considerando 5.000 casos, de acordo com as prerrogativas já explanadas anteriormente, adicionando-se as grandezas referentes aos custos externos com a utilização de variação aleatória destes, no intuito de se considerar a análise de incertezas proposta. Os dados de entrada podem ser observados por meio da Tabela 7.1 a seguir, com os resultados de uma simulação efetuada.

Tabela 7.1 - Simulação para 5.000 casos considerando externalidades.

\begin{tabular}{|c|c|c|c|c|c|}
\hline ATRIBUTO & $\begin{array}{c}\text { SOLAR } \\
\text { FOTOVOLTAICA }\end{array}$ & EÓLICA & $\begin{array}{l}\text { BIOMASSA } \\
\text { CANA }\end{array}$ & PCH & GMG a DIESEL \\
\hline Potência Nominal de Carga (kW) & 100 & 100 & 100 & 100 & 100 \\
\hline Funcionamento Diário Médio (h/dia) & 12 & 12 & 12 & 12 & 12 \\
\hline Energia Anual Média Necessária (kWh/ano) & $438.000,00$ & $438.000,00$ & $438.000,00$ & $438.000,00$ & $438.000,00$ \\
\hline Fator de Capacidade & 0,2416 & 0,4258 & 1 & 1 & 1 \\
\hline Potência Nominal de Geração (kW) & 413,91 & 234,85 & 100 & 100 & 100 \\
\hline Vida Útil do Sistema (ano) & 25 & 15 & 25 & 30 & 20 \\
\hline Distância da Carga (km) & 0 & 0 & 0 & 0,48 & 0 \\
\hline Custo de Implantação da Linha ( $\mathrm{R} \$ / \mathrm{km})$ & 0 & 0 & 0 & $13.967,00$ & 0 \\
\hline Perdas na Linha ( $\%$ da energia) & $0 \%$ & $0 \%$ & $0 \%$ & $7,94 \%$ & $0 \%$ \\
\hline Perdas Anuais (kWh/ano) & 0 & 0 & 0 & $34.777,20$ & 0 \\
\hline Custo da Energia Perdida (R $\$ / \mathrm{kWh})$ & 0 & 0 & 0 & 0,2000 & 0 \\
\hline Custo Anual das Perdas (R $\$ / a n o)$ & 0 & 0 & 0 & $6.955,44$ & 0 \\
\hline Taxa de Juros (a.a.) & $6 \%$ & $6 \%$ & $6 \%$ & $6 \%$ & $6 \%$ \\
\hline Período de Estudo (ano) & 15 & 15 & 15 & 15 & 15 \\
\hline FRC de Todo o Período de Estudo & 0,1030 & 0,1030 & 0,1030 & 0,1030 & 0,1030 \\
\hline Custo de Implantaçao $(\mathrm{R} \$ / \mathrm{kW})$ & $14.557,00$ & $1.343,00$ & $1.425,00$ & $1.647,00$ & $1.127,00$ \\
\hline Investimento Inicial ( $\mathrm{R} \$)$ & $6.025 .248,34$ & $315.406,29$ & $142.500,00$ & $171.334,33$ & $112.700,00$ \\
\hline Valor Residual (R\$) & $1.005 .650,25$ & 0 & $23.784,11$ & $35.745,91$ & $11.756,44$ \\
\hline CA de Implantação (R $\$(k W . a n o))$ & $1.248,67$ & 138,28 & 122,23 & 139,61 & 103,93 \\
\hline Custo de O\&M (\% do Investimento) & $1,61 \%$ & $0 \%$ & $3,10 \%$ & $0 \%$ & $0 \%$ \\
\hline Custo de O\&M (R\$/(kW.ano)) & 20,14 & 0 & 3,78 & 0 & 0 \\
\hline Custo de O\&M (R\$/kWh) & 0 & 0,0075 & 0 & 0,0156 & 0,0813 \\
\hline Custo de O\&M (R\$/(kW.ano)) & 0 & 14,00 & 0 & 68,44 & 355,89 \\
\hline Custo de Combustível (R\$/kWh) & 0 & 0 & 0,0761 & 0 & 0,559 \\
\hline Custo de Combustível (R $\$(k W . a n o))$ & 0 & 0 & 333,37 & 0 & $2.447,28$ \\
\hline CA de O\&M (R\$/(kW.ano)) & 20,14 & 14,00 & 337,15 & 68,44 & $2.803,17$ \\
\hline Externalidade: Saúde Humana (R $\$ / k W h)$ & 0,018113 & 0,002788 & 0,027249 & 0,001136 & 0,016446 \\
\hline Externalidade: Ecossistema (R $\$ / \mathrm{kWh})$ & 0,001705 & 0,001628 & 0 & 0,000118 & 0,037994 \\
\hline Externalidade: Solos/Colheitas (R $\$ / k W h)$ & 0,000020 & 0,000030 & 0,002369 & 0,000319 & 0,001848 \\
\hline Externalidade: Alteração Climática (R\$/kWh) & 0,013872 & 0,001640 & 0,004701 & 0,000530 & 0,012696 \\
\hline Externalidade: Poluição das Águas (R\$/kWh) & 0 & 0 & 0 & 0 & 0,001573 \\
\hline Externalidade: Ruído (R\$/kWh) & 0 & 0,000180 & 0 & 0 & 0 \\
\hline Externalidade: Danos sobre Estradas (R $\$ / \mathrm{kWh})$ & 0 & 0 & 0,000664 & 0 & 0 \\
\hline Custo da Externalidade (R $\$ / \mathrm{kWh})$ & 0,03371 & 0,00627 & 0,03498 & 0,00210 & 0,07056 \\
\hline CA da Externalidade (R $\$ /(\mathrm{kW}$. ano $))$ & 35,67 & 11,69 & 153,23 & 9,21 & 309,04 \\
\hline CAE TOTAL (R\$/(kW.ano)) & $1.304,48$ & 163,96 & 612,61 & 286,81 & $3.216,14$ \\
\hline Custo Equivalente da Energia ( $\mathbf{R} \$ \mathbf{k W h}$ ) & 1,2327 & 0,0879 & 0,1399 & 0,0655 & 0,7343 \\
\hline
\end{tabular}


Relembrando que as células amarelas com fonte vermelha representam dados de entrada aleatórios, e as duas últimas linhas contêm os valores de CEE e CAET. Vale ressaltar que por possuir dados aleatórios, os valores apresentados na tabela caracterizam somente um exemplo de simulação.

Ressalta-se que as faixas de valores aleatórios de cunho técnico-financeiro utilizadas na simulação correspondem aos valores da Tabela 4.14. E, as faixas de valores aleatórios dos custos de externalidades correspondem aos custos apresentados por intermédio das tabelas Tabela 6.17, Tabela 6.18, Tabela 6.19, Tabela 6.20 e Tabela 6.21.

Os resultados da simulação são apresentados por meio da Tabela 7.2 e dos gráficos apresentados a seguir que demonstram os valores médios, desvio padrão e probabilidade de 95\% dos casos ocorrerem com valor inferior a determinado custo.

Tabela 7.2 - Resultados da simulação para 5.000 casos com externalidades.

\begin{tabular}{|c|c|c|c|c|c|}
\hline GRANDEZA & $\begin{array}{c}\text { SOLAR } \\
\text { FOTOVOLTAICA }\end{array}$ & EÓLICA & BIOMASSA & PCH & $\begin{array}{l}\text { GMG a } \\
\text { DIESEL }\end{array}$ \\
\hline CAET Médio [R \$/(kW.ano)] & $1.024,46$ & 255,05 & 824,75 & 344,99 & $3.989,64$ \\
\hline Desvio Padrão [R \$/(kW.ano)] & 221,56 & 55,60 & 175,66 & 33,71 & 496,70 \\
\hline $\mathrm{P} 95 \%$ [R \$(kW.ano)] & $1.371,95$ & 340,94 & $1.100,03$ & 401,73 & $4.761,12$ \\
\hline CEE Médio [R\$/kWh] & 0,90638 & 0,15017 & 0,18822 & 0,07858 & 0,91001 \\
\hline Desvio Padrão [R $\$ / \mathrm{kWh}]$ & 0,20985 & 0,03372 & 0,04058 & 0,00775 & 0,11186 \\
\hline $\mathrm{P} 95 \%[\mathrm{R} \$ / \mathrm{kWh}]$ & 1,26465 & 0,20490 & 0,25115 & 0,09173 & 1,08473 \\
\hline
\end{tabular}

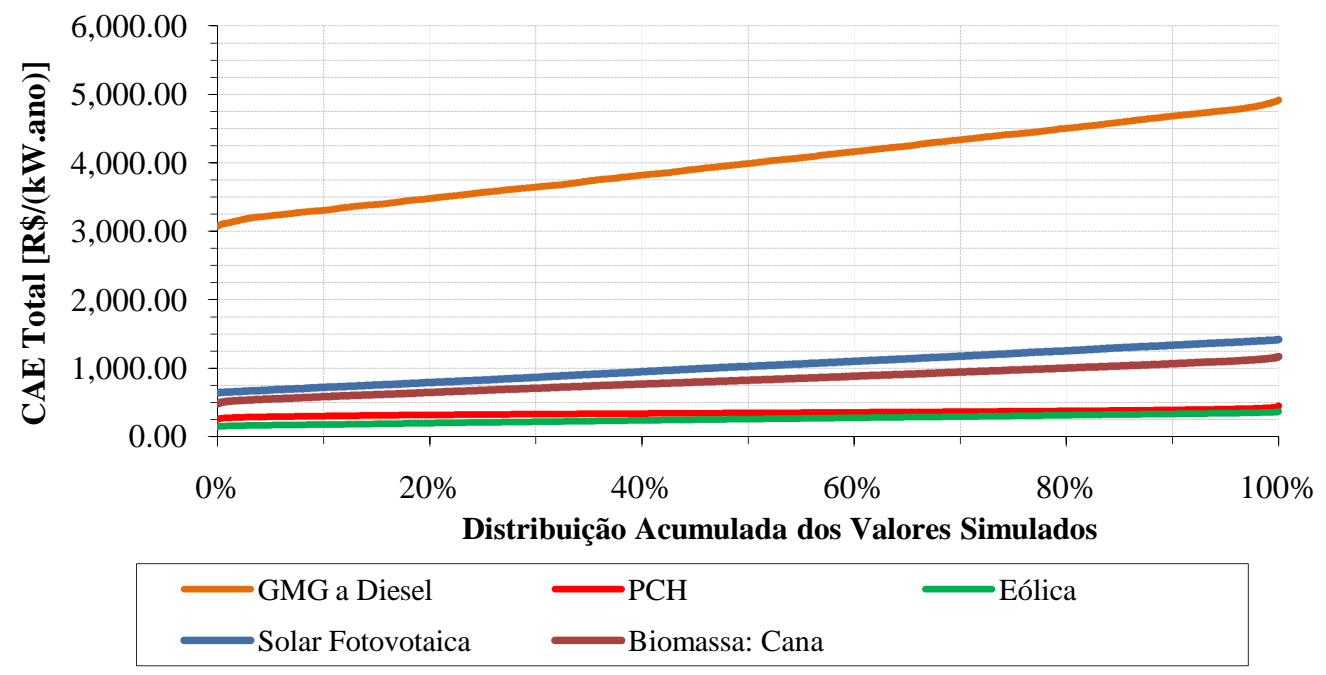

Gráfico 7.1 - Simulação do CAET para 5.000 casos com externalidades. 


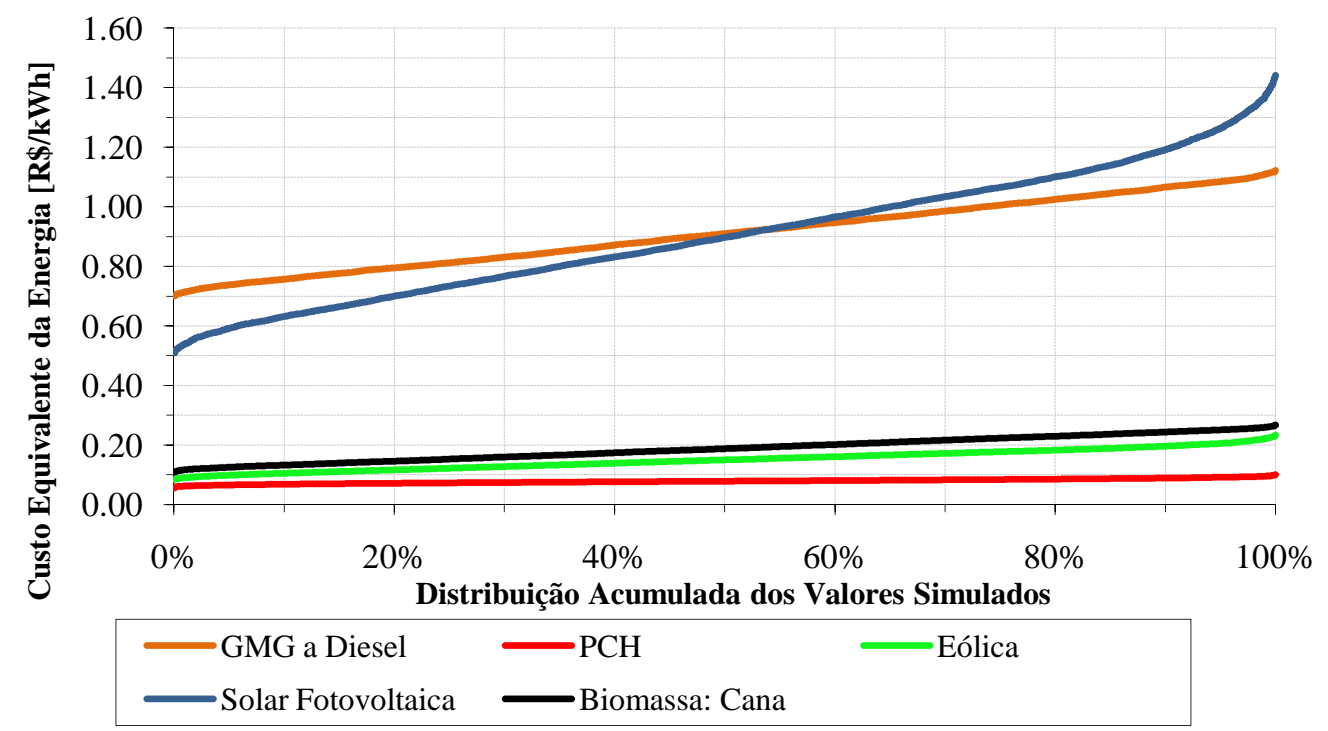

Gráfico 7.2 - Simulação do CEE para 5.000 casos com externalidades.

A tabela com os resultados da simulação revela que a solução com o menor CAET é a geração eólica, com custo médio de $\mathrm{R} \$ 255,05 /(\mathrm{kW}$.ano), seguida da geração por $\mathrm{PCH}$, com custo médio de $\mathrm{R} \$ 344,99 /(\mathrm{kW}$.ano), demonstrando que continuam a apresentar os menores custos anuais já que os valores estimados de externalidades destas soluções também são os menores, e, o CAET para a utilização da geração a diesel, com custo médio de $\mathrm{R} \$ 3.989,64 /(\mathrm{kW}$. ano), mostrou-se o mais elevado.

De acordo com os dados simulados, nota-se que a geração por PCH continua sendo a solução de menor custo, com custo médio equivalente de $\mathrm{R} \$ 78,58 / \mathrm{MWh}$, mesmo com a inclusão das externalidades. Tal fato decorre de que os custos externos associados a esta solução são muito baixos.

Nota-se que a geração eólica, quando comparada à geração por biomassa de cana, tornouse ainda mais atrativa com a inclusão dos custos de externalidades (20,21\% mais barata), do que quando eram comparados somente aspectos técnico-financeiros (4,95\% mais barata). Tal fato está associado ao custo externo da geração por biomassa ser menor apenas do que o custo externo relacionado à geração a diesel, principalmente devido ao alto custo externo da estimativa dos danos a saúde.

Pelo fato de o diesel possuir os maiores custos relativos a impactos ambientais, percebe-se que este perde sua atratividade em relação à solução fotovoltaica. Pois quando são avaliados apenas aspectos técnico-financeiros o diesel é uma solução 3\% mais barata que a 
solução fotovoltaica, e com a inclusão das externalidades a solução fotovoltaica passa a ser aproximadamente $0,5 \%$ mais atrativa, porém devido à consideração de incertezas, concluise que as duas alternativas possuem o mesmo custo de energia equivalente.

Considerando a estimativa de simulações que indiquem grandezas situadas abaixo de $95 \%$ dos valores do CEE, nota-se que somente as soluções PCH (R \$91,73/MWh), e eólica ( $\mathrm{R}$ \$ 204,90/MWh), possuem custos menores que a maior taxa de distribuição de energia a consumidores do subgrupo B2 (Rural) pesquisada (R $\$ 242,31 / \mathrm{MWh})^{30}$. Nota-se novamente a diminuição da atratividade da biomassa de cana, devido à inclusão dos custos dos impactos ambientais considerados.

Nota-se também que para a estimativa P95\% a solução com maior CEE indicado é a fotovoltaica. Desta forma a disparidade entre a comparação da geração a diesel e a solução fotovoltaica, quando analisados o custo médio e o custo P95\%, justifica-se pelo alto desvio-padrão para a simulação dos valores da solução fotovoltaica (em torno de 23,15\%) que faz com que tais valores sejam menos próximos do valor médio estimado.

Entretanto nota-se um aumento da competitividade da solução fotovoltaica em relação à geração a diesel, e tal competitividade poderia ser incrementada caso fossem consideradas externalidades positivas tais como a Redução Certificada de Emissões (RCE), que tratam de certificados que são emitidos quando ocorre a redução da emissão de gases do efeito estufa (GEE). Uma breve abordagem a respeito da externalidade positiva resultante da inclusão de créditos relativos à redução de emissões será efetuada a seguir.

\subsection{Avaliação de custos equivalentes com a inclusão de externalidades positivas (crédito de carbono)}

Crédito de Carbono ou Redução Certificada de Emissões (RCE) são certificados emitidos quando ocorre a redução da emissão de gases do efeito estufa (GEE). Por convenção, uma tonelada de dióxido de carbono $\left(\mathrm{CO}_{2}\right)$ equivalente corresponde a um crédito de carbono, que pode ser negociado no mercado internacional. A redução da emissão de outros gases

\footnotetext{
${ }^{30}$ Taxa referente à tarifa da CELTINS para o subgrupo considerado, B2 (Rural).
} 
que contribuem para o efeito estufa também pode ser convertida em créditos de carbono, utilizando o conceito de carbono equivalente ${ }^{31}$ (Instituo EDP).

Tais créditos geram um mercado para a redução dos GEE, dando um valor monetário à redução de emissão. As cotas de emissão, por sua vez, são determinadas por meio de acordos internacionais. Sendo assim, as entidades que não conseguem atingir suas metas tornam-se compradoras dos créditos disponibilizados pelas entidades que conseguirem diminuir suas emissões abaixo das cotas de emissão estipulada, e, a comercialização ocorre por intermédio das Bolsas de Carbono. Atualmente as principais bolsas de comercialização são a Chicago Climate Exchange (CCX) e a European Climate Exchange (ECX), onde são encontradas uma vasta gama de transações se utilizando de tais certificados.

Entende-se que a sensibilização de tais créditos como diferenciais de custos, tratam de uma externalidade positiva das atividades do setor elétrico, logo, é possível notar que tais certificados passarão a compor o Custo da Externalidade (CEX). Por sua vez, o Custo da Externalidade será interpretado como a subtração entre as cargas ambientais, estimadas anteriormente, e os créditos, relativos à redução de emissões.

Desta forma para que a estimativa de custos externos considere os créditos de carbono é imprescindível o conhecimento da cotação de tais certificados e a quantidade de emissão evitada pelas soluções de geração em estudo.

As cotações utilizadas neste estudo são baseadas em informações retiradas diretamente da ECX baseadas em contratos de compra e venda, firmados na referência outubro de 2009, de acordo com estimativas médias relativas às transações de oferta e demanda efetuada por intermédio deste agente. Os valores de cotação foram elaborados por meio da Tabela 7.3 a seguir. Devido às cotações serem apresentadas em Euro se fez necessária a conversão para a moeda brasileira. Desta forma, utilizou-se a taxa de câmbio média do real em relação ao euro em outubro de 2009, que foi de $\mathrm{R} \$ 2,59 / €$.

\footnotetext{
${ }^{31}$ Carbono equivalente: É baseado no potencial de aquecimento global das toneladas emitidas pelos GEE. O potencial de aquecimento global do $\mathrm{CO}_{2}$ foi estipulado como 1. Já o gás metano $\left(\mathrm{CH}_{4}\right)$ por possuir um potencial 21 vezes maior que o do $\mathrm{CO}_{2}$, possui $\mathrm{CO}_{2}$ equivalente igual a 21. Portanto, uma tonelada de metano reduzida corresponde a 21 créditos de carbono. Os demais GEE possuem o seguinte potencial de aquecimento global: Óxido Nitroso $\left(\mathrm{N}_{2} \mathrm{O}\right)=310$; Hidrofluorcarbonetos $(\mathrm{HFCs})=140 \sim 11700$; Perfluorcarbonetos $(\mathrm{PFCs})=6500 \sim 9200$; Hexafluoreto de Enxofre $\left(\mathrm{SF}_{6}\right)=23900$; (Instituo EDP).
} 
Tabela 7.3 - Resumo de oferta e demanda de RCE na ECX.

\begin{tabular}{|c|c|r|r|r|}
\multicolumn{2}{|c|}{ MERCADO } & VOLUME MÉDIO (ton) & PREÇO MÉDIO (€/ton) & PREÇO MÉDIO (R\$̣/ton) \\
\hline \multirow{2}{*}{ Europa } & Oferta & 2.450 .000 & 9,80 & 25,38 \\
\cline { 2 - 6 } & Demanda & 4.350 .000 & 12,67 & 32,81 \\
\hline \multirow{2}{*}{ EUA } & Oferta & 6.672 .000 & 12,57 & 32,56 \\
\cline { 2 - 6 } & Demanda & 7.472 .000 & 15,45 & 40,02 \\
\hline
\end{tabular}

Já para a consideração da quantidade de emissão evitada, segundo estimativas da EPIA, quando uma fonte fotovoltaica desconectada da rede é utilizada para substituir um gerador a diesel, esta deixa de emitir $1 \mathrm{~kg} / \mathrm{kWh}$ de $\mathrm{CO}_{2}$ equivalente. Sendo assim podemos estimar um intervalo de incerteza para o crédito relacionado a esta externalidade entre $\mathrm{R} \$ 25,38 / \mathrm{MWh}$ e R\$ 40,02/MWh.

No caso da energia eólica, segundo dados do Global Wind Energy Outlook (GWEO), elaborado pelo Greanpeace e Global Wind Energy Council, em 2008, a utilização de tal solução proporciona uma economia na emissão de aproximadamente $600 \mathrm{~g} / \mathrm{kWh}$ de $\mathrm{CO}_{2}$ equivalente. Logo o intervalo de incertezas para o crédito relacionado pode ser estimado entre R\$ 15,23/MWh e R\$ 24.01/MWh.

Para a geração por biomassa de bagaço de cana, segundo informações da Rede de Tecnologia Social (RTS), a utilização de tal solução proporciona uma economia de emissão de aproximadamente 0,5 ton/MWh de $\mathrm{CO}_{2}$ equivalente. Desta forma se pode estimar um intervalo de incerteza para o crédito entre R \$ 12,69/MWh e R \$ 20.01/MWh.

E, segundo dados da empresa Pesqueiro Energia S/A (Bosmin, 2007), a utilização de PCHs proporciona uma economia de emissão de aproximadamente 0,525 ton/ $\mathrm{MWh}$ de $\mathrm{CO}_{2}$ equivalente. Desta forma, o intervalo de incertezas para o crédito pode ser estimado entre $\mathrm{R} \$ 13,32 / \mathrm{MWh}$ e R \$ 21,01/MWh.

Logo, para se estimar o CEE e o CAET considerando os custos externos positivos relativos aos créditos de carbono, faz-se necessária a realização de nova simulação utilizando o software EXCEL. Considerando 5.000 casos, e se adicionando as grandezas referentes aos custos externos negativos (cargas ambientais) e positivos (créditos de carbono), com a utilização de variação aleatória dos custos estimados, no intuito de se considerar a análise de incertezas proposta. 
Os resultados da simulação são apresentados por intermédio dos gráficos e da tabela a seguir, que demonstra os valores médios, desvio padrão e probabilidade de $95 \%$ dos casos ocorrerem com valor inferior a determinado custo.

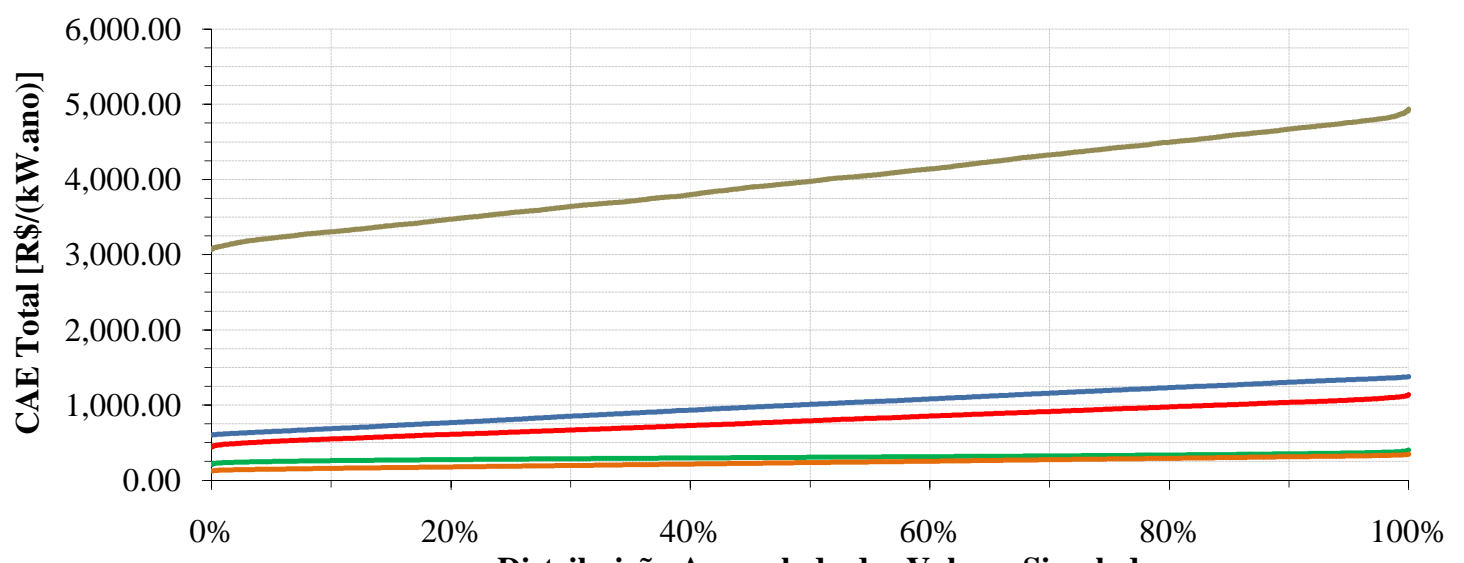

Distribuição Acumulada dos Valores Simulados

\begin{tabular}{|ll|}
\hline GMG a Diesel & PCH \\
Solar Fotovotaica & Biomassa: Cana \\
\hline
\end{tabular}

Gráfico 7.3 - Simulação do CAET para 5.000 casos com externalidades (positivas e negativas).

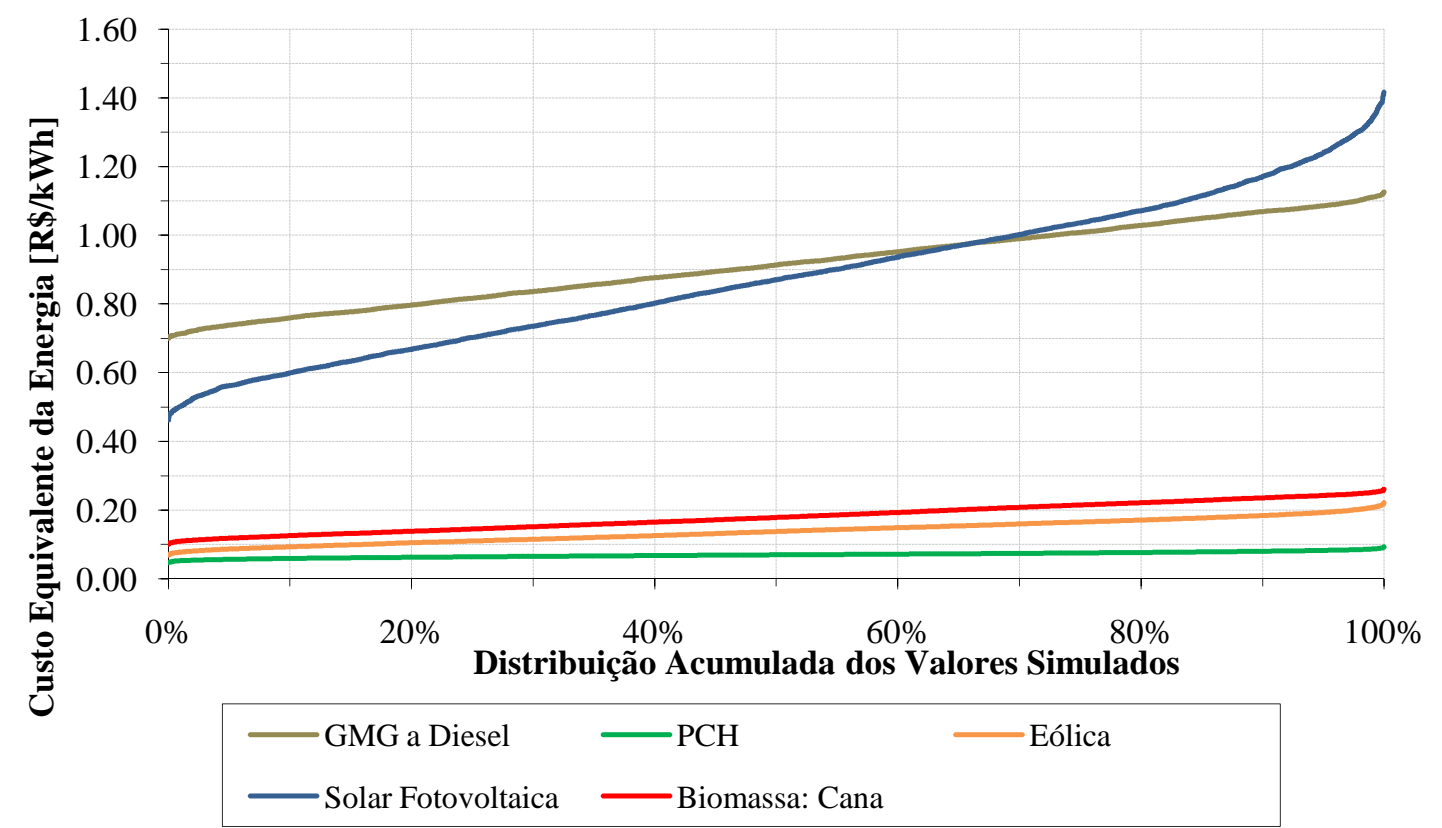

Gráfico 7.4 - Simulação do CEE para 5.000 casos com externalidades (positivas e negativas). 
Tabela 7.4 - Resultados da Simulação para 5.000 casos com externalidades (positivas e negativas).

\begin{tabular}{|l|c|c|c|c|c|}
\hline \multicolumn{1}{|c|}{ GRANDEZA } & $\begin{array}{c}\text { SOLAR } \\
\text { FOTOVOLTAICA }\end{array}$ & EÓLICA & BIOMASSA & PCH & GMG a DIESEL \\
\hline CAET Médio [R\$/(kW.ano)] & $1.002,74$ & 234,90 & 789,76 & 306,03 & $3.980,13$ \\
\hline Desvio Padrão [R\$/(kW.ano)] & 222,44 & 55,02 & 177,66 & 34,44 & 494,67 \\
\hline P95\% [R\$/(kW.ano)] & $1.339,58$ & 320,34 & $1.063,28$ & 363,39 & $4.755,49$ \\
\hline CEE Médio [R\$/kWh] & 0,87738 & 0,13812 & 0,17960 & 0,06982 & 0,91313 \\
\hline Desvio Padrão [R\$/kWh] & 0,21190 & 0,03393 & 0,04043 & 0,00783 & 0,11213 \\
\hline P95\% [R\$/kWh] & 1,23980 & 0,19332 & 0,24256 & 0,08279 & 1,08555 \\
\hline
\end{tabular}

A tabela com os resultados da simulação revelam que a geração eólica é ainda a solução com menor CAET, com custo médio de $\mathrm{R} \$ 234,90 /(\mathrm{kW}$.ano), uma redução de 7,9\% em relação a simulação considerando apenas as externalidades negativas. Seguindo a eólica, temos a PCH que apresenta um custo médio de $\mathrm{R} \$ 306,03 /(\mathrm{kW}$.ano), tendo uma redução de 11,3\% no seu custo anual relativamente a situação considerando apenas externalidades negativas. Sendo assim, a geração por PCH apresenta a maior redução percentual das fontes estudadas. Já que para a biomassa de bagaço de cana se nota uma redução de 4,2\%, enquanto a solução fotovoltaica apresentou redução de apenas $2,1 \%$.

A geração a diesel consta na tabela apenas para comparação, já que seus valores não sofrem influência quando consideradas as externalidades positivas. Tal fato pode ser comprovado pela mínima alteração entre os valores da simulação considerando as externalidades positivas e negativas e os valores da simulação considerando apenas as externalidades negativas. A mínima variação citada decorre da análise de sensibilidade proposta, considerando as incertezas associadas.

Com relação ao CEE, a geração por $\mathrm{PCH}$ se mantêm com o menor custo com uma redução de $11,15 \%$ em relação à análise considerando apenas externalidades negativas, com custo médio de R\$69,82/MWh. Tal redução se deve ao fato de que o custo de externalidade positiva é maior que o custo das externalidades negativas, conseqüentemente há uma redução do CEE inclusive em relação à estimativa onde se consideram apenas fatores técnico-financeiros (R\$ 76,69/MWh). A mesma redução é observada para a solução eólica, que anteriormente era estimada em $\mathrm{R} \$ 144,02 / \mathrm{MWh}$, considerando-se somente os aspectos técnico-financeiros, e com a inclusão de todas as externalidades avaliadas (positivas e negativas) passou a ser estimada em R $\$ 138,12 / \mathrm{MWh}$. 
Tal redução faz com que a atratividade da solução eólica em relação à biomassa de cana seja acrescida em aproximadamente 3\%. Já que o custo da externalidade da biomassa, apesar de ter sido reduzido, ainda é representado por uma parcela aditiva no custo equivalente da energia.

Com a inclusão das externalidades positivas, o CEE da solução fotovoltaica se torna 3,9\% mais atrativo do que o da geração a diesel. Tal fato é decorrente da diminuição do CEX com a consideração da parcela relativa às externalidades positivas.

Considerando a estimativa de simulações que indiquem grandezas situadas abaixo de $95 \%$ dos valores do CEE, nota-se que a PCH e a eólica continuam a apresentar custos inferiores aos praticados pelas distribuidoras de energia pesquisadas para consumidores do subgrupo B2 - Rural (R\$ 242,31/MWh). Entretanto, a biomassa de cana com um custo de R\$ 242,56/MWh fica bem próxima de atingir tal teto, mostrando o aumento de sua competitividade, já que para a análise considerando apenas externalidades negativas tal solução era $3,4 \%$ mais cara que a tarifa rural pesquisada. 


\section{CONCLUSÕES E SUGESTÕES}

O presente estudo foi realizado no intuito de se considerar a crescente demanda de inclusão elétrica atualmente proposta pelas políticas governamentais do país, a escassez gradativa de recursos naturais e a necessidade de diversificação da matriz energética para a utilização de fontes alternativas de energia através do conceito de geração distribuída. Indicando-se a necessidade de quebra de paradigma com relação à cultura já enraizada do sistema atual que é baseado na geração centralizada e distribuição da energia através de extensas linhas de transmissão/distribuição.

Sendo assim, efetuou-se a descrição das diversas formas de geração de energia elétrica a serem avaliadas, observando questões técnico-financeiras, tais como: (i) participação na matriz energética; (ii) potencialidade; (iii) custos envolvidos para implantação, O\&M; (iv) avaliação de subsídios.

Inicialmente, optou-se pela análise comparativa da viabilidade econômica das soluções a serem avaliadas, considerando-se custos de implantação, O\&M, através do método de análise de sensibilidade. Desta forma, identificou-se que a geração por PCH apresenta um grande potencial de atratividade, principalmente por se tratar de uma tecnologia bem disseminada no Brasil. Já a geração a diesel e solar fotovoltaica, apresentaram-se como as soluções mais onerosas, para a análise em questão.

De forma a refletir a expectativa de sustentabilidade sob os diversos prismas (econômico, ambiental, social, político), consideram-se algumas externalidades do setor elétrico na forma de diferenciais de custo, principalmente as externalidades decorrentes de impactos ambientais causados pelas diversas etapas do processo de produção de energia elétrica.

Sendo assim, foi possível se efetuar uma avaliação econômica diferenciada para a determinação dos custos equivalentes da geração de energia, não considerando apenas itens orçamentários convencionais, mas também itens relativos a aspectos de outra natureza. Nota-se então que a consideração das externalidades pode afetar de forma substancial o custo equivalente da energia, fato que pode ser observado através do aumento da atratividade para a solução eólica, que desponta como a segunda alternativa mais barata, e 
possui um dos menores custos ambientais, sendo mais onerosa somente que a geração por $\mathrm{PCH}$.

As PCH indicam uma forma rápida e eficiente de prover energia, além de ter se mostrado muito atrativa tanto na análise puramente técnico-financeira, quanto na análise incluindo custos ambientais onde continuou sendo a solução mais barata. A biomassa de cana também se mostrou uma alternativa economicamente viável, porém de menor atratividade que as soluções PCH e eólica.

As soluções mais caras são representadas pela geração solar fotovoltaica e geração a diesel, porém estas apresentam estimativas de custo muito próximas, e a geração a diesel começa a perder sua atratividade quando são incluídos os custos ambientais na avaliação econômica, tendo em vista que os custos ambientais relacionados à solução fotovoltaica são menores que os associados à geração a diesel.

Apesar de a geração a diesel ser considerada uma das soluções menos atrativas pelas estimativas deste estudo, sabe-se que se trata de uma alternativa de simples operação e já bastante difundida, motivos pelos quais é uma das alternativas mais utilizadas no suprimento a cargas isoladas em todo o território nacional.

Entretanto, evidencia-se que o subsídio destinado a produção através de fontes nãorenováveis, como o diesel, poderia ser destinado ao incentivo à produção de energia elétrica através das fontes alternativas que foram estudadas. Auxiliando assim a capacitação dos empreendimentos para o atendimento às demandas, cada vez mais crescentes, de sustentabilidade ambiental. Pois até mesmo a solução fotovoltaica, que se mostrou a mais onerosa entre as alternativas renováveis, passa a ser mais atrativa que o diesel, de acordo com a abordagem proposta.

É importante ressaltar que as estimativas de custos externos consideradas devem ser tratadas como indicadores dos efeitos dos impactos ambientais, devido aos motivos previamente apresentados. Todavia, é notável que a utilização de combustíveis fósseis passe a ser bastante prejudicada, de acordo com a abordagem proposta, e, existe atualmente grande relevância na inclusão de tal abordagem no intuito de se suportar políticas de incentivos e apoiar decisões de planejamento futuro. 


\subsection{Sugestões para trabalhos futuros}

Nota-se que existe uma evolução positiva e gradual com relação aos estudos de avaliação econômica, em termos metodológicos e de rigor, e conseqüentemente, da consistência e confiabilidade dos dados apresentados. Entretanto, com relação aos custos de externalidades, muitos autores ainda consideram que as estimativas de valor econômico obtidas não deveriam ser consideradas como resultados rigorosos, e sim como valores indicativos da ordem de grandeza dos impactos ambientais do setor elétrico.

Reconhece-se assim a necessidade de desenvolvimento de investigação adicional e prioritária, na medida em que tais estimativas já atualmente fomentam a tomada de decisões estratégicas para o planejamento do setor. Pois existe a necessidade de que os estudos de avaliação econômica dos custos externos sejam consensualmente aceitos para suportar de maneira definitiva todo o processo de tomada de decisão.

Entende-se que a transferência de resultados da avaliação econômica das externalidades, ora proposta, baseia-se na necessidade de se efetuar uma avaliação diferenciada incluindo uma abordagem multidisciplinar, porém a estimativa de tais custos através de estudos de casos nacionais traria um acréscimo de extrema valia para estudos posteriores.

A consideração de externalidades e seus respectivos diferenciais de custo podem causar alterações substanciais no custo da energia (Severino, 2008). Entretanto, nota-se que este tipo de consideração apresenta uma razoável bibliografia quando se trata principalmente das externalidades ambientais negativas (cargas ambientais). Já para as externalidades sociais ainda existe um longo caminho a ser percorrido para que se possa utilizar estas como diferenciais de custo, abrindo caminho para a consideração de tal tema na avaliação de alternativas de geração de energia.

Haja vista a ocorrência da reunião de Copenhague e a grande expectativa relacionada à concretização de acordos quanto à redução de emissões, há de se considerar a possibilidade de uma variação na cotação das RCE e de maiores subsídios para a produção através de fontes menos poluentes. Desta forma, entende-se que tais variações poderiam compor análises futuras no intuito de se efetuar as comparações propostas por este estudo. 


\section{REFERÊNCIAS BIBLIOGRÁFICAS}

ADVFN Portal Financeiro. (Outubro de 2009). Acesso em Novembro de 2009, disponível em ADVFN Portal Financeiro:

http://metamaster.blogs.advfn.com/2009/10/30/fechamento-de-outubro-2009/

ANEEL - Agência Nacional de Energia Elétrica. (2008). Atlas de Energia Elétrica do Brasil. Brasília.

ANP. (2009). Agência Nacional do Petróleo, Gás Natural e Biocombustíveis. Acesso em Novembro de 2009, disponível em ANP: http://www.anp.gov.br/

Araujo, A. C. (2007). Tese (Doutorado em Ciências em Planejamento Energético) Programa de Pós Graduação de Engenharia. Perdas e Inadimplência na Atividade de Distribuição de Energia Elétrica no Brasil . Rio de Janeiro, RJ, Brasil: Universidade Federal do Rio de Janeiro.

Areva Koblitz. (s.d.). Acesso em Novembro de 2009, disponível em http://www.koblitz.com.br/

Bermann, C. (2003). Energia no Brasil: Para quê? Para quem? São Paulo: FASE.

Bosmin. (2007). Pesqueiro PCH. Castrolândia, Paraná, Brasil.

Boyle, G. (2000). Renewable Energy: Power for a System Future. Oxford University Press and The Open University.

Camargo, I. M. (1998). Noções básicas de engenharia econômica: aplicações ao setor elétrico. Brasília: FINATEC.

CELTINS. (2009). REDE ENERGIA. Acesso em Novembro de 2009, disponível em CELTINS: http://www.gruporede.com.br/Celtins/

Comissão Européia. (2001). Acesso em Outubro de 2009, disponível em Externe Information System: http:/www.externe.info

CRESESB. (2001). Atlas do Potencial Eólico Brasileiro. Brasília.

Dixon, J., Scura, L., Carpenter, R., \& Sherman, P. (1994). Economic Analysis of Environmental Impacts. Londres: Earthscan Publications Ltd.

ELETROBRAS. (2009). Acesso em Novembro de 2009, disponível em Site da Eletrobrás: http://www.eletrobras.gov.br

European Photovoltaic Industry Association - EPIA. (2009). Acesso em Novembro de 2009, disponível em European Photovoltaic Industry Association: http://www.epia.org/

European Renewable Energy Council (EREC). (2005). Acesso em Novembro de 2009, disponível em http://erec-renewables.org/publications/scenario_2040.htm 
Figueroa, F. E. (1996). Dissertação de Mestrado. Avaliação Econômica de Ambientes Naturais - O Caso das Áreas Alagadas - Uma Proposta para a Represa do Lobo. Itirapina, SP, Brasil: UFSCar.

FinanceOne. (s.d.). Acesso em Novembro de 2009, disponível em Site da FinanceOne: http://www.financeone.com.br/histdolar

Friedrich, R., \& Bickel, P. (2001). Estimation of External Costs Using the ImpactPathway-Approach. Stuttgart: Universidade de Stuttgart.

Gadrey, J., \& Jany-Catrice, F. (2006). O Novos Indicadores de Riqueza. São Paulo: SENAC.

Greanpeace; Global Wind Energy Council. (2008). Global Wind Energy Outlook. Acesso em Novembro de 2009, disponível em Global Wind Energy Council: http://www.gwec.net

IAEA - International Atomic Energy Agency. (s.d.). Acesso em Novembro de 2009, disponível em Site da International Atomic Energy Agency: http://www.iaea.org/

IEA - International Energy Agency. (2009). Acesso em Outubro de 2009, disponível em International Energy Agency: http://www.iea.org/

IEA - International Energy Agency. (2009). Key World Energy Statistics. Paris.

Instituo EDP. (s.d.). Acesso em Novembro de 2009, disponível em Site do Instituto EDP: http://www.institutoedp.com.br/institutoedp/credito_carbono/credito_carbono.asp

Kreith, F., \& Kreider, J. F. (1985). Principles of Solar Engineering. Filadélfia: Taylor \& Francis.

Krupnick, A. J., \& Burtraw, D. (1997). The Social Costs of Eletricity: Do the Numbers Add Up? Resources for the Future.

Lascio, M. A. (2007). Notas de Aula: Planejamento Energético. Brasília, Distrito Federal, Brasil: Universidade de Brasíllia - Departamento de Engenharia Elétrica.

Martins, Á., Fernandes, M., Rodrigues, V., \& Ramos, T. (1998). The National Implementation in the EU of the Externe Accounting Framework. Lisboa.

Merico, L. F. (1996). Introdução a Economia Ecológica. Blumenau: EDIFURB.

MME - Ministério de Minas de Energia. (2009). Acesso em 2009, disponível em Site do Programa Luz para Todos: http://luzparatodos.mme.gov.br/luzparatodos/

MME. (2004). Consulta Pública para Contribuições quanto a Metodologia e Parâmetros Utilizados para os Valores de Referência. Brasília, DF, Brasil.

OANDA - Olsen and Associate. (s.d.). Acesso em Novembro de 2009, disponível em OANDA, The Currency Site: http://www.oanda.com/currency/historical-rates 
ONS - Operador Nacional do Sistema Elétrico. (s.d.). Acesso em Outubro de 2009, disponível em Site da ONS: http://www.ons.org.br

OTA - Office of Technology Assessment. (1994). Studies of the Environmental Costs of Eletricity. Washington: U.S. Government Printing Office.

PETROBRÁS. (s.d.). Petrobrás. Acesso em Novembro de 2009, disponível em http://www.petrobras.com.br

PNUD - Programa das Nações Unidas para o Desenvolvimento. (2009). Acesso em Outubro de 2009, disponível em Site do PNUD: http://www.pnud.org.br

Portal Brasil. (2009). Acesso em Novembro de 2009, disponível em Site do Portal Brasil: http://www.portalbrasil.net/igpm.htm

Queiroz, H. (2007). Economia da Energia: Fundamentos Econômicos, Evolução Histórica e Organização Industrial. Rio de Janeiro: Elsevier.

Ramage, J., \& Scurlock, J. B. (1996). Renewable Energy: Power for a Sustainable Future. New York: Oxford University Press.

REN 21. (2007). Renewables 2007 - Global Status Report.

RTS - Rede de Tecnologia Social. (s.d.). Acesso em Novembro de 2009, disponível em Site da Rede de Tecnologia Social: http://www.rts.org.br/

Santos, R., Martinho, S., \& Antunes, P. (2001). Estudo Sobre o Sector Eléctrico e Ambiente: Avaliação Econômica dos Impactes Ambientais do Sector Eléctrico. Lisboa.

Severino, M. M. (2008). Tese de Doutorado em Engenharia Elétrica. Avaliação TécnicoEconômica de um Sistema Híbrido de Geração Distribuída para Atendimento a Comunidades Isoladas da Amazônia . Brasília, DF, Brasil: Universidade de Brasília.

Souza, H. M. (2002). Apresentação: I Seminário RIO-BRASIL: O Desafio da Energia Eólica. Alternativas Energéticas: Solar e Eólica . Rio de Janeiro, RJ, Brasil.

Stefano, F. (2008). Do bagaço ao megawatt. Revista Exame .

Tomalsquim, M. T. (2003). Fontes Renováveis de Energia no Brasil. Rio de Janeiro: Interciência.

Veronese, H. D. (2004). Trabalho de Conclusão de Curso (Graduação em Engenharia Elétrica) - Departamento de Engenharia Elétrica. Análise Econômico-Financeira de Fontes Alternativas no Atendimento a uma Carga Isolada Considerando Incertezas . Brasília, DF, Brasil: Universidade de Brasília.

Weingrill, N. (2007). Qual a diferença entre o álcool de cana e o de milho? Super Interessante . 


\section{APÊNDICES}

APÊNDICE I

APÊNDICE II

APÊNDICE III
PROGRAMAS GOVERNAMENTAIS

CORREÇÕES DE VALORES PELO IGP-M

ATUALIZAÇÃO DAS ESTIMATIVAS DE

CUSTOS AMBIENTAIS 


\section{APÊNDICE I - PROGRAMAS GOVERNAMENTAIS}

\section{Programa de Incentivo as Fontes Alternativas de Energia (PROINFA)}

Este programa foi criado em 26 de abril de 2002, através da Lei n. ${ }^{0} 10.438 / 2002$ e foi revisado pela Lei n. ${ }^{\circ}$ 10.762/2003, com o intuito de promover o incentivo à produção de energia elétrica por meio de fontes alternativas diversificando a matriz energética nacional, reduzir a emissão de GEEs e valorizar as características e potencialidades regionais no intuito de gerar novos empregos, capacitação e mão de obra qualificada.

Com o suporte do BNDES, que criou um programa de investimento em fontes alternativas renováveis de energia elétrica, o PROINFA previa a instalação de $3.300 \mathrm{MW}$ de capacidade que seriam integrados ao SIN. As fontes contempladas são PCH, biomassa e eólica. Onde a energia produzida pelas usinas geradoras é comprada pela ELETROBRÁS, com garantia de aquisição pelos primeiros 20 anos de operação das mesmas.

Além do intuito explicitado anteriormente, com este programa e seus 144 projetos contratados (19 Estados) se esperava a criação de 15.000 empregos diretos e indiretos, a diversificação dos produtores e de fontes de energia, absorção de novas tecnologias e a complementaridade, tendo em vista a sazonalidade da energia hídrica, já que esta responde por mais de $90 \%$ da geração de energia elétrica e por aproximadamente $42 \%$ da matriz energética nacional.

O programa tinha como meta a sua plena operação até o final de 2006, porém este prazo já foi prorrogado para 2008 e até o momento pelas pesquisas realizadas em estudos da ANEEL e ELETROBRÁS o programa deverá continuar a ser estendido até 2010. Pois o projeto encontrou diversos entraves desde sua criação, grande exemplo disso é que impulsionado pelo racionamento, após sua criação a legislação demorou aproximados dois anos para ser ajustada, muitos projetos foram concentrados em um único empreendedor, houve necessidade de revisão das concessões bem como dos projetos pelos novos sócios e a oferta de atendimento pelo parque industrial não acompanhou a demanda que se necessitava para as fontes contempladas (um exemplo claro é o da energia eólica que é 
ineficiente em atender a demanda de aero geradores, devido a escassez de fabricantes no Brasil), bem como surgiram entraves relativos a licenças ambientais e a conexão à rede.

Existia a perspectiva de que em 2009 o programa atendesse $10 \%$ do consumo anual de energia elétrica do país, com o fornecimento através de fontes alternativas, porém o programa atingiu até agosto de 2009 somente a marca de 87 empreendimentos em operação, totalizando 1.825,26 MW (925,54 MW em PCH, 514,34 MW em Biomassa, 385,38 MW em Eólica), marco negativo já que o total previsto é de 144 empreendimentos.

Sendo que 18 usinas (184,03 MW) que entraram em operação em 2009, estão aguardando regularização para operação comercial. Observa-se que o potencial instalado ultrapassa até o momento $55,31 \%$ do total de geração previsto para o programa.

A capacidade instalada pelo programa até o momento não corresponde a $60 \%$ da capacidade de usinas do SIN como Ilha Solteira e Xingó, conforme pode ser observado pelo gráfico abaixo, motivos pelos quais o PROINFA foi prorrogado até dezembro de 2010, através da Lei 11.943/2009.

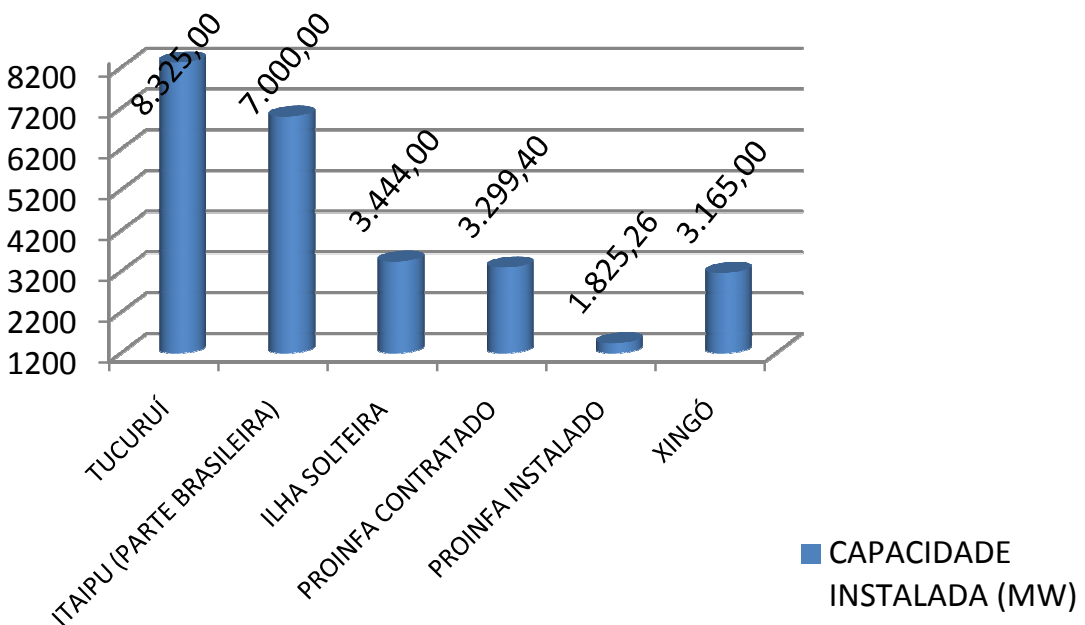

Elaboração própria, à partir de dados do Operador Nacional do Sistema Elétrico (ONS) ${ }^{32}$.

Gráfico A I.1 - Comparação de capacidade instalada SIN e PROINFA contratada/instalada.

\footnotetext{
${ }^{32}$ Para Itaipu não se considera a energia adquirida do Paraguai, e sim somente as turbinas pertencentes à parcela brasileira do empreendimento.
} 
A Tabela A I.1 abaixo apresenta o potencial e a quantidade de centrais contratadas e em operação até agosto de 2009, segundo dados da ELETROBRÁS e MME.

Tabela A I.1 - PROINFA resultados consolidados.

\begin{tabular}{|l|r|r|r|r|r|r|}
\hline \multicolumn{1}{|c|}{ FONTE } & $\begin{array}{c}\text { QUANTIDADE } \\
\text { DE CENTRAIS } \\
\text { CONTRATADAS }\end{array}$ & $\begin{array}{c}\text { POTÊNCIAL } \\
\text { CONTRATADO } \\
\text { (MW) }\end{array}$ & $\begin{array}{c}\text { QUANTIDADE } \\
\text { DE CENTRAIS } \\
\text { EM OPERAÇÃO }\end{array}$ & $\begin{array}{c}\text { POTÊNCIAL } \\
\text { EM OPERAÇÃO } \\
\text { (MW) }\end{array}$ & $\begin{array}{c}\text { QUANTIDADE } \\
\text { DE CENTRAIS EM } \\
\text { CONSTRUÇÃO }\end{array}$ & $\begin{array}{c}\text { POTENCIAL EM } \\
\text { CONSTRUÇÃO } \\
\text { (MW) }\end{array}$ \\
\hline PCHS & 63 & $1.191,24$ & 46 & 925,54 & 15 & 1 \\
\hline BIOMASSA & 27 & 685,24 & 20 & 514,34 & 34 \\
\hline EÓLICA & 54 & $1.422,92$ & 23 & 385,38 & 14 & \\
\hline TOTAL & $\mathbf{1 4 4}$ & $\mathbf{3 . 2 9 9 , 4}$ & $\mathbf{8 9}$ & $\mathbf{1 . 8 2 5 , 2 6}$ & $\mathbf{3 4 5 , 8}$ \\
\hline
\end{tabular}

Fonte: ELETROBRÁS e MME, Coordenação Geral de Fontes Alternativas.

As informações prestadas a respeito do PROINFA foram retiradas de consultas ao site do MME e ELETROBRÁS, e têm por objetivo acrescentar informações quanto à evolução deste programa governamental subsidiando dados utilizados ao longo deste estudo. A seguir podem ser observadas algumas informações prestadas pelo MME relativas aos resultados apresentados pelo programa até agosto de 2009. 


\section{USINAS CONTRATADAS RESUMO GERAL}

\begin{tabular}{|c|c|c|c|c|c|c|c|c|c|c|c|c|c|c|c|}
\hline \multirow{2}{*}{ Fonte } & & \multirow{2}{*}{\multicolumn{2}{|c|}{$\begin{array}{c}\text { Operaçäo comercial } \\
\text { pelo PROINFA }\end{array}$}} & \multirow{3}{*}{$\begin{array}{c}\text { Concluidas } \\
\text { aguardando } \\
\text { regularizaçaão } \\
\text { op.comercial } \\
\text { pelo Proinfa } \\
0\end{array}$} & \multirow{2}{*}{\multicolumn{2}{|c|}{ Em construçäo }} & \multicolumn{6}{|c|}{ Nâo Iniciada construção } & \multirow{2}{*}{\multicolumn{2}{|c|}{$\begin{array}{l}\text { Sub judicel em } \\
\text { rescisão } \\
\text { contratual }\end{array}$}} & \multirow{2}{*}{$\begin{array}{l}\text { TOTAL } \\
\text { contratado }\end{array}$} \\
\hline & & & & & & & \multicolumn{2}{|c|}{ Com EPC } & \multicolumn{2}{|c|}{ Sem EPC } & \multicolumn{2}{|c|}{ Total } & & & \\
\hline \multirow{2}{*}{ PCH } & Qde & 48 & $73,0 \%$ & & 15 & $23,8 \%$ & 0 & $0,0 \%$ & 1 & $1,6 \%$ & 1 & $1.6 \%$ & 1 & $1,6 \%$ & 63 \\
\hline & MW & 825,54 & $77,7 \%$ & 0,00 & 249,00 & $20,8 \%$ & 0,00 & $0,0 \%$ & 6,70 & $0,8 \%$ & 6,70 & $0,6 \%$ & 10,00 & $0,8 \%$ & $1.181,24$ \\
\hline \multirow{2}{*}{ BIOMASSA } & Qde & 19 & $70,4 \%$ & $t^{\prime}$ & 1 & $3,7 \%$ & 0 & $0,0 \%$ & 0 & $0,0 \%$ & 0 & $0,0 \%$ & 6 & $22,2 \%$ & 27 \\
\hline & MW & 504,34 & $73,6 \%$ & 10,00 & 36,00 & $5,3 \%$ & 0,00 & $0,0 \%$ & 0,00 & $0,0 \%$ & 0,00 & $0,0 \%$ & 134,90 & $19,7 \%$ & 685,24 \\
\hline \multirow{2}{*}{ EOLICA } & Qde & 23 & $42,6 \%$ & 0 & 14 & $25,9 \%$ & 14 & $25,9 \%$ & 3 & $5.6 \%$ & 17 & $31,5 \%$ & 0 & $0,0 \%$ & 54 \\
\hline & MW & 385,38 & $27,1 \%$ & 0,00 & 445,80 & $31,3 \%$ & 381,34 & $26,8 \%$ & 210,40 & $14,8 \%$ & 591,74 & $41,6 \%$ & 0,00 & $0,0 \%$ & $1.422,92$ \\
\hline \multirow{2}{*}{$\begin{array}{c}\text { TOTAL } \\
\text { CONTRATADO }\end{array}$} & Qde & 88 & $61.1 \%$ & 1 & 30 & $20.8 \%$ & 14 & $9,7 \%$ & 4 & $2.8 \%$ & 18 & $12,5 \%$ & 7 & $4.9 \%$ & 144 \\
\hline & MW & $1.815,26$ & $55,0 \%$ & 10.00 & 730,80 & $22,1 \%$ & 381,34 & $11,6 \%$ & 217,10 & $6.6 \%$ & 598,44 & $18,1 \%$ & 144,90 & $4,4 \%$ & $3.299,40$ \\
\hline \multirow{2}{*}{ Sub total PCH } & Qde & & & 81 & & $96,8 \%$ & & & & & & & 2 & $3,2 \%$ & 63 \\
\hline & MW & & & 1.175 & & $98,6 \%$ & & & & & & & 17 & $1,4 \%$ & $1.191,24$ \\
\hline \multirow{2}{*}{ Sub total BiO } & Qde & & & 21 & & $77,8 \%$ & & & & & & & 6 & $22,2 \%$ & 27 \\
\hline & MW & & & 550 & & $80,3 \%$ & & & & & & & 135 & $19,7 \%$ & 685,24 \\
\hline \multirow{2}{*}{ Sub total EOL } & Qde & & & 37 & & $88,5 \%$ & & & & & & & 17 & $31.5 \%$ & 54 \\
\hline & MW & & & 831 & & $58,4 \%$ & & & & & & & 592 & $41,6 \%$ & $1.422,82$ \\
\hline \multirow{2}{*}{ Sub total Geral } & Qde & & & 119 & & $82,6 \%$ & & & & & & & 25 & $17,4 \%$ & 144 \\
\hline & MW & & & $.556,06$ & & $77,5 \%$ & & & & & & & 743 & $22,5 \%$ & $3.299,40$ \\
\hline
\end{tabular}

Fonte: MME, 08/2009. 


\section{Qranisa \\ EM OPERAÇÃO COMERCIAL}

\begin{tabular}{|l|l|c|c|c|c|c|c|}
\hline \multirow{2}{*}{ FONTE } & \multicolumn{3}{|c|}{ Em operação } & \multicolumn{2}{c|}{ TOTAL } \\
\cline { 2 - 8 } & Qde & MW & $\%$ & Qde & MW \\
\hline PCH & 46 & 925,54 & $73 \%$ & 63 & 1.191 \\
\hline BIOMASSAS & 20 & 514,54 & $75 \%$ & 27 & 085 \\
\hline EÓLICAS & 23 & 385,38 & $27 \%$ & 54 & 1.423 \\
\hline TOTAI & 89 & $\mathbf{1 8 2 5 , 2 6}$ & $5.5 \%$ & $\mathbf{1 4 4}$ & $\mathbf{3 2 9 . 9}$ \\
\hline
\end{tabular}

\begin{tabular}{|c|c|}
\hline $\begin{array}{l}\text { PCH Canoa Quebrada } \\
\text { PCHEng. José Gelásio da Foct } \\
\text { PCHRondonópolis } \\
\text { PCH Senador Jonas Pinheiro } \\
\text { PCHZé Fernando }\end{array}$ & \\
\hline $\begin{array}{l}\text { PCH Irara } \\
\text { PCH Jatai } \\
\text { PCH Mambaill } \\
\text { PCH Mosquitäo } \\
\text { PCH Piranhas } \\
\text { PCH Retiro Velho } \\
\text { UTE Goiasa Goiatuba Alcool } \\
\text { UTE Jalles Nachado }\end{array}$ & \\
\hline
\end{tabular}

\begin{tabular}{|lr|}
\hline PCH Alto Sucuriú & MS \\
PCH Aquarius & MS \\
PCHBuriti & MS \\
PCHPonte filta & MS \\
\hline
\end{tabular}

UTEEcoluz $\quad P R$ UTE Usaciga
UTE WINIMPORT

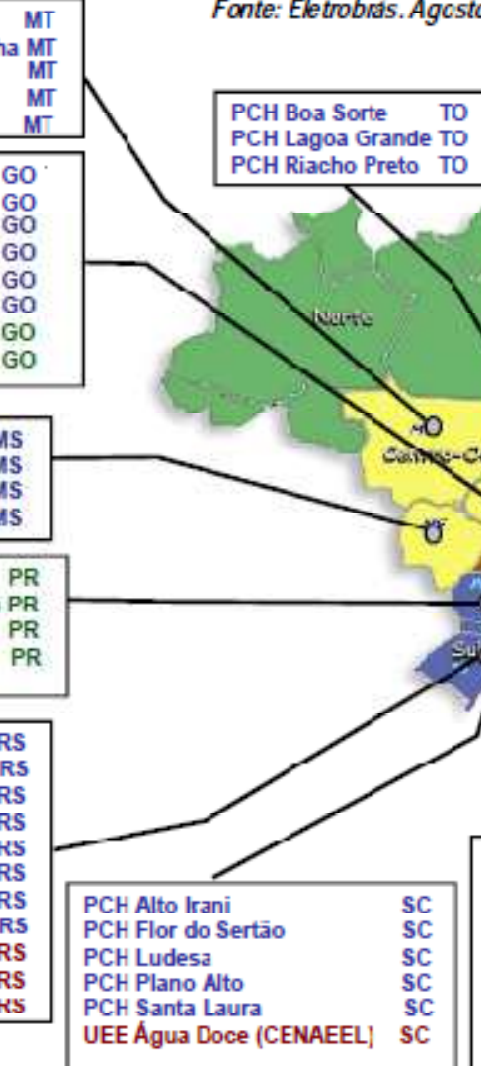

PCH Caçador PCH Carlos Gonzatto PCH Cotipor

PCH tesmerald

PCH Jararaca

PCH Linha Emília

UEEDos indios

UEEOsório

UEE Osorio
UtE Sangradouro

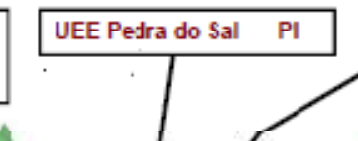

UEE Beberibe

CE EEE For do Rio Choró $\quad$ CE

\begin{tabular}{|ll|}
\hline IITFGiaca II & PR \\
UEE Allatroz & PB \\
UEE Atlaticica & PB \\
IIFF Camurim & PR \\
UEE Caravela & PB \\
UEE Coelhos I & PB \\
UEE Coolhos II & PB \\
UEE Coelhos III & PB \\
UEE Coethos IV & PB \\
IIFF Mataraca & PR \\
UEE Millennium & PB \\
UEEPresiderte & PB \\
\hline
\end{tabular}

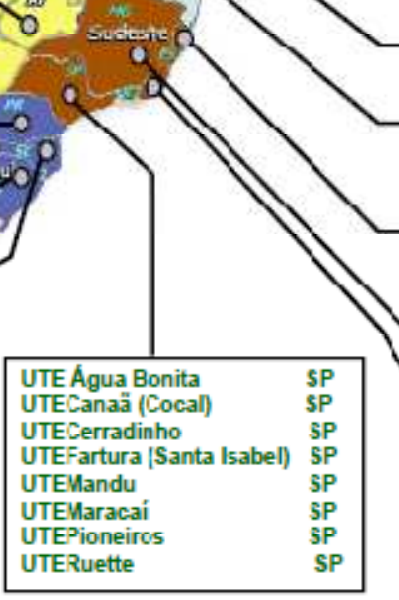

UTElolando Leite SE

PCH Cachoeira da Lixa BA $\mathrm{PCH}$ Coline 1
$\mathrm{PCH}$ Coline 2 $B A$ PCH Fumbia IV ES $\begin{array}{ll}\text { PCH São Pedro } & \text { ES } \\ \text { PCH צãu Simaãu } & \text { ES }\end{array}$ PCH Carangola PCH Cocais Grande

rCII Calheiros
PCH Monte Serr

$\begin{array}{lll}\text { PCH Santa Fé } & \text { RJ } \\ \text { rClI Santa Rosa II } & \text { RJ }\end{array}$

RJ

MG

Fonte: MME, 08/2009. 
EM CONSTRUÇĀOO

\begin{tabular}{|l|c|c|c|c|c|}
\hline \multirow{2}{*}{ FONTE } & \multicolumn{2}{|c|}{ Em construção } & \multicolumn{2}{c|}{ TOTAL } \\
\cline { 2 - 6 } & Qde & MW & $\%$ & Qde & MW \\
\hline PCH & 15 & 249,00 & $21 \%$ & 63 & 1.191 \\
\hline BIOMASSAS & 1 & 36,00 & $5 \%$ & 27 & 685 \\
\hline EOLICAS & 14 & 445,80 & $31 \%$ & 54 & 1.423 \\
\hline TOTAL & 30 & 730,80 & $22 \%$ & 144 & 3.299 \\
\hline
\end{tabular}

Fonte: Eletrobruss. Agostol 2009

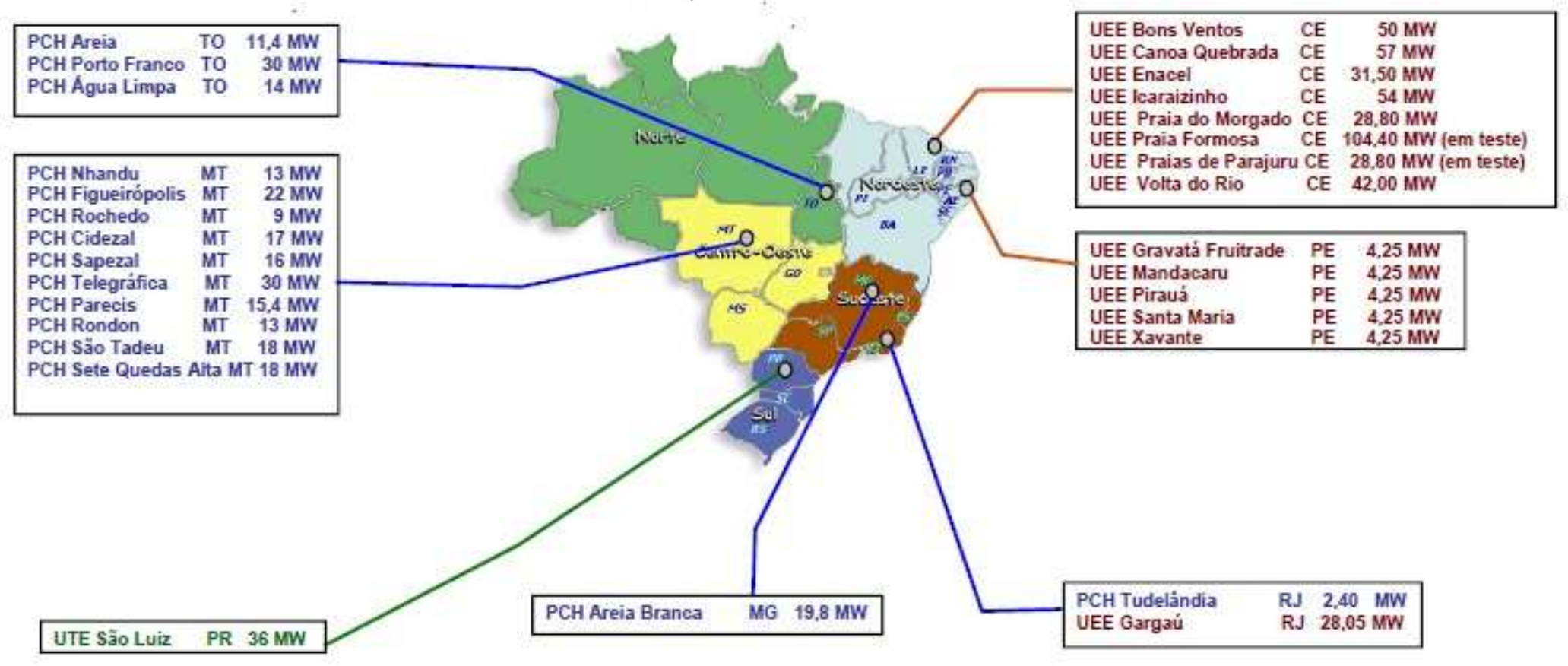

Fonte: MME, 08/2009. 


\section{Pranive \\ NÃO INICIADA A CONSTRUÇÃO}

\begin{tabular}{|l|c|c|c|c|c|}
\hline \multirow{2}{*}{ FONTE } & \multicolumn{3}{|c|}{$\begin{array}{c}\text { Năo iniciada a } \\
\text { construçäo }\end{array}$} & \multicolumn{2}{c|}{ TOTAL } \\
\cline { 2 - 6 } & Qde & MW & $\%$ & Qde & MW \\
\hline PCH & 1 & 6,70 & $1 \%$ & 63 & 1.191 \\
\hline BIOMASSAS & 0 & 0,00 & $0 \%$ & 27 & 685 \\
\hline EOLICAS & 17 & 591,74 & $42 \%$ & 54 & 1.423 \\
\hline TOTAL & 18 & 598,44 & $18 \%$ & 144 & 3.299 \\
\hline
\end{tabular}

Fonte: Eletrobras. Agosto 2009

$\begin{array}{ll}\text { UEE Aquibatä } & \text { SC } \\ \text { UEE Bom Jardim } & \text { SC } \\ \text { UEE Campo Belo } & \text { SC } \\ \text { UEE Cascata } & \text { SC } \\ \text { UEE Cruz Alta } & \text { SC } \\ \text { UEE Púlpito } & \text { SC } \\ \text { UEE Rio do Ouro } & \text { SC } \\ \text { UEE Salto } & \text { SC } \\ \text { UEE Santo Antônio } & \text { SC } \\ \text { PCH Salto das Flores } & \text { SC }\end{array}$

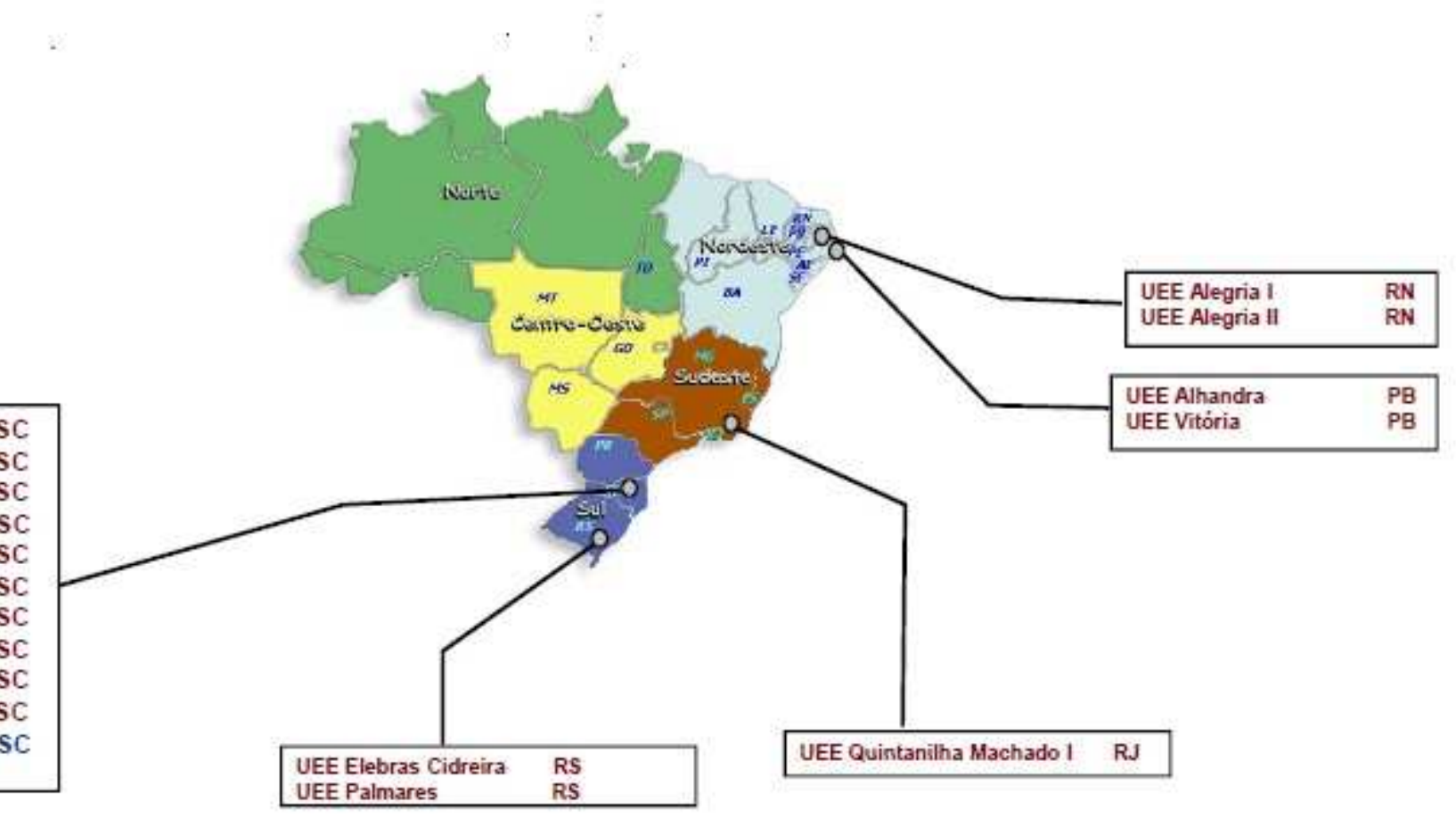

Fonte: MME, 08/2009. 


\section{Programa Nacional de Universalização do Acesso e Uso da Energia Elétrica (LUZ}

\section{PARA TODOS)}

Tal programa foi instituído pelo Decreto de Lei n. ${ }^{\circ}$ 4.873/2003 e é coordenado pelo MME com participação da ELETROBRÁS e de suas empresas controladas e tem por objetivo levar energia elétrica as comunidades sem acesso a esta, localizadas principalmente em municípios com baixo IDH, de forma a utilizar a energia como um balizador para o desenvolvimento socioeconômico destas comunidades, contribuindo para a redução da pobreza, aumento da renda familiar e do bem-estar. Facilitando a integração da comunidade com outros programas sociais que viabilizam serviços de saúde, educação e saneamento básico.

A meta inicial do programa era de levar eletricidade a mais de 2 milhões de residências no meio rural, em um prazo de 5 anos (2008), entretanto tal prazo foi prorrogado até 2010 tendo em vista a existência de demanda adicional a prevista quando do lançamento do programa. Estima-se que o atendimento será ampliado em 50\%, levando eletricidade a 3 milhões de residências.

Os recursos financeiros necessários para o programa são provenientes do governo federal, por meio da CDE e da Reserva Global de Reversão (RGR), dos governos dos estados envolvidos e dos agentes executores. Sendo que a CDE disponibiliza recursos a fundo perdido (subvenção econômica), assim como os recursos provenientes dos governos estaduais, enquanto os recursos da RGR são disponibilizados na forma de financiamento.

As alternativas de atendimento das cargas se dão através de 3 opções: (a) extensão da rede; (b) sistemas de geração descentralizada com redes isoladas; (c) sistemas de geração individuais.

Importante ressaltar que o programa observa as seguintes prioridades ${ }^{33}$ : (a) projetos de eletrificação rural paralisados, por falta de recursos, que atendam comunidades e povoados rurais; (b) municípios com índice de atendimento a domicílio inferior a 85\%, calculado com base no Censo 2000; (c) municípios com IDH inferior à média estadual; (d)

\footnotetext{
${ }^{33}$ A lista de prioridades está presente no site do programa Luz para Todos do MME. Disponível em $\langle$ http://luzparatodos.mme.gov.br/luzparatodos/>.
} 
comunidades atingidas por barragens de usinas hidroelétricas ou por obras do sistema elétrico; (e) projetos que enfoquem o uso produtivo da energia elétrica e que fomentem o desenvolvimento local integrado; (f) escolas públicas, postos de saúde e poços de abastecimento d'água; (g) assentamentos rurais; (h) projetos para desenvolvimento da agricultura familiar ou de atividades de artesanato de base familiar; (i) atendimento de pequenos e médios agricultores; (j) populações do entorno de unidades de Conservação da Natureza; e (k) populações em áreas de uso específico de comunidades especiais, tais como minorias raciais, comunidades remanescentes de quilombos e comunidades extrativistas.

O Luz para Todos, alcançou em junho de 2009 a meta inicial de 2 milhões de residências atendidas com eletricidade e segundo informações do MME, a meta de instalação da demanda adicional de 1 milhão de residências deve ser concluída até setembro de 2010.

Ficam evidentes as melhorias sociais propiciadas pelo programa, uma vez que ao propiciar o acesso à energia elétrica, a qualidade de vida no campo é melhorada, favorecendo a permanência das famílias no campo. Os consumidores passam a adquirir eletrodomésticos e equipamentos rurais elétricos, permitindo o aumento da renda, melhoria do saneamento básico, saúde e o fortalecimento do capital social das localidades atendidas.

Estima-se também que, aproximadamente, 300 mil empregos, diretos e indiretos são gerados em conseqüência da implantação do programa, que dá prioridade ao uso de mãode-obra local e à compra de materiais e equipamentos nacionais fabricados nas regiões próximas a localidade a ser atendida.

Em pesquisa realizada pelo Instituto de Pesquisa Econômica Aplicada (IPEA) no ano de $2006^{34}$, constata-se que houve um aumento considerável na aquisição de eletrodomésticos em residências atendidas pelo Luz para Todos. Outro ponto interessante da pesquisa diz respeito ao êxodo rural, pois $23,1 \%$ dos entrevistados afirmaram que pelo menos um dos familiares deixaria o campo caso não tivessem acesso a eletricidade.

Levando em consideração a meta de aproximadamente 3 milhões de unidades atendidas, isso significaria que até o final de 2010 aproximadamente 700 mil pessoas podem

\footnotetext{
${ }^{34}$ Pesquisa sob coordenação do Ministério de Minas e Energia.
} 
permanecer na zona rural por causa das melhores perspectivas oferecidas através do acesso a energia.

Segundo a EPE, em 2007 foram realizadas mais de 1,8 milhões de ligações residenciais, em parte devido ao crescimento vegetativo da população, porém em sua grande maioria devido ao programa Luz para Todos. Podemos observar através da tabela abaixo que apesar de a maior parte das ligações terem ocorrido na região Sudeste, o maior impacto ocorreu nas regiões Norte e Nordeste, principais alvos do programa, juntamente com a região Centro-Oeste.

Tabela A I.2 - Unidades consumidoras - variação 2006/2007.

\begin{tabular}{|c|c|c|c|c|}
\hline \multirow{2}{*}{ Reglâo } & \multirow{2}{*}{2006} & \multirow{2}{*}{2007} & \multicolumn{2}{|c|}{ varlaçäo } \\
\hline & & & absoluta & $\%$ \\
\hline Norte & 2.620 & 2.745 & 125 & 4,8 \\
\hline Sudeste & 21.390 & 25.101 & 702 & 2,9 \\
\hline Sul & 7.319 & 7.520 & 201 & 2,8 \\
\hline Centro-Oeste & 3.579 & 3.703 & 125 & 3,5 \\
\hline
\end{tabular}

Fonte: EPE, 2008. Valores em 1.000 unidades. 


\section{APÊNDICE II - CORREÇÕES DE VALORES PELO IGP-M}

O IGP-M é calculado mensalmente pela Fundação Getúlio Vargas (FGV) e é divulgado no final de cada mês de referência. Foi criado inicialmente para ser um indicador que balizaria as correções de alguns títulos emitidos pelo Tesouro Nacional e Depósitos Bancários com renda pós-fixada acima de um ano. Posteriormente passou a ser o índice utilizado para a correção de contratos de aluguel e como indexador das tarifas de energia elétrica (Portal Brasil, 2009).

É composto pelo Índice de Preços por Atacado (IPA), que tem peso de $60 \%$ do índice, o Índice de Preços ao Consumidor (IPC), que tem peso de $30 \%$ do índice e pelo Índice Nacional de Custo da Construção (INCC), representando 10\% do índice. E, a cada dez dias a FGV divulga as variações prévias que comporão o índice referente ao período completo analisado.

Tabela A II.1 - Dados do IGP-M simplificado, 1995 até outubro de 2009.

\begin{tabular}{|r|r|r|r|r|r|r|r|r|r|r|r|r|r|}
\hline & JAN & FEV & MAR & ABR & MAI & JUN & JUL & AGO & SET & OUT & NOV & DEZ & ACUMULADO \\
\hline $\mathbf{1 9 9 5}$ & 0,92 & 1,39 & 1,12 & 2,10 & 0,58 & 2,46 & 1,82 & 2,20 & $-0,71$ & 0,52 & 1,20 & 0,71 & $15,23 \%$ \\
\hline $\mathbf{1 9 9 6}$ & 1,73 & 0,97 & 0,40 & 0,32 & 1,55 & 1,02 & 1,35 & 0,28 & 0,10 & 0,19 & 0,20 & 0,73 & $9,18 \%$ \\
\hline $\mathbf{1 9 9 7}$ & 1,77 & 0,43 & 1,15 & 0,68 & 0,21 & 0,74 & 0,09 & 0,09 & 0,48 & 0,37 & 0,64 & 0,84 & $7,73 \%$ \\
\hline $\mathbf{1 9 9 8}$ & 0,96 & 0,18 & 0,19 & 0,13 & 0,14 & 0,38 & $-0,17$ & $-0,16$ & $-0,08$ & 0,08 & $-0,32$ & 0,45 & $1,78 \%$ \\
\hline $\mathbf{1 9 9 9}$ & 0,84 & 3,61 & 2,83 & 0,71 & $-0,29$ & 0,36 & 1,55 & 1,56 & 1,45 & 1,70 & 2,39 & 1,81 & $20,10 \%$ \\
\hline $\mathbf{2 0 0 0}$ & 1,24 & 0,35 & 0,15 & 0,23 & 0,31 & 0,85 & 1,57 & 2,39 & 1,16 & 0,38 & 0,29 & 0,63 & $9,95 \%$ \\
\hline $\mathbf{2 0 0 1}$ & 0,62 & 0,23 & 0,56 & 1,00 & 0,86 & 0,98 & 1,48 & 1,38 & 0,31 & 1,18 & 1,10 & 0,22 & $10,37 \%$ \\
\hline $\mathbf{2 0 0 2}$ & 0,36 & 0,06 & 0,09 & 0,56 & 0,83 & 1,54 & 1,95 & 2,32 & 2,40 & 3,87 & 5,19 & 3,75 & $25,30 \%$ \\
\hline $\mathbf{2 0 0 3}$ & 2,33 & 2,28 & 1,53 & 0,92 & $-0,26$ & $-1,00$ & $-0,42$ & 0,38 & 1,18 & 0,38 & 0,49 & 0,61 & $8,69 \%$ \\
\hline $\mathbf{2 0 0 4}$ & 0,88 & 0,69 & 1,13 & 1,21 & 1,31 & 1,38 & 1,31 & 1,22 & 0,69 & 0,39 & 0,82 & 0,74 & $12,42 \%$ \\
\hline $\mathbf{2 0 0 5}$ & 0,39 & 0,30 & 0,85 & 0,86 & $-0,22$ & $-0,44$ & $-0,34$ & $-0,65$ & $-0,53$ & 0,60 & 0,40 & $-0,01$ & $1,20 \%$ \\
\hline $\mathbf{2 0 0 6}$ & 0,92 & 0,01 & $-0,23$ & $-0,42$ & 0,38 & 0,75 & 0,18 & 0,37 & 0,29 & 0,47 & 0,75 & 0,32 & $3,84 \%$ \\
\hline $\mathbf{2 0 0 7}$ & 0,50 & 0,27 & 0,34 & 0,04 & 0,04 & 0,26 & 0,28 & 0,98 & 1,29 & 1,05 & 0,69 & 1,76 & $7,74 \%$ \\
\hline $\mathbf{2 0 0 8}$ & 1,09 & 0,53 & 0,74 & 0,69 & 1,61 & 1,98 & 1,76 & $-0,32$ & 0,11 & 0,98 & 0,38 & $-0,13$ & $9,80 \%$ \\
\hline $\mathbf{2 0 0 9}$ & $-0,44$ & 0,26 & $-0,74$ & $-0,15$ & $-0,07$ & $-0,10$ & $-0,43$ & $-0,36$ & 0,42 & 0,05 & - & - & $-1,55 \%$ \\
\hline
\end{tabular}

Fonte: Portal Brasil. Disponível em 〈http://www.portalbrasil.net/igpm.htm $>$ 
Como é de conhecimento, a divulgação do VETEF data do final de março de 2004 (resultado de consulta pública do PROINFA) e a divulgação do VN por meio da resolução 488/2002 apresenta tais valores para a vigência de junho de 2001. De forma a atualizar tais valores para a referência outubro de 2009, faz-se necessária a correção de tais valores através do IGP-M, já que tal índice é o atual balizar dos aumentos da energia elétrica. A tabela acima demonstra de forma simplificada o índice divulgado pela FGV desde 1995 para subsidiar as atualizações necessárias.

A atualização do VETEF relativo à consulta pública do MME, possuía os valores iniciais elencados na segunda linha da Tabela A II.2 abaixo. Efetuando-se a atualização de tais valores pelo IGP-M através dos índices de abril de 2004 até outubro de 2009 foi possível obter os resultados apresentados pela tabela a seguir. Os resultados apresentados para 2005, 2006, 2007 e 2008, representam o índice acumulado dos respectivos anos.

Tabela A II.2 - Correção do VETEF pelo IGP-M.

\begin{tabular}{ccccc}
\hline MÊS/ANO & IGP-M $(\%)$ & $\mathbf{P C H}$ & EÓLICA & BIO CANA \\
\hline VALOR EM MARÇO 2004 & $\mathrm{R} \$ \mathbf{1 1 7 , 0 2}$ & $\mathrm{R} \$ \mathbf{2 0 4 , 3 5}$ & $\mathrm{R} \$ \mathbf{9 3 , 7 7}$ \\
\hline Abr/04 & 1,21 & $\mathrm{R} \$ 118,44$ & $\mathrm{R} \$ 206,82$ & $\mathrm{R} \$ 94,90$ \\
\hline Mai/04 & 1,31 & $\mathrm{R} \$ 119,99$ & $\mathrm{R} \$ 209,53$ & $\mathrm{R} \$ 96,15$ \\
\hline Jun/04 & 1,38 & $\mathrm{R} \$ 121,64$ & $\mathrm{R} \$ 212,42$ & $\mathrm{R} \$ 97,47$ \\
\hline Jul/04 & 1,31 & $\mathrm{R} \$ 123,24$ & $\mathrm{R} \$ 215,21$ & $\mathrm{R} \$ 98,75$ \\
\hline Ago/04 & 1,22 & $\mathrm{R} \$ 124,74$ & $\mathrm{R} \$ 217,83$ & $\mathrm{R} \$ 99,96$ \\
\hline Set/04 & 0,69 & $\mathrm{R} \$ 125,60$ & $\mathrm{R} \$ 219,33$ & $\mathrm{R} \$ 100,6$ \\
\hline Out/04 & 0,39 & $\mathrm{R} \$ 126,09$ & $\mathrm{R} \$ 220,19$ & $\mathrm{R} \$ 101,04$ \\
\hline Nov/04 & 0,82 & $\mathrm{R} \$ 127,12$ & $\mathrm{R} \$ 222,00$ & $\mathrm{R} \$ 101,87$ \\
\hline Dez/04 & 0,74 & $\mathrm{R} \$ 128,07$ & $\mathrm{R} \$ 223,64$ & $\mathrm{R} \$ 102,62$ \\
\hline 2005 & 1,2 & $\mathrm{R} \$ 129,60$ & $\mathrm{R} \$ 226,32$ & $\mathrm{R} \$ 103,85$ \\
\hline 2006 & 3,84 & $\mathrm{R} \$ 134,58$ & $\mathrm{R} \$ 235,01$ & $\mathrm{R} \$ 107,84$ \\
\hline 2007 & 7,74 & $\mathrm{R} \$ 145,00$ & $\mathrm{R} \$ 253,20$ & $\mathrm{R} \$ 116,19$ \\
\hline 2008 & 9,8 & $\mathrm{R} \$ 159,21$ & $\mathrm{R} \$ 278,02$ & $\mathrm{R} \$ 127,57$ \\
\hline Jan/09 & $-0,44$ & $\mathrm{R} \$ 158,50$ & $\mathrm{R} \$ 276,79$ & $\mathrm{R} \$ 127,01$ \\
\hline Fev/09 & 0,26 & $\mathrm{R} \$ 158,92$ & $\mathrm{R} \$ 277,51$ & $\mathrm{R} \$ 127,34$ \\
\hline Mar/09 & $-0,74$ & $\mathrm{R} \$ 157,74$ & $\mathrm{R} \$ 275,46$ & $\mathrm{R} \$ 126,40$ \\
\hline Abr/09 & $-0,15$ & $\mathrm{R} \$ 157,50$ & $\mathrm{R} \$ 275,05$ & $\mathrm{R} \$ 126,21$ \\
\hline Mai/09 & $-0,07$ & $\mathrm{R} \$ 157,39$ & $\mathrm{R} \$ 274,85$ & $\mathrm{R} \$ 126,12$ \\
\hline Jun/09 & $-0,1$ & $\mathrm{R} \$ 157,24$ & $\mathrm{R} \$ 274,58$ & $\mathrm{R} \$ 126,00$ \\
\hline Jul/09 & $-0,43$ & $\mathrm{R} \$ 156,56$ & $\mathrm{R} \$ 273,40$ & $\mathrm{R} \$ 125,45$ \\
\hline Ago/09 & $-0,36$ & $\mathrm{R} \$ 156,00$ & $\mathrm{R} \$ 272,41$ & $\mathrm{R} \$ 125,00$ \\
\hline Set/09 & 0,42 & $\mathrm{R} \$ 156,65$ & $\mathrm{R} \$ 273,56$ & $\mathrm{R} \$ 125,53$ \\
\hline Out/09 & 0,05 & $\mathrm{R} \$ 156,73$ & $\mathrm{R} \$ 273,70$ & $\mathrm{R} \$ 125,59$ \\
\hline VALOR ATUALIZADO & $\mathrm{R} \$ \mathbf{1 5 6 , 7 3}$ & $\mathrm{R} \$ \mathbf{2 7 3 , 7 0}$ & $\mathrm{R} \$ \mathbf{1 2 5 , 5 9}$ \\
\hline
\end{tabular}


Já a atualização do VN possuía os valores apresentados na segunda linha da Tabela A II.3 Correção do VN pelo IGP-MTabela A II.3 a seguir. Efetuando a atualização de tais valores pelo IGP-M através dos índices de julho de 2001 até outubro de 2009, obteve-se o seguinte resultado. Os resultados apresentados para 2002, 2003, 2004, 2005, 2006, 2007 e 2008, representam o índice acumulado dos respectivos anos.

Tabela A II.3 - Correção do VN pelo IGP-M.

\begin{tabular}{|c|c|c|c|c|c|}
\hline MÊS/ANO & IGP-M (\%) & PCH & EÓLICA & BIOMASSA & SOLAR \\
\hline \multicolumn{2}{|c|}{ VALOR EM JUNHO 2001} & $\mathbf{R} \$ 79,29$ & $\mathbf{R} \$ 112,21$ & $\mathbf{R} \$ \mathbf{8 9 , 8 6}$ & $\mathrm{R} \$ 264,12$ \\
\hline Jul/01 & 1,48 & $\mathrm{R} \$ 80,46$ & $\mathrm{R} \$ 113,87$ & $\mathrm{R} \$ 91,19$ & $\mathrm{R} \$ 268,03$ \\
\hline Ago/01 & 1,38 & $\mathrm{R} \$ 81,57$ & $\mathrm{R} \$ 115,44$ & $\mathrm{R} \$ 92,45$ & $\mathrm{R} \$ 271,73$ \\
\hline Set/01 & 0,31 & $\mathrm{R} \$ 81,83$ & $\mathrm{R} \$ 115,80$ & $\mathrm{R} \$ 92,73$ & $\mathrm{R} \$ 272,57$ \\
\hline Out/01 & 1,18 & $\mathrm{R} \$ 82,79$ & $\mathrm{R} \$ 117,17$ & $\mathrm{R} \$ 93,83$ & $\mathrm{R} \$ 275,79$ \\
\hline Nov/01 & 1,1 & $\mathrm{R} \$ 83,70$ & $\mathrm{R} \$ 118,46$ & $\mathrm{R} \$ 94,86$ & $\mathrm{R} \$ 278,82$ \\
\hline Dez/01 & 0,22 & $\mathrm{R} \$ 83,89$ & $\mathrm{R} \$ 118,72$ & $\mathrm{R} \$ 95,07$ & $\mathrm{R} \$ 279,43$ \\
\hline 2002 & 25,3 & $\mathrm{R} \$ 105,11$ & $\mathrm{R} \$ 148,75$ & $\mathrm{R} \$ 119,12$ & $\mathrm{R} \$ 350,13$ \\
\hline 2003 & 8,69 & $\mathrm{R} \$ 114,24$ & $\mathrm{R} \$ 161,68$ & $\mathrm{R} \$ 129,47$ & $\mathrm{R} \$ 380,56$ \\
\hline 2004 & 12,42 & $\mathrm{R} \$ 128,43$ & $\mathrm{R} \$ 181,76$ & $\mathrm{R} \$ 145,56$ & $\mathrm{R} \$ 427,82$ \\
\hline 2005 & 1,2 & $\mathrm{R} \$ 129,98$ & $\mathrm{R} \$ 183,94$ & $\mathrm{R} \$ 147,30$ & $\mathrm{R} \$ 432,96$ \\
\hline 2006 & 3,84 & $\mathrm{R} \$ 134,97$ & $\mathrm{R} \$ 191,00$ & $\mathrm{R} \$ 152,96$ & $\mathrm{R} \$ 449,58$ \\
\hline 2007 & 7,74 & $\mathrm{R} \$ 145,41$ & $\mathrm{R} \$ 205,79$ & $\mathrm{R} \$ 164,80$ & $\mathrm{R} \$ 484,38$ \\
\hline 2008 & 9,8 & $\mathrm{R} \$ 159,66$ & $\mathrm{R} \$ 225,95$ & $\mathrm{R} \$ 180,95$ & $\mathrm{R} \$ 531,85$ \\
\hline Jan/09 & $-0,44$ & $\mathrm{R} \$ 158,96$ & $\mathrm{R} \$ 224,96$ & $\mathrm{R} \$ 180,15$ & $\mathrm{R} \$ 529,51$ \\
\hline Fev/09 & 0,26 & $\mathrm{R} \$ 159,37$ & $\mathrm{R} \$ 225,54$ & $\mathrm{R} \$ 180,62$ & $\mathrm{R} \$ 530,88$ \\
\hline Mar/09 & $-0,74$ & $\mathrm{R} \$ 158,19$ & $\mathrm{R} \$ 223,87$ & $\mathrm{R} \$ 179,28$ & $\mathrm{R} \$ 526,96$ \\
\hline Abr/09 & $-0,15$ & $\mathrm{R} \$ 157,96$ & $\mathrm{R} \$ 223,54$ & $\mathrm{R} \$ 179,01$ & $\mathrm{R} \$ 526,17$ \\
\hline Mai/09 & $-0,07$ & $\mathrm{R} \$ 157,85$ & $\mathrm{R} \$ 223,38$ & $\mathrm{R} \$ 178,89$ & $\mathrm{R} \$ 525,80$ \\
\hline Jun/09 & $-0,1$ & $\mathrm{R} \$ 157,69$ & $\mathrm{R} \$ 223,16$ & $\mathrm{R} \$ 178,71$ & $\mathrm{R} \$ 525,27$ \\
\hline Jul/09 & $-0,43$ & $\mathrm{R} \$ 157,01$ & $\mathrm{R} \$ 222,20$ & $\mathrm{R} \$ 177,94$ & $\mathrm{R} \$ 523,01$ \\
\hline Ago/09 & $-0,36$ & $\mathrm{R} \$ 156,45$ & $\mathrm{R} \$ 221,40$ & $\mathrm{R} \$ 177,30$ & $\mathrm{R} \$ 521,13$ \\
\hline Set/09 & 0,42 & $\mathrm{R} \$ 157,10$ & $\mathrm{R} \$ 222,33$ & $\mathrm{R} \$ 178,05$ & $\mathrm{R} \$ 523,32$ \\
\hline Out/09 & 0,05 & $\mathrm{R} \$ 157,18$ & $\mathrm{R} \$ 222,44$ & $\mathrm{R} \$ 178,13$ & $\mathrm{R} \$ 523,58$ \\
\hline VALOR AT & UALIZADO & $R \$ 157,18$ & $\mathrm{R} \$ 222,44$ & R\$ 178,13 & $\mathrm{R} \$ \mathbf{5 2 3 , 5 8}$ \\
\hline
\end{tabular}




\section{APÊNDICE III - ATUALIZAÇÃO DAS ESTIMATIVAS DE CUSTOS}

\section{AMBIENTAIS}

Após a escolha dos estudos a serem utilizados para se efetuar a transferência de resultados, é necessário observar que os mesmos datam de períodos que não o atual, além das distintas localizações geográficas e moedas utilizadas na valoração econômica das externalidades do setor elétrico.

O estudo de Pearce, por exemplo, utiliza-se da libra esterlina britânica para valores de 1990 para divulgar as estimativas de custos ambientais, enquanto o estudo de implantação do ExternE em Portugal se utiliza da ECU para valores de 1995, e o estudo de implantação nacional do ExternE na Alemanha, utiliza-se do Euro para valores de 2000 para a divulgação dos resultados da avaliação.

De forma a simplificar a avaliação, faz-se necessária a atualização dos índices monetários para a moeda nacional na presente data, ou seja, a estimativa deve ser baseada no real brasileiro. Para tanto, deve-se levar em conta as taxas de câmbio entre as moedas citadas e a moeda nacional, bem como a atualização dos índices de mercado, durante o período transcorrido entre a estimativa inicial e a data de corte para a estimativa atual (novembro 2009). Sendo assim, todos os índices e cotações considerados neste estudo dizem respeito a divulgações dos índices econômicos e taxas de câmbio até outubro de 2009. A seguir serão discutidas atualizações para os estudos mencionados anteriormente.

\section{Pearce}

O estudo de Pearce se utiliza da cotação da libra esterlina britânica do ano de 1990. Como é de conhecimento, o real brasileiro está em vigor desde julho de 1994, data posterior a utilizada para a estimativa de Pearce. Desta forma a metodologia utilizada para a atualização dos valores estimados por Pearce é baseada na utilização da cotação média da libra em relação ao real, desde 1995 até outubro de 2009, além da correção dos valores pelo IGP-M médio dos anos de 1995 até outubro de 2009. 
A seguir, estão demonstrados os índices do IGP-M para o período em questão, bem como a cotação do real brasileiro em relação à libra.

Tabela A III.1 - Dados do IGP-M simplificados, 1995 até outubro de 2009.

\begin{tabular}{|r|r|r|r|r|r|r|r|r|r|r|r|r|r|}
\hline & JAN & FEV & MAR & ABR & MAI & JUN & JUL & AGO & SET & OUT & NOV & DEZ & ACUMULADO \\
\hline $\mathbf{1 9 9 5}$ & 0,92 & 1,39 & 1,12 & 2,10 & 0,58 & 2,46 & 1,82 & 2,20 & $-0,71$ & 0,52 & 1,20 & 0,71 & $15,23 \%$ \\
\hline $\mathbf{1 9 9 6}$ & 1,73 & 0,97 & 0,40 & 0,32 & 1,55 & 1,02 & 1,35 & 0,28 & 0,10 & 0,19 & 0,20 & 0,73 & $9,18 \%$ \\
\hline $\mathbf{1 9 9 7}$ & 1,77 & 0,43 & 1,15 & 0,68 & 0,21 & 0,74 & 0,09 & 0,09 & 0,48 & 0,37 & 0,64 & 0,84 & $7,73 \%$ \\
\hline $\mathbf{1 9 9 8}$ & 0,96 & 0,18 & 0,19 & 0,13 & 0,14 & 0,38 & $-0,17$ & $-0,16$ & $-0,08$ & 0,08 & $-0,32$ & 0,45 & $1,78 \%$ \\
\hline $\mathbf{1 9 9 9}$ & $\mathbf{0}, 84$ & 3,61 & 2,83 & 0,71 & $-0,29$ & 0,36 & 1,55 & 1,56 & 1,45 & 1,70 & 2,39 & 1,81 & $20,10 \%$ \\
\hline $\mathbf{2 0 0 0}$ & 1,24 & 0,35 & 0,15 & 0,23 & 0,31 & 0,85 & 1,57 & 2,39 & 1,16 & 0,38 & 0,29 & 0,63 & $9,95 \%$ \\
\hline $\mathbf{2 0 0 1}$ & 0,62 & 0,23 & 0,56 & 1,00 & 0,86 & 0,98 & 1,48 & 1,38 & 0,31 & 1,18 & 1,10 & 0,22 & $10,37 \%$ \\
\hline $\mathbf{2 0 0 2}$ & 0,36 & 0,06 & 0,09 & 0,56 & 0,83 & 1,54 & 1,95 & 2,32 & 2,40 & 3,87 & 5,19 & 3,75 & $25,30 \%$ \\
\hline $\mathbf{2 0 0 3}$ & 2,33 & 2,28 & 1,53 & 0,92 & $-0,26$ & $-1,00$ & $-0,42$ & 0,38 & 1,18 & 0,38 & 0,49 & 0,61 & $8,69 \%$ \\
\hline $\mathbf{2 0 0 4}$ & 0,88 & 0,69 & 1,13 & 1,21 & 1,31 & 1,38 & 1,31 & 1,22 & 0,69 & 0,39 & 0,82 & 0,74 & $12,42 \%$ \\
\hline $\mathbf{2 0 0 5}$ & 0,39 & 0,30 & 0,85 & 0,86 & $-0,22$ & $-0,44$ & $-0,34$ & $-0,65$ & $-0,53$ & 0,60 & 0,40 & $-0,01$ & $1,20 \%$ \\
\hline $\mathbf{2 0 0 6}$ & 0,92 & 0,01 & $-0,23$ & $-0,42$ & 0,38 & 0,75 & 0,18 & 0,37 & 0,29 & 0,47 & 0,75 & 0,32 & $3,84 \%$ \\
\hline $\mathbf{2 0 0 7}$ & 0,50 & 0,27 & 0,34 & 0,04 & 0,04 & 0,26 & 0,28 & 0,98 & 1,29 & 1,05 & 0,69 & 1,76 & $7,74 \%$ \\
\hline $\mathbf{2 0 0 8}$ & 1,09 & 0,53 & 0,74 & 0,69 & 1,61 & 1,98 & 1,76 & $-0,32$ & 0,11 & 0,98 & 0,38 & $-0,13$ & $9,80 \%$ \\
\hline $\mathbf{2 0 0 9}$ & $-0,44$ & 0,26 & $-0,74$ & $-0,15$ & $-0,07$ & $-0,10$ & $-0,43$ & $-0,36$ & 0,42 & 0,05 & - & - & $-1,55 \%$ \\
\hline
\end{tabular}

Fonte: Portal Brasil. Disponível em <http://www.portalbrasil.net/igpm.htm>

Tabela A III.2 - Taxa de câmbio anual média libra X real brasileiro.

\begin{tabular}{cccc}
\hline ANO & $\begin{array}{c}\text { COTAÇÃO } \\
\text { MÉDIA }\end{array}$ & $\begin{array}{c}\text { COTAÇÃO } \\
\text { MÁXIMA }\end{array}$ & $\begin{array}{c}\text { COTAÇÃO } \\
\text { MÍNIMA }\end{array}$ \\
\hline $\mathbf{1 9 9 5}$ & $\mathrm{R} \$ 1,50$ & $\mathrm{R} \$ 1,52$ & $\mathrm{R} \$ 1,48$ \\
$\mathbf{1 9 9 6}$ & $\mathrm{R} \$ 1,57$ & $\mathrm{R} \$ 1,77$ & $\mathrm{R} \$ 1,47$ \\
$\mathbf{1 9 9 7}$ & $\mathrm{R} \$ 1,77$ & $\mathrm{R} \$ 1,89$ & $\mathrm{R} \$ 1,67$ \\
$\mathbf{1 9 9 8}$ & $\mathrm{R} \$ 1,92$ & $\mathrm{R} \$ 2,04$ & $\mathrm{R} \$ 1,80$ \\
$\mathbf{1 9 9 9}$ & $\mathrm{R} \$ 2,95$ & $\mathrm{R} \$ 3,53$ & $\mathrm{R} \$ 1,97$ \\
$\mathbf{2 0 0 0}$ & $\mathrm{R} \$ 2,77$ & $\mathrm{R} \$ 3,04$ & $\mathrm{R} \$ 2,56$ \\
$\mathbf{2 0 0 1}$ & $\mathrm{R} \$ 3,43$ & $\mathrm{R} \$ 4,22$ & $\mathrm{R} \$ 2,86$ \\
\hline $\mathbf{2 0 0 2}$ & $\mathrm{R} \$ 4,49$ & $\mathrm{R} \$ 6,30$ & $\mathrm{R} \$ 3,26$ \\
$\mathbf{2 0 0 3}$ & $\mathrm{R} \$ 5,09$ & $\mathrm{R} \$ 6,02$ & $\mathrm{R} \$ 4,60$ \\
\hline $\mathbf{2 0 0 4}$ & $\mathrm{R} \$ 5,36$ & $\mathrm{R} \$ 5,84$ & $\mathrm{R} \$ 5,04$ \\
$\mathbf{2 0 0 5}$ & $\mathrm{R} \$ 4,44$ & $\mathrm{R} \$ 5,23$ & $\mathrm{R} \$ 3,76$ \\
\hline $\mathbf{2 0 0 6}$ & $\mathrm{R} \$ 4,02$ & $\mathrm{R} \$ 4,41$ & $\mathrm{R} \$ 3,68$ \\
\hline $\mathbf{2 0 0 7}$ & $\mathrm{R} \$ 3,90$ & $\mathrm{R} \$ 4,24$ & $\mathrm{R} \$ 3,52$ \\
\hline $\mathbf{2 0 0 8}$ & $\mathrm{R} \$ 3,37$ & $\mathrm{R} \$ 4,13$ & $\mathrm{R} \$ 2,96$ \\
\hline $\mathbf{2 0 0 9}$ & $\mathrm{R} \$ 3,18$ & $\mathrm{R} \$ 3,52$ & $\mathrm{R} \$ 2,74$ \\
\hline Média & $\mathrm{R} \$ \mathbf{3 , 3 2}$ & $\mathbf{R} \$ \mathbf{3 , 8 5}$ & $\mathbf{R} \$ \mathbf{2 , 8 9}$ \\
\hline
\end{tabular}

Fonte: (OANDA - Historical Exchange Rates). Disponível em 〈http://www.oanda.com/convert/fxhistory $>$ 
A transposição dos resultados para o ano base de 1995 e a utilização da média de cotação e do índice de mercado se fez necessária devido a fatores, tais como: (i) a vigência do real somente a partir de julho de 1994; (ii) as exorbitantes oscilações do IGP-M durante o período de 1990 até 1994, devido aos altos índices inflacionários; e (iii) a desaceleração da economia britânica no início dos anos 90.

Estando a média do IGP-M, entre o período de 1995 até outubro de 2009, em 9,452\%, e a média da cotação do real em relação à libra em aproximadamente $\mathrm{R} \$ 3,32$, torna-se possível então efetuar a atualização das estimativas de Pearce, que resultaram na tabela a seguir.

Tabela A III.3 - Estimativa de custos ambientais de Pearce atualizada.

\begin{tabular}{ccccc}
\hline TECNOLOGIA DE PRODUÇÃO & DIESEL & SOLAR & EÓLICA & HIDRO \\
\hline CATEGORIA DE IMPACTO & & CUSTO $\left(\mathbf{R} \mathbf{~} \mathbf{2 0 0 9}_{\mathbf{M W h}} \mathbf{M}\right.$ & \\
\hline $\begin{array}{c}\text { Saúde Humana } \\
\text { Mortalidade } \\
\text { Doença }\end{array}$ & 10,53 & 2,54 & 1,45 & 1,09 \\
& 4,36 & $\mathrm{NE}$ & $\mathrm{NE}$ & $\mathrm{NE}$ \\
\hline Danos sobre a Colheita & 1,82 & 0 & 0 & 0 \\
\hline Danos sobre Floresta & 35,58 & 0 & 0 & 0 \\
\hline Redução da Biodiversidade & $\mathrm{NE}$ & $\mathrm{NE}$ & $\mathrm{NE}$ & $\mathrm{NE}$ \\
\hline Ruído & $\mathrm{NE}$ & $\mathrm{NE}$ & $\mathrm{NE}$ & $\mathrm{NE}$ \\
\hline Aquecimento Global & 12,71 & 0 & 0 & 0,36 \\
\hline Impacto Visual & $\mathrm{NE}$ & $\mathrm{NE}$ & $\mathrm{NE}$ & $\mathrm{NE}$ \\
\hline Poluição das Águas & 1,78 & 0 & 0 & 0 \\
\hline Contaminação dos Solos & $\mathrm{NE}$ & $\mathrm{NE}$ & $\mathrm{NE}$ & $\mathrm{NE}$ \\
\hline TOTAL & $\mathbf{6 6 , 7 8}$ & $\mathbf{2 , 5 4}$ & $\mathbf{1 , 4 5}$ & $\mathbf{1 , 4 5}$ \\
\hline
\end{tabular}

\section{ExternE Portugal}

A implantação nacional em Portugal do projeto ExternE utilizou a ECU do ano de 1995 para divulgar as estimativas encontradas através dos estudos de Martins (1999), e segundo o próprio autor tal unidade teve a cotação média de US\$ 1,25 no referido ano.

Desta forma, a metodologia de atualização dos valores estimados em Portugal se utiliza da cotação do real em relação ao dólar em $1995(\mathrm{R} \$$ 0,92) e a respectiva atualização dos valores pelo IGP-M acumulado de 1995 até outubro de 2009. Por intermédio da Tabela A III.4 a seguir podemos observar a cotação do real em relação ao dólar no período de 1995 até outubro de 2009. 
Tabela A III.4 - Cotação do real em relação ao dólar, 1995 até outubro de 2009.

\begin{tabular}{cccccc}
\hline ANO & $\begin{array}{c}\text { COTAÇÃO } \\
\text { MÉDIA }\end{array}$ & ANO & $\begin{array}{c}\text { COTAÇÃO } \\
\text { MÉDIA }\end{array}$ & ANO & $\begin{array}{c}\text { COTAÇÃO } \\
\text { MÉDIA }\end{array}$ \\
\hline 1995 & $\mathrm{R} \$ 0,92$ & 2000 & $\mathrm{R} \$ 1,83$ & 2005 & $\mathrm{R} \$ 2,43$ \\
1996 & $\mathrm{R} \$ 1,00$ & 2001 & $\mathrm{R} \$ 2,35$ & 2006 & $\mathrm{R} \$ 2,18$ \\
1997 & $\mathrm{R} \$ 1,08$ & 2002 & $\mathrm{R} \$ 2,92$ & 2007 & $\mathrm{R} \$ 1,95$ \\
1998 & $\mathrm{R} \$ 1,16$ & 2003 & $\mathrm{R} \$ 3,08$ & 2008 & $\mathrm{R} \$ 1,83$ \\
1999 & $\mathrm{R} \$ 1,81$ & 2004 & $\mathrm{R} \$ 2,93$ & 2009 & $\mathrm{R} \$ 1,74$ \\
\hline
\end{tabular}

Fonte: FinanceOne. Disponível em 〈http://www.financeone.com.br/histdolar $>$

Desta forma, utilizando-se da metodologia descrita, foram obtidos os resultados apresentados nas tabelas a seguir.

Tabela A III.5 - Estimativa de custos ambientais do ExternE Portugal atualizada, hidroeletricidade.

\begin{tabular}{cc}
\hline CICLO DA HIDROELETRICIDADE & CUSTO ATUALIZADO $\left(\mathbf{R}_{\mathbf{2 0 0 9}} \mathbf{\text { MWh}} \mathbf{\text { ) }}\right.$ \\
\hline Saúde Humana & 0,06 \\
\hline Mortalidade & 0,02 \\
Doença & 0,04 \\
\hline Saúde Pública e dos Trabalhadores & 0,95 \\
\hline Danos sobre Colheitas & 0,28 \\
\hline Ecossistemas & $\mathrm{NQ}$ \\
\hline Ruído & $\mathrm{NG}$ \\
\hline Impacto Visual & $\mathrm{NG}$ \\
\hline Ozônio na Saúde & 0,09 \\
\hline Aquecimento Global & 0,55 \\
\hline TOTAL & $\mathbf{1 , 9 3}$
\end{tabular}

Tabela A III.6 - Estimativa de custos ambientais ExternE Portugal atualizada, biomassa.

\begin{tabular}{cc}
\hline CICLO DA BIOMASSA & CUSTO ATUALIZADO (R\$MWh) \\
\hline Saúde Humana & 27,45 \\
\hline Mortalidade & 18,17 \\
Doença & 9,28 \\
\hline Danos sobre Colheitas & 2,42 \\
\hline Ecossistemas & NQ \\
\hline Ruído & NG \\
\hline Impacto Visual & NG \\
\hline Danos sobre Estradas & 0,65 \\
\hline Aquecimento Global & 5,83 \\
\hline TOTAL & $\mathbf{3 6}-\mathbf{3 7}$
\end{tabular}




\section{ExternE Alemanha}

A implantação nacional na Alemanha do projeto ExternE utilizou para a divulgação de estimativas o Euro com a cotação do ano 2000. Sendo assim, a metodologia de atualização dos valores estimados na Alemanha se utiliza da cotação do real em relação ao euro em 2000 (aproximadamente, $\mathrm{R} \$ 1,69$, de acordo com o Portal Brasil e OANDA) e a respectiva atualização de valores pelo IGP-M acumulado entre 2000 e outubro de 2009.

Utilizando-se da metodologia descrita, os resultados da atualização das estimativas do projeto alemão são apresentados por intermédio da Tabela A III.7 a seguir.

Tabela A III.7 - Estimativa de custos ambientais ExternE Alemanha atualizada.

\begin{tabular}{|c|c|c|c|}
\hline TECNOLOGIA DE PRODUÇÃO & SOLAR & EÓLICA & HIDRO \\
\hline \multicolumn{4}{|c|}{ CUSTOS $(\mathbf{R} \$ \mathbf{2 0 0 9} / \mathbf{M W h})$} \\
\hline \multicolumn{4}{|c|}{ Custo dos Danos } \\
\hline Ruído & 0 & 0,19 & 0 \\
\hline Saúde & 17,33 & 2,77 & 0,20 \\
\hline Danos sobre a Colheita & 0 & 0,03 & 0 \\
\hline Ecossistema & \multicolumn{3}{|c|}{ Custos da Precaução } \\
\hline Aquecimento Global & 1,54 & 1,54 & 0,12 \\
\hline TOTAL & $\mathbf{3 1 , 5 8}$ & $\mathbf{6 , 0 7}$ & $\mathbf{0 , 4 4}$ \\
\hline
\end{tabular}

